The genetic background of methane emission by dairy cows 


\section{Thesis committee}

\section{Promotor}

Prof. Dr H. Bovenhuis

Personal chair at Animal Breeding and Genomics

Wageningen University \& Research

\section{Co-promotor}

Dr M.H.P.W. Visker

Researcher, Animal Breeding and Genomics

Wageningen University \& Research

\section{Other members}

Prof. Dr I.J.M. de Boer, Wageningen University \& Research Prof. Dr W.J.J. Gerrits, Wageningen University \& Research Prof. Dr N. Gengler, University of Liège, Belgium

Dr E.P.C. Koenen, CRV, Arnhem, the Netherlands

This research was conducted under the auspices of the Graduate School of Wageningen Institute of Animal Sciences (WIAS). 


\title{
The genetic background of methane emission by dairy cow
}

\author{
Sabine van Engelen
}

\section{Thesis}

submitted in fulfillment of the requirements for the degree of doctor

at Wageningen University

by the authority of the Rector Magnificus,

Prof. Dr A.P.J. Mol,

in the presence of the

Thesis Committee appointed by the Academic Board

to be defended in public

on Wednesday 28 March 2018

at 4 p.m. in the Aula. 
Van Engelen, S.

The genetic background of methane emission by dairy cows, 144 pages.

PhD thesis, Wageningen University, Wageningen, the Netherlands (2018)

With references, with summaries in English and Dutch

ISBN: 978-94-6343-732-5

DOI: $10.18174 / 430631$ 


\begin{abstract}
Van Engelen, S. (2018). The genetic background of methane emission by dairy cows. PhD thesis, Wageningen University, the Netherlands
\end{abstract}

Dairy products are important food sources which contain nutrients that are essential for human development and healthy ageing. Greenhouse gasses are formed during the production of dairy of which methane $\left(\mathrm{CH}_{4}\right)$ emission by dairy cows is the single largest source. A reduction in $\mathrm{CH}_{4}$ emission could be achieved via selective breeding, though this requires genetic variation in $\mathrm{CH}_{4}$ emission. In order to quantify the genetic variation in $\mathrm{CH}_{4}$ emission, 3 different indicators were used. The first indicator was $\mathrm{CH}_{4}$ emission predicted based on milk fatty acids (FA) which were measured using gas chromatography. Different FA based $\mathrm{CH}_{4}$ prediction equations were used and 12 to $44 \%$ of the variation was due to genetic differences between cows. The second indicator was $\mathrm{CH}_{4}$ emission measured with breath sensors. The breath of cows was analysed during milking in automatic milking systems. Genetics explained 3 to $12 \%$ of the total variation in this $\mathrm{CH}_{4}$ indicator. The third indicator was $\mathrm{CH}_{4}$ emission predicted based on milk mid-infrared (MIR) spectra. Of this indicator, between 17 and $21 \%$ of the total variation could be attributed to genetic factors. These results suggest that there is genetic variation in $\mathrm{CH}_{4}$ emission and selective breeding for lower $\mathrm{CH}_{4}$ emission is possible. The correlations between sensor measured $\mathrm{CH}_{4}$ emission and milk MIR predicted $\mathrm{CH}_{4}$ emission were low, indicating that both indicators explain a different part of the variation in true $\mathrm{CH}_{4}$ emission. The accuracy of the estimated breeding values (EBV) of these $\mathrm{CH}_{4}$ indicators confirms this suggestion. Combining information from sensor measured $\mathrm{CH}_{4}$ emission with milk MIR predicted $\mathrm{CH}_{4}$ emission increases the accuracy of the EBV compared to using them separately. Correlations of sensor measured $\mathrm{CH}_{4}$ emission and milk MIR predicted $\mathrm{CH}_{4}$ emission with breeding goal traits (production and fertility traits) were low to medium. Genetic correlations between $\mathrm{CH}_{4}$ emission and production traits ranged between -0.61 and 0.65 , and genetic correlations between $\mathrm{CH}_{4}$ emission and fertility traits ranged between -0.32 and 0.38 . These results suggest that inclusion of $\mathrm{CH}_{4}$ emission in the breeding goal has a minor impact on the breeding goal traits studied. These correlations, however, are estimated on relatively small datasets. Increasing the amount of data by using EBV, correlations between the EBV of the $\mathrm{CH}_{4}$ indicators and the EBV of six breeding goal traits were also low to medium. In conclusion, there is a possibility to use selective breeding to reduce $\mathrm{CH}_{4}$ emission by dairy cows with an anticipated minor impact on other breeding goal traits. 

"Nothing is as powerful as an idea whose time has come

All my life, I've had doubts about who I am, where I belonged Now, I'm like the arrow that springs from the bow

No hesitation, no doubts

The path is clear"

Project one (2009) 



\section{Contents}

$\begin{array}{ll}\text { Abstract } & 5\end{array}$

$\begin{array}{ll}\text { Chapter } 1 \text { General introduction } & 11\end{array}$

Chapter 2 Genetic study of methane production predicted from milk fat composition in dairy cows

Chapter 3 Genetic Background of Methane Emission by Dutch Holstein

Friesian Cows Measured with Infrared Sensors in Automatic

Milking Systems

Chapter 4 Genetic Background of Milk Mid Infrared predicted Methane

Emission and Relationship with Sensor Measured Methane

Emission in Dutch Dairy Cows

55

Chapter 5 Correlations of Milk Mid Infrared predicted and Sensor Measured

Methane Emission with Production and Fertility Traits in Dutch

Dairy Cows

73

Chapter 6 General discussion

93

Summary

Samenvatting 129

Curriculum vitae

Acknowledgements

Colophon 

1

General introduction 



\subsection{Introduction}

Dairy products are important food sources which contain nutrients that are essential for human development and healthy ageing (van Staveren et al., 2008; Heaney, 2009). A few examples of these essential nutrients are the minerals calcium, potassium, and magnesium. Many people have insufficient intake of these minerals and consumption of dairy products could help to meet the shortfall in these minerals (Nicklas et al., 2009). Furthermore, an increase in mothers that are employed is associated with a higher demand for baby formula that is produced from whey or milk powder (Lagrange et al., 2015). The demand for dairy products is expected to increase in the future as the human population is growing (Steinfeld, 2006). It is currently anticipated that more than 9 billion people will inhabit this planet by 2050 (United Nations, 2015).

The production of dairy products, however, also has a negative impact on the environment, as during its production greenhouse gasses (GHG) are being formed. Global milk production is responsible for $2.7 \%$ of the total anthropogenic GHG emissions (FAO, 2010) of which methane $\left(\mathbf{C H}_{4}\right)$ emission by dairy cows is the single largest source (Gerber et al., 2013). Methane is a harmful GHG that is 28 times more harmful than carbon dioxide $\left(\mathbf{C O}_{2}\right)$ over a time period of 100 years (IPCC, 2014). Each individual dairy cow emits between 60 and $160 \mathrm{~kg}$ of $\mathrm{CH}_{4}$ per year depending on the feed intake and size (Hristov et al., 2013). This results in a global average GHG production of approximately $2.4 \mathrm{~kg}$ of $\mathrm{CO}_{2}$ equivalent per $\mathrm{kg}$ of fat and protein corrected milk (FAO, 2010). A reduction in $\mathrm{CH}_{4}$ emission by dairy cows is therefore wanted.

A reduction in $\mathrm{CH}_{4}$ emission could be achieved by using different $\mathrm{CH}_{4}$ mitigation strategies like management, feeding, microbial, and breeding strategies (Beauchemin et al., 2008;Buddle et al., 2011;Cottle et al., 2011). Management strategies focus more on the reduction of $\mathrm{CH}_{4}$ emission on the whole farm level rather than on individual animal level. For example, reducing the amount of unproductive cows on the farm and improving the reproductive rate of the cows (Cottle et al., 2011). Feeding strategies are a proven method to reduce $\mathrm{CH}_{4}$ emission, but their reduction has been found to be short-term or costly to maintain (Beauchemin et al., 2008; Hristov et al., 2013). For example, adding lipids to the diet could give a 10 to $25 \%$ reduction in $\mathrm{CH}_{4}$ emission in practice, but long-term effectiveness of additional lipids needs further investigation (Beauchemin et al., 2008). Microbial strategies, including defaunation and vaccination, have not been found to give a consistent and long-term reduction of $\mathrm{CH}_{4}$ emission (Cottle et al., 
2011; Hristov et al., 2013). Breeding strategies have the advantage that they are costeffective to implement and could give permanent and cumulative reduction in $\mathrm{CH}_{4}$ emission. A combination of $\mathrm{CH}_{4}$ mitigation strategies compatible with the type of farm has, therefore, been proposed (Buddle et al., 2011).

\subsection{Emission of methane by dairy cows}

Methane is produced in response to feed degradation in the rumen of the dairy cow. A large part of the degradation is done by anaerobic microorganisms in the rumen that can ferment feed particles that mono-gastric animals cannot ferment (Dijkstra et al., 2011a). Fermentation by the microorganisms (bacteria, protozoa, and fungi) is via the production of enzymes by these microorganism that are used to ferment feed particles (Russell and Rychlik, 2001;Castillo-González et al., 2014). The host provides the microorganisms a habitat to live in and utilizes the fermentation products formed in the rumen like microbial protein, $\mathrm{CO}_{2}$, hydrogen, and volatile fatty acids (VFA) (Russell and Rychlik, 2001; Cottle et al., 2011).

The production of hydrogen is the main driver behind the production of $\mathrm{CH}_{4}$ in the rumen (Castillo-González et al., 2014). Rumen $\mathrm{pH}$ is lowered by increasing hydrogen concentrations in the rumen and a lower $\mathrm{pH}$ decreases the efficiency of fermentation by the microorganisms (Weimer, 1996). Cellulose degrading bacteria, for example, prefer a neutral $\mathrm{pH}$ and their activity and growth decreases when the $\mathrm{pH}$ in the rumen decreases (Weimer, 1996). Methane-producing archaea called methanogens use the hydrogen in the rumen to form $\mathrm{CH}_{4}$ and, thereby, stabilize the $\mathrm{pH}$ in the rumen (Hungate, 1967;Morgavi et al., 2010;Cottle et al., 2011). The produced $\mathrm{CH}_{4}$ is then belched by the cow from the mouth and nose, and only a small part of the $\mathrm{CH}_{4}$ leaves the cow via the rectum (Murray et al., 1976; Muñoz et al., 2012).

The relationship between the host, the rumen microorganisms, and the amount of $\mathrm{CH}_{4}$ produced is complex. Determining which microorganisms are present in the rumen, their function, and their activity is still a challenge (Tapio et al., 2017). Not only are certain bacteria known to ferment multiple different substrates, but also are multiple bacteria known to ferment the same substrate (Bergman, 1990). Interactions between microorganisms, like commensalism and competition, are not uncommon and add to the complexity of the microbiota in the rumen. When selecting low and high $\mathrm{CH}_{4}$ emitting sheep, however, differences in composition of the microorganisms present in the rumen were found (Kittelmann et al., 2014). Furthermore, the abundance of certain groups of microbial genes have been found to be indicative for $\mathrm{CH}_{4}$ emission (Roehe et al., 2016). These results indicate that the 
composition and activity of the rumen microorganisms are different for low and high $\mathrm{CH}_{4}$ emitting animals. Interestingly, part of the variation in the composition and activity of the microorganisms is explained by the genetic background of the host (Roehe et al., 2016).

Mechanisms of the host, which are partially due to the genetics of the host, that influence the composition and activity of the microorganisms are not fully understood. An example of a mechanism of the host that influences the microorganisms is rumen retention time. Shorter rumen retention time could favor fast-growing microorganisms over slow-growing, thereby influencing the amount of $\mathrm{CH}_{4}$ produced (Hegarty, 2004) and rumen retention time has a genetic background (Smuts et al., 1995). Other possible mechanisms are complex interactions with receptors in the rumen wall and antibodies present in the saliva (Tapio et al., 2017). Although not all mechanisms are understood and known, the influence of the genetics of the host on $\mathrm{CH}_{4}$ production could be utilized by selective breeding for reduced $\mathrm{CH}_{4}$ emission.

Breeding for reduced $\mathrm{CH}_{4}$ emission by dairy cows, however, requires individual $\mathrm{CH}_{4}$ emission of many dairy cows (Buddle et al., 2011). Currently, the 'golden standard' for measuring $\mathrm{CH}_{4}$ emission is the climate respiration chamber (CRC). The use of CRC to measure $\mathrm{CH}_{4}$ emission on many dairy cows is impractical and expensive (Dehareng et al., 2012). Therefore, the use of indicators for $\mathrm{CH}_{4}$ emission as a phenotype that could be used in selective breeding has been proposed. This thesis focuses on three different types of indicators for $\mathrm{CH}_{4}$ emission: 1) indicator based on milk fat composition; 2) indicator based on milk mid-infrared (MIR) spectra; 3) indicator based on $\mathrm{CH}_{4}$ and $\mathrm{CO}_{2}$ concentrations measured in the breath of the cow (see Figure 1.1).

\subsection{Methane emission indicator based on milk fat composition}

Methane emission is linked through the VFA produced in the rumen with milk fat composition. Cows producing high or low levels of $\mathrm{CH}_{4}$ have different microorganisms, but also show a distinction in VFA produced by these microorganisms (Hernandez-Sanabria et al., 2010;Malmuthuge and Guan, 2017). The most important VFA in this respect are acetate, propionate, and butyrate (Bergman, 1990). Most of the VFA produced will be absorbed from the rumen and some will be transported to the mammary gland where they are used for de-novo synthesis of milk fatty acids (FA)(Garton, 1963;Ma, 2012). Different ratios between the VFA are 
Indicator 2:

Methane measured via sensors in automatic milking systems

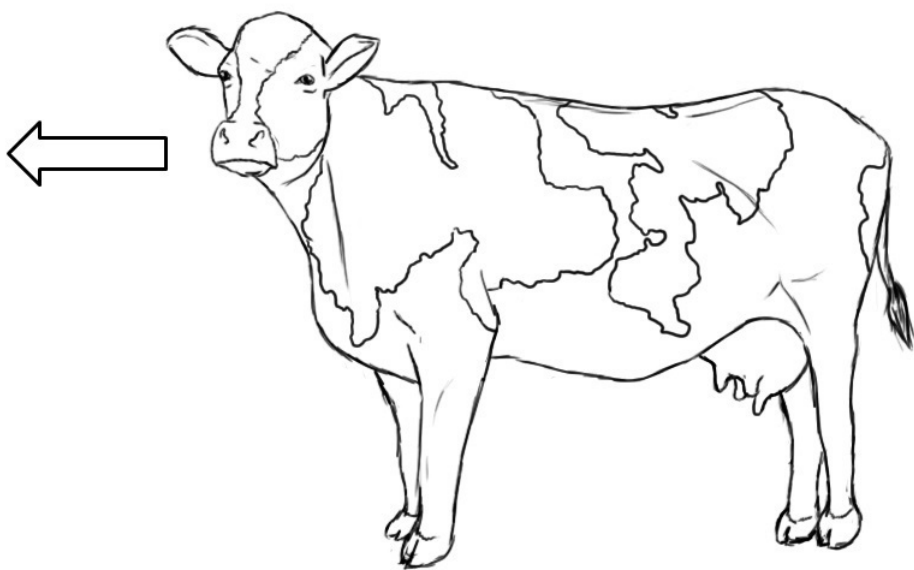

Indicator 1:

Methane predicted via milk fatty acids determined with gas chromatography

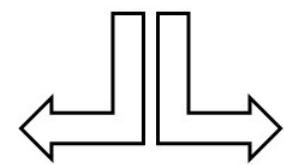

Indicator 3:

Methane predicted via milk mid-infrared spectra

Figure 1.1 Overview of the three different indicators used in this thesis

linked with different types of FA produced in the udder. For example, a larger amount of acetate available to the mammary gland is linked with higher production of even chain milk FA C4:0 to C16:0 (Ma, 2012;Van Lingen, 2017). Another group of milk FA that has been linked to rumen microorganisms are the odd and branched chain fatty acids (OBCFA) (Vlaeminck et al., 2004). The amount and composition of the OBCFA in the milk has been linked with different types of microorganisms in the rumen (Vlaeminck et al., 2004; van Gastelen and Dijkstra, 2016). There is thus a link between the microorganisms present in the rumen, $\mathrm{CH}_{4}$ emission, and milk fat composition (Jami et al., 2014).

Several studies have developed $\mathrm{CH}_{4}$ prediction equations based on milk FA (expressed as g/100 g of fat) (Chilliard et al., 2009;Dijkstra et al., 2011b;Mohammed et al., 2011). Milk FA profiles were determined in these studies via gas chromatography, a method that is known to separate FA accurately. The prediction equations developed depend on the found relationships between $\mathrm{CH}_{4}$ and milk FA and had coefficients of determination $\left(\mathbf{R}^{2}\right)$ ranging between 0.73 and 0.95 . The results of these studies indicated that milk FA determined via gas chromatography could be a useful indicator for $\mathrm{CH}_{4}$ emission. However, when studying the relationship between $\mathrm{CH}_{4}$ and milk $\mathrm{FA}$ in an independent dataset, some relationships changed and became less pronounced (van Lingen et al., 2014). It was, thus, argued that milk FA have a moderate potential to predict $\mathrm{CH}_{4}$. 


\subsection{Methane emission indicator based on milk MIR spectra}

As mentioned above, milk composition is linked with the processes in the rumen (Jami et al., 2014) and can be studied using mid-infrared (MIR) spectroscopy. Milk MIR spectra represent the different chemical compounds present in the milk. Like visible light, MIR is part of electromagnetic radiation and has wavelengths between 2,500 and 25,000 nanometer. The absorption of energy of 1,060 specific wavelengths that are part of this region are known to reflect the vibration of organic molecules like carbohydrates and fats (Dufour, 2009). The interferogram that shows the absorption of energy of the wavenumbers is then transformed via a Fourier transformation into an infrared spectrum (Soyeurt et al., 2006; Subramanian and Rodriguez-Saona, 2009). The technique of MIR to determine milk composition is routinely applied to determine milk fat and protein content, can be used to determine milk FA composition (Soyeurt et al., 2006; Rutten et al., 2011), and has potential to provide an indicator for $\mathrm{CH}_{4}$ emission.

The use of milk MIR to predict $\mathrm{CH}_{4}$ emission has been used in several studies (Dehareng et al., 2012; Vanlierde et al., 2016)[Van Gastelen et al. submitted]. The $\mathrm{R}^{2}$ found in these studies are quite variable ranging between 0.25 and 0.93 . In the review by Van Gastelen and Dijkstra (2016), it is argued that the predictive power of milk MIR is moderate. Currently, milk MIR spectra of all cows participating in the milk production recording (MPR) are being collected. The simplicity of implementing this $\mathrm{CH}_{4}$ prediction equation in practice is an advantage.

\subsection{Methane emission indicator based on breath samples}

Sensor measurements of $\mathrm{CH}_{4}$ concentrations in the breath of the cow during automatic milking system (AMS) visits could be used as an indicator for $\mathrm{CH}_{4}$ emission. An overview of the measurement set-up used in this thesis can be found in Figure 1.2. With this measurement set-up, $\mathrm{CH}_{4}$ emitted during an AMS visit is measured and this is an indicator of $\mathrm{CH}_{4}$ emission during a full day. These sensor measurements are, thus, a direct measurement method for $\mathrm{CH}_{4}$ emitted by the dairy cows. But these measurements are also influenced by the distance between the sensor and the head of the cow (Lassen et al., 2012; Hammond et al., 2016).

Two other studies have used sensors in AMS to measure $\mathrm{CH}_{4}$ concentrations present in the breath of the cow (Garnsworthy et al., 2012; Lassen et al., 2012). These studies have reported a $R^{2}$ of 0.79 (Garnsworthy et al., 2012) and repeatabilities ranging between 0.26 and 0.46 (Lassen et al., 2012). These values indicate that sensor 


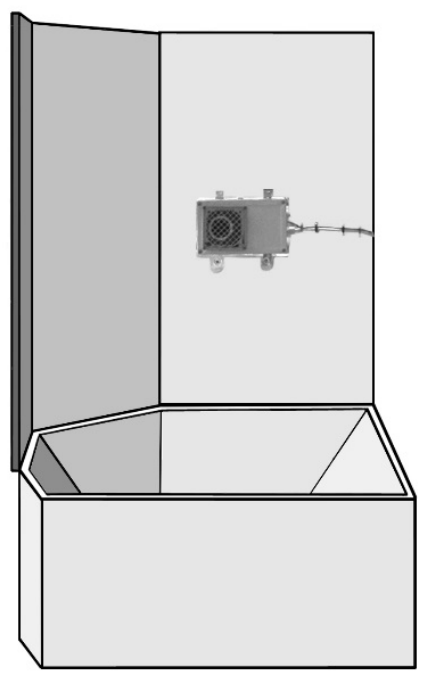

Figure 1.2 Overview of measurement set-up in the automatic milking system made from a cow perspective. Figure shows the feedthrough with the plastic screen above. In the screen the sensor was installed.

measurements during AMS visits could give repeatable $\mathrm{CH}_{4}$ phenotypes that could be used as indicator for $\mathrm{CH}_{4}$ emission.

\subsection{Aim and outline of this thesis}

With this thesis I would like to answer the main question, whether there is genetic variation in $\mathrm{CH}_{4}$ emission by dairy cows. In order to quantify the genetic variation in $\mathrm{CH}_{4}$ emission, 3 different indicators were used. The genetic variation present in these indicators could be used for selective breeding for lower $\mathrm{CH}_{4}$ emission. Selective breeding is not the only method that could be used to reduce $\mathrm{CH}_{4}$ emission by dairy cows. Other strategies to reduce $\mathrm{CH}_{4}$ emission are also addressed in the main project of which this $\mathrm{PhD}$ thesis is part. The main project is funded by Top Institute Food and Nutrition and combines the knowledge of nutrition, microbiology, modeling, and genetics to reduce $\mathrm{CH}_{4}$ emission by dairy cows (see box 1.1).

In chapter 2 genetic variation in $\mathrm{CH}_{4}$ yield ( $\mathrm{g} / \mathrm{kg}$ dry matter intake (DMI)) predicted with milk $\mathrm{FA}$ is quantified. $\mathrm{CH}_{4}$ yield was predicted with three different prediction equations containing milk FA determined by gas chromatography. These prediction equations are applied to a dataset that was developed by the Dutch Milk Genomics Initiative and contains data on more than 1,900 dairy cows. In chapter 3 genetic variation in $\mathrm{CH}_{4}$ emission measured with sensors during $\mathrm{AMS}$ visits is quantified. $\mathrm{CH}_{4}$ and $\mathrm{CO}_{2}$ concentrations are measured with a sensor in the breath of the cows. These measurements are summed into three $\mathrm{CH}_{4}$ emission indicators per AMS visit. Data of more than 123,000 AMS visits of 1,500 dairy cows are used. In chapter 4 genetic variation in $\mathrm{CH}_{4}$ emission predicted with milk MIR spectra is quantified. Three different prediction equations are applied to a dataset of more than 1,300 dairy cows. Furthermore, these three milk MIR predicted $\mathrm{CH}_{4}$ phenotypes are compared to the three sensor measured $\mathrm{CH}_{4}$ phenotypes. In chapter $\mathbf{5}$ the phenotypic and genetic correlations between two types of $\mathrm{CH}_{4}$ emission indicators with breeding goal traits for production and fertility are quantified. The two types of $\mathrm{CH}_{4}$ emission 
indicators are the three sensor measured $\mathrm{CH}_{4}$ phenotypes and the three milk MIR predicted $\mathrm{CH}_{4}$ phenotypes. In chapter 6 , the general discussion, the phenotype methane emission is further explored with respect to breeding. In the first part of this chapter, the results of a genome-wide association study on all three $\mathrm{CH}_{4}$ emission indicators are described. In the second part, selection indexes are made containing both sensor measured $\mathrm{CH}_{4}$ phenotypes and milk MIR predicted $\mathrm{CH}_{4}$ phenotypes. In the last part, correlations between estimated breeding values of sires for $\mathrm{CH}_{4}$ emission with estimated breeding values for production, health, and fertility traits are estimated.

\section{Textbox 1: Top Institute Food and Nutrition project Reduced methane emissions from dairy cows}

The work described in this thesis was part of the Top Institute Food and Nutrition (TIFN) project 'Reduced methane emission from dairy cows'. This project aimed at increasing knowledge about methane emission from dairy cows in order to decrease the ecological footprint of dairy production. The project team had a multidisciplinary expertise, comprising experts in Animal Breeding and Genetics, Animal Nutrition, Dairy Science and Technology, and Microbiology. The project team consisted of four PhD candidates and three postdocs. The team was based at Wageningen University and collaborated with researchers from the industrial parties CRV, Lely Industries and Qlip. Financial support was obtained from Centraal Bureau Levensmiddelenhandel (CBL), Cooperative cattle improvement organization CRV, Federatie Nederlandse Levensmiddelen Industrie (FNLI), Lely Industries NV, Ministry of Economic Affairs, Qlip BV, Wageningen University and Research, and ZuivelNL.

The key objectives of the TIFN project were:

1. To develop and validate an indicator for methane emission in milk.

2. To quantify the variation in methane emission and relationships with milk composition, fertility and longevity.

3. To characterize the composition and functionality of the rumen microbiota.

4. To unravel the interplay between cow, microbiota and feed.

5. To develop mathematical models of methane emission from dairy cows and dairy herds.

The research described in this thesis deals with objective 2: quantification of the variation in methane emission.

\subsection{References}

Beauchemin, K. A., M. Kreuzer, F. O'Mara, and T. A. McAllister. 2008. Nutritional management for enteric methane abatement: A review. Aust J Exp Agric 48(12):21-27. 
Bergman, E. N. 1990. Energy contributions of volatile fatty acids from the gastrointestinal tract in various species. Physiological Reviews 70(2):567-590.

Buddle, B. M., M. Denis, G. T. Attwood, E. Altermann, P. H. Janssen, R. S. Ronimus, C. S. Pinares-Patiño, S. Muetzel, and D. Neil Wedlock. 2011. Strategies to reduce methane emissions from farmed ruminants grazing on pasture. Vet J 188(1):11-17.

Castillo-González, A., M. Burrola-Barraza, J. Domínguez-Viveros, and A. ChávezMartínez. 2014. Rumen microorganisms and fermentation. Arch Med Vet 46(3):349-361.

Chilliard, Y., C. Martin, J. Rouel, and M. Doreau. 2009. Milk fatty acids in dairy cows fed whole crude linseed, extruded linseed, or linseed oil, and their relationship with methane output. J. Dairy Sci. 92(10):5199-5211.

Cottle, D. J., J. V. Nolan, and S. G. Wiedemann. 2011. Ruminant enteric methane mitigation: A review. Anim Prod Sci 51(6):491-514.

Dehareng, F., C. Delfosse, E. Froidmont, H. Soyeurt, C. Martin, N. Gengler, A. Vanlierde, and P. Dardenne. 2012. Potential use of milk mid-infrared spectra to predict individual methane emission of dairy cows. Animal 6(10):1694-1701.

Dijkstra, J., O. Oenema, and A. Bannink. 2011a. Dietary strategies to reducing $\mathrm{N}$ excretion from cattle: Implications for methane emissions. Current Opinion in Environmental Sustainability 3(5):414-422.

Dijkstra, J., S. M. van Zijderveld, J. A. Apajalahti, A. Bannink, W. J. J. Gerrits, J. R. Newbold, H. B. Perdok, and H. Berends. 2011b. Relationships between methane production and milk fatty acid profiles in dairy cattle. Anim. Feed Sci. and Technol. 166-167:590-595.

Dufour, É. 2009. Chapter 1 - principles of infrared spectroscopy a2 - sun, da-wen. Pages 1-27 in Infrared spectroscopy for food quality analysis and control. Academic Press, San Diego.

FAO. 2010. Greenhouse gas emissions from the dairy sector - a life cycle assessment. in Food and Agriculture Organization of the United Nations. FAO, Rome.

Garnsworthy, P. C., J. Craigon, J. H. Hernandez-Medrano, and N. Saunders. 2012. Onfarm methane measurements during milking correlate with total methane production by individual dairy cows. J. Dairy Sci. 95(6):3166-3180.

Garton, G. 1963. The composition and bio-synthesis of milk lipids. Journal of lipid research 4:237-254.

Gerber, P. J., H. Steinfeld, B. Henderson, A. Mottet, C. Opio, J. Dijkman, A. Falcucci and G. Tempio. 2013. Tackling climate change through livestock - a global assessment of emissions and mitigation opportunities. in Food and Agriculture Organization of the United Nations. FAO, Rome. 
Hammond, K. J., L. A. Crompton, A. Bannink, J. Dijkstra, D. R. Yáñez-Ruiz, P. O’Kiely, E. Kebreab, M. A. Eugène, Z. Yu, K. J. Shingfield, A. Schwarm, A. N. Hristov, and C. K. Reynolds. 2016. Review of current in vivo measurement techniques for quantifying enteric methane emission from ruminants. Anim. Feed Sci. and Technol. 219:13-30.

Heaney, R. P. 2009. Dairy and bone health. J Am Coll Nutr 28(sup1):82S-90S.

Hegarty, R. S. 2004. Genotype differences and their impact on digestive tract function of ruminants: A review. Aust J Exp Agric 44(5):459-467.

Hernandez-Sanabria, E., L. L. Guan, L. A. Goonewardene, M. Li, D. F. Mujibi, P. Stothard, S. S. Moore, and M. C. Leon-Quintero. 2010. Correlation of particular bacterial pcr-denaturing gradient gel electrophoresis patterns with bovine ruminal fermentation parameters and feed efficiency traits. Appl. Environ. Microbiol. 76(19):6338-6350.

Hristov, A. N., J. Oh, J. L. Firkins, J. Dijkstra, E. Kebreab, G. Waghorn, H. P. S. Makkar, A. T. Adesogan, W. Yang, C. Lee, P. J. Gerber, B. Henderson, and J. M. Tricarico. 2013. Special topics - mitigation of methane and nitrous oxide emissions from animal operations: I. A review of enteric methane mitigation options. J. Anim. Sci. 91(11):5045-5069.

Hungate, R. E. 1967. Hydrogen as an intermediate in the rumen fermentation. Arch Mikrobiol 59(1):158-164.

IPCC. 2014. Climate change 2014: Synthesis report. Contribution of working groups $\mathrm{i}$, ii and iii to the fifth assessment report of the intergovermental panel on climate change, ed. R.K. Pachauri and I.A. Meyer. Geneva, Switzerland.

Jami, E., B. A. White, and I. Mizrahi. 2014. Potential role of the bovine rumen microbiome in modulating milk composition and feed efficiency. PLoS ONE 9(1):e85423.

Kittelmann, S., C. S. Pinares-Patiño, H. Seedorf, M. R. Kirk, S. Ganesh, J. C. McEwan, and P. H. Janssen. 2014. Two different bacterial community types are linked with the low-methane emission trait in sheep. PLoS ONE 9(7):e103171.

Lagrange, V., D. Whitsett, and C. Burris. 2015. Global market for dairy proteins. Journal of Food Science 80(S1):A16-A22.

Lassen, J., P. Lovendahl, and J. Madsen. 2012. Accuracy of noninvasive breath methane measurements using fourier transform infrared methods on individual cows. J. Dairy Sci. 95(2):890-898.

Ma, L. 2012. Regulatory factors of milk fat synthesis in dairy cows Pages 4 - 36. Virginia Polytechnic Institute and State University. 
Malmuthuge, N. and L. L. Guan. 2017. Understanding host-microbial interactions in rumen: Searching the best opportunity for microbiota manipulation. J Anim Sci Biotechnol 8(1):8.

Mohammed, R., S. M. McGinn, and K. A. Beauchemin. 2011. Prediction of enteric methane output from milk fatty acid concentrations and rumen fermentation parameters in dairy cows fed sunflower, flax, or canola seeds. J. Dairy Sci. 94(12):6057-6068.

Morgavi, D., E. Forano, C. Martin, and C. Newbold. 2010. Microbial ecosystem and methanogenesis in ruminants. Animal 4(07):1024-1036.

Muñoz, C., T. Yan, D. A. Wills, S. Murray, and A. W. Gordon. 2012. Comparison of the sulfur hexafluoride tracer and respiration chamber techniques for estimating methane emissions and correction for rectum methane output from dairy cows. J. Dairy Sci. 95(6):3139-3148.

Murray, R. M., A. M. Bryant, and R. A. Leng. 1976. Rates of production of methane in the rumen and large intestine of sheep. Br. J. Nutr. 36(1):1-14.

Nicklas, T. A., C. E. O'Neil, and V. L. Fulgoni lii. 2009. The role of dairy in meeting the recommendations for shortfall nutrients in the american diet. J Am Coll Nutr 28(1 SUPPL):73S-81S.

Roehe, R., R. J. Dewhurst, C.-A. Duthie, J. A. Rooke, N. McKain, D. W. Ross, J. J. Hyslop, A. Waterhouse, T. C. Freeman, M. Watson, and R. J. Wallace. 2016. Bovine host genetic variation influences rumen microbial methane production with best selection criterion for low methane emitting and efficiently feed converting hosts based on metagenomic gene abundance. PLoS Genet. 12(2):e1005846.

Russell, J. B. and J. L. Rychlik. 2001. Factors that alter rumen microbial ecology. Science 292(5519):1119-1122.

Rutten, M. J. M., H. Bovenhuis, J. M. L. Heck, and J. A. M. van Arendonk. 2011. Predicting bovine milk protein composition based on fourier transform infrared spectra. J. Dairy Sci. 94(11):5683-5690.

Smuts, M., H. H. Meissner, and P. B. Cronje. 1995. Retention time of digesta in the rumen: Its repeatability and relationship with wool production of merino rams. J Anim Sci 73(1):206-210.

Soyeurt, H., P. Dardenne, F. Dehareng, G. Lognay, D. Veselko, M. Marlier, C. Bertozzi, P. Mayeres, and N. Gengler. 2006. Estimating fatty acid content in cow milk using mid-infrared spectrometry. J. Dairy Sci. 89(9):3690-3695.

Steinfeld, H., P. Gerber, T. Wassenaar, V. Castel, M. Rosales, and C. de Haan. 2006. Livestock's long shadow - environmental issues and options. Food and Agriculture Organization of the United Nations, Rome, Itally. 
Subramanian, A. and L. Rodriguez-Saona. 2009. Chapter 7 - fourier transform infrared (ftir) spectroscopy a2 - sun, da-wen. Pages 145-178 in Infrared spectroscopy for food quality analysis and control. Academic Press, San Diego.

Tapio, I., T. J. Snelling, F. Strozzi, and R. J. Wallace. 2017. The ruminal microbiome associated with methane emissions from ruminant livestock. J Anim Sci Biotechnol 8(1):7.

United Nations. 2015. World population prospects: The 2015 revision, key findings and advance tables. Working paper no. Esa/p/wp.241.

Van Gastelen, S. and J. Dijkstra. 2016. Prediction of methane emission from lactating dairy cows using milk fatty acids and mid-infrared spectroscopy. J. Sci. Food Agric. 96:3963-3968.

Van Lingen, H. J. 2017. Assessing methane emission from dairy cows. Pages 1 - 16. van Lingen, H. J., L. A. Crompton, W. H. Hendriks, C. K. Reynolds, and J. Dijkstra. 2014. Meta-analysis of relationships between enteric methane yield and milk fatty acid profile in dairy cattle. J. Dairy Sci. 97(11):7115-7132.

Van Staveren, W. A., J. M. Steijns, and L. C. P. G. M. de Groot. 2008. Dairy products as essential contributors of (micro-) nutrients in reference food patterns: An outline for elderly people. J Am Coll Nutr 27(6):747S-754S.

Vanlierde, A., M. L. Vanrobays, N. Gengler, P. Dardenne, E. Froidmont, H. Soyeurt, S. McParland, E. Lewis, M. H. Deighton, M. Mathot, and F. Dehareng. 2016. Milk midinfrared spectra enable prediction of lactation-stage-dependent methane emissions of dairy cattle within routine population-scale milk recording schemes. Anim Prod Sci 56(3):258-264.

Vlaeminck, B., V. Fievez, H. van Laar, and D. Demeyer. 2004. Rumen odd and branched chain fatty acids in relation to in vitro rumen volatile fatty acid productions and dietary characteristics of incubated substrates. J Anim Physiol Anim Nutr (Berl) 88(11-12):401-411.

Weimer, P. J. 1996. Why don't ruminal bacteria digest cellulose faster? J. Dairy Sci. 79(8):1496-1502. 



\section{2 \\ Short Communication: Genetic study of methane production predicted from milk fat composition in dairy cows}

S. van Engelen, ${ }^{1,2}$, H. Bovenhuis², J. Dijkstra ${ }^{3}$, J.A.M. van Arendonk ${ }^{1,2}$, and M.H.P.W. Visker ${ }^{1,2}$

${ }^{1}$ Top Institute Food and Nutrition, P.O. Box 557, 6700 AN, Wageningen, the Netherlands; ${ }^{2}$ Wageningen University \& Research Animal Breeding and Genomics, P.O. Box 338, $6700 \mathrm{AH}$, Wageningen, the Netherlands; ${ }^{3}$ Animal Nutrition Group, Wageningen University, P.O. Box 338, 6700 AH, Wageningen, the Netherlands

Journal of Dairy Science (2015) 98:8223-8226 


\begin{abstract}
Dairy cows produce enteric methane, a greenhouse gas with 25-times the global warming potential of $\mathrm{CO}_{2}$. Breeding could make a permanent, cumulative, and longterm contribution to methane reduction. Due to a lack of accurate, repeatable, individual methane measurements needed for breeding, indicators of methane production based on milk fatty acids (FA) have been proposed. The aim of the present study was to quantify the genetic variation for predicted methane yields. The milk fat composition of 1,905 first lactation Dutch Holstein-Friesian cows was used to investigate three different predicted methane yields (in $\mathrm{g} / \mathrm{kg} \mathrm{DMI}$ ): Methane1, Methane2, and Methane3. Methane1 was based on the milk fat proportions of C17:0anteiso, C18:1trans10+11, C18:1cis11, and C18:1cis13 $\left(R^{2}=\right.$ 0.73). Methane 2 was based on C4:0, C18:0, C18:1trans10+11, and C18:1cis11 $\left(R^{2}=\right.$ 0.70). Methane3 was based on $C 4: 0, C 6: 0$, and $C 18: 1$ trans10+11 $\left(R^{2}=0.63\right)$. Predicted methane yields were demonstrated to be heritable traits, with heritabilities between 0.12 and 0.44 . Breeding can, thus, be used to decrease methane production predicted based on milk fatty acids.
\end{abstract}

Key words: predicted methane yield, milk fatty acid, dairy cow 


\subsection{Introduction}

Dairy cows produce enteric methane, a greenhouse gas with 25-times the global warming potential of $\mathrm{CO}_{2}$ (Forster, 2007). To reduce methane production, a combination of strategies, like feeding strategies, should be considered (Patra, 2012; Hristov et al., 2013). Breeding could be a useful addition to any combination of strategies, making a permanent, cumulative, and long-term contribution to reducing methane production.

Breeding for reduced methane production can only be achieved when the trait in question shows variation and part of that variation is heritable. To quantify (genetic) variation, many animals need to be evaluated for the new trait of methane production (Buddle et al., 2011). This evaluation is difficult due to a lack of accurate, repeatable, individual methane measurements. Alternatively, evaluation of methane production can be based on associated traits that are easier to record. Indicators of methane production based on milk fatty acids (FA) that are related to rumen conditions and methane production have been proposed by several authors (Chilliard et al., 2009; Dijkstra et al., 2011; Mohammed et al., 2011).

The aim of this study was to apply such indicators to a large number of dairy cows with known milk fat composition in order to quantify the genetic variation for predicted methane production.

\subsection{Materials and Methods}

Milk fat composition of morning milk samples from 1,905 first lactation (63 to 282 days in lactation) Dutch Holstein-Friesian cows from 398 herds was obtained from the Dutch Milk Genomics Initiative. Milk fat composition was determined by gas chromatography as described by Stoop et al. (2008) and expressed in grams per 100 grams of fat. Stoop et al. (2008) and Bouwman et al. (2011) previously provided detailed descriptions of the experimental set-up.

Three methane $\left(\mathrm{CH}_{4}\right)$ prediction equations were derived from the dataset of Dijkstra et al. (2011) and applied to our data. The FA in these equations are expressed in grams per 100 grams of fat. The first prediction equation (Methane1) was reported by Dijkstra et al. (2011).

$\mathrm{CH}_{4}$ (in g/kg DMI) $=24.60+8.74 *$ C17:0anteiso $-1.97 *$ C18:1trans10+11 - $9.09 *$ C18:1cis11 + 5.07* C18:1cis13 (Methane1). 
The coefficient of determination $\left(\mathbf{R}^{2}\right)$ of Methane1 was 0.73 . The $R^{2}$ was corrected for experiment effects as described in St-Pierre (2001). A second prediction equation (Methane2) was derived excluding FA that were present in relatively different concentrations (difference between datasets larger than $40 \%$ ) in our dataset compared to the one of Dijkstra et al. $\left(2011 ; R^{2}=0.70\right)$.

$\mathrm{CH}_{4}($ in $\mathrm{g} / \mathrm{kg} \mathrm{DMI})=28.60-1.13 * \mathrm{C} 4: 0+0.36 * \mathrm{C} 18: 0-2.57 * \mathrm{C} 18: 1$ trans $10+11-$ $9.29 *$ C18:1cis11 (Methane2).

A third prediction equation (Methane3) was derived excluding FA with relatively different concentrations and FA with concentrations $<1 \mathrm{~g} / 100 \mathrm{~g}$ fat in our dataset as well as the one of Dijkstra et al. $\left(2011 ; R^{2}=0.63\right)$.

$\mathrm{CH}_{4}($ in $\mathrm{g} / \mathrm{kg} \mathrm{DMI})=27.13-3.04 * \mathrm{C} 4: 0+2.71 * \mathrm{C} 6: 0-1.63 * \mathrm{C} 18: 1$ trans $10+11$ (Methane3).

Note that C18:1trans10 and C18:1trans11 were individually available in our dataset and added together before applying the methane prediction equation. Analyses were performed for the predicted methane yields and for individual FA used in the methane prediction equations. Data of three cows were removed due to high levels of C18:1trans10+11 that deviated more than nine phenotypic standard deviations from the mean and were considered outliers. Normality of the traits was examined and observations with a residual effect $>3.5$ based on model 1 were considered outliers and removed. Not all cows had complete data on milk fat composition, resulting in different numbers of observations for the different traits (Table 2.1).

Genetic parameters and variance components were estimated using the following model in ASReml Version 2.0 (Gilmour, 2006):

$Y_{i j k l}=\mu+b_{1} * \operatorname{dim}_{i j k l}+b_{2} * e^{-0.05 * d i m} i_{i j k l}+b_{3} * a f c_{i j k l}+b_{4} * \operatorname{afc}_{i j k l}{ }^{2}+$ season $_{i}+\operatorname{sirecode~}_{j}+$ animalk $_{k}+$ herd $_{l}+\mathrm{e}_{\mathrm{ijkl}}($ model 1$)$

where $Y_{\mathrm{ijkl}}$ is the dependent variable; $\mu$ is the general mean; $\operatorname{dim}_{\mathrm{ijkl}}$ is the covariate describing the effect of the number of days in milking; af $\mathrm{c}_{\mathrm{ijk}}$ is the covariate describing the effect of age at first calving; season $n_{i}$ is the fixed effect of the class calving season (June-August 2004, September-November 2004, or December 2004February 2005); sirecode $e_{j}$ is the fixed effect of the difference in genetic level between cows sired by different groups of proven bulls and young bulls, animal $\mathrm{l}_{\mathrm{k}}$ is the random 
additive genetic effect of animal; herdı is the random effect of herd; and $\mathrm{e}_{\mathrm{ijkl}}$ is the random error effect. The heritability $\left(\mathbf{h}^{\mathbf{2}}\right)$ was calculated as follows:

$$
h^{2}=\frac{\sigma_{\mathrm{A}}^{2}}{\sigma_{\mathrm{A}}^{2}+\sigma_{\mathrm{E}}^{2}}
$$

This heritability is often referred to as the intraherd heritability (Heringstad et al. 2006) and these estimates are very similar to heritability estimates from a model with herd as a fixed effect. The interherd heritability $\left(\mathbf{h}^{2}{ }_{\text {inter }}\right)$ was calculated as follows:

$$
h_{\text {inter }}^{2}=\frac{\sigma_{\mathrm{A}}^{2}}{\sigma_{\text {herd }}^{2}+\sigma_{\mathrm{A}}^{2}+\sigma_{\mathrm{E}}^{2}}
$$

The proportion of variance explained by herd was calculated as follows:

$$
\text { Herd }=\frac{\sigma_{\text {herd }}^{2}}{\sigma_{\text {herd }}^{2}+\sigma_{A}^{2}+\sigma_{E}^{2}}
$$

\subsection{Results and Discussion}

\subsubsection{Descriptive statistics}

Results are presented in Table 2.1. The means of methane yields predicted based on milk FA ranged from $20.9 \mathrm{~g} / \mathrm{kg}$ DMI for Methane3 to $23.6 \mathrm{~g} / \mathrm{kg}$ DMI for Methane1, and the means of the individual FA ranged from $0.08 \%$ of total fat for C18:1cis 13 to $8.73 \%$ for $\mathrm{C} 18: 0$. The ranges of predicted methane yields in the current study are similar to the ranges of methane yields in the study of Dijkstra et al. (2011). The ranges of predicted methane yields in this study were $17.3-28.2$ (g/kg DMI) for Methane1, 14.6 - 24.4 for Methane2, and 17.7 - 23.5 for Methane3. The range of measured methane (in g/kg DMI) in the study of Dijkstra et al. (2011) was $17.3-25.3$ and the range of predicted methane (Methane1; in $\mathrm{g} / \mathrm{kg} \mathrm{DMI}$ ) was 17.6 - 23.9. Predicted methane yields of this study are also in line with the meta-analysis of Van Lingen et al. (2014), with 15.9 - 27.9 (in g/kg DMI) for measured methane and 15.5 25.5 (in $\mathrm{g} / \mathrm{kg} \mathrm{DMI}$ ) for methane predicted based on milk fat composition.

\subsubsection{Methane prediction equations}

Methane yields in this study were predicted based on milk FA because milk FA are suggested to be indicative of rumen conditions and, consequently, of methane production in the rumen. Methane and volatile FA (VFA) are mainly produced in the 
Table 2.1 Milk production traits, predicted methane yields based on milk fat composition, and individual milk fatty acids for first lactation Dutch dairy cows. Table contains number of observations $(n)$, mean, coefficient of variation (CV), phenotypic standard deviation $\left(\sigma_{p}\right)$, heritability $\left(h^{2} ; h^{2}=\sigma_{A}^{2} / \sigma_{A}^{2}+\sigma^{2} E\right)$, interherd heritability $\left(h^{2}{ }_{\text {inter; }} h^{2}{ }_{\text {inter }}=\sigma^{2}{ }_{A} / \sigma^{2}\right.$ Herd $+\sigma^{2}{ }_{A}+$ $\left.\sigma^{2} \mathrm{E}\right)$, and variance explained by the herd (Herd; Herd $=\sigma^{2}$ Herd $/ \sigma^{2}$ Herd $+\sigma^{2} A+\sigma^{2}$ ) with their respective standard errors in brackets

\begin{tabular}{|c|c|c|c|c|c|c|c|}
\hline Traits & $\mathrm{n}$ & Mean $^{1}$ & $\mathrm{CV}(\%)^{1}$ & $\sigma_{p}{ }^{2}$ & $h^{2}$ & $h^{2}$ inter & Herd \\
\hline \multicolumn{8}{|l|}{ Milk production traits } \\
\hline Milk yield (in kg) & 1,901 & 13.41 & 20 & 2.64 & $0.39_{(0.10)}$ & $0.29(0.03)$ & $0.29(0.03)$ \\
\hline Fat yield (in kg) & 1,901 & 0.58 & 19 & 0.11 & $0.32(0.09)$ & $0.25(0.02)$ & $0.25(0.02)$ \\
\hline Fat percentage & 1,902 & 4.36 & 16 & 0.70 & $0.47_{(0.10)}$ & $0.44_{(0.09)}$ & $0.07(0.02)$ \\
\hline Protein yield (in kg) & 1,901 & 0.47 & 20 & 0.09 & $0.21(0.08)$ & $0.13(0.05)$ & $0.38(0.03)$ \\
\hline Protein percentage & 1,902 & 3.51 & 8 & 0.29 & $0.61_{(0.12)}$ & $0.48(0.10)$ & $0.20(0.02)$ \\
\hline $\mathrm{FPCM}^{3}$ & 1,902 & 14.01 & 18 & 2.50 & $0.33(0.10)$ & $0.22(0.07)$ & $0.32(0.03)$ \\
\hline \multicolumn{8}{|c|}{ Predicted methane yields (in $\mathrm{g} / \mathrm{kg} \mathrm{DMI}$ ) } \\
\hline Methane1 4 & 1,838 & 23.62 & 6 & 1.38 & $0.12(0.06)$ & $0.05(0.03)$ & $0.55(0.02)$ \\
\hline Methane $2^{5}$ & 1,898 & 21.34 & 6 & 1.23 & $0.20_{(0.07)}$ & $0.12(0.05)$ & $0.38(0.03)$ \\
\hline Methane3 6 & 1,898 & 20.87 & 4 & 0.82 & $0.44(0.10)$ & $0.30_{(0.07)}$ & $0.31_{(0.03)}$ \\
\hline \multicolumn{8}{|c|}{ Milk fatty acids (in g/100 g of fat) } \\
\hline $\mathrm{C} 4: 0$ & 1,898 & 3.50 & 8 & 0.28 & $0.42(0.09)$ & $0.35(0.08)$ & $0.16_{(0.02)}$ \\
\hline C6:0 & 1,898 & 2.23 & 7 & 0.16 & $0.46(0.10)$ & $0.39(0.09)$ & $0.15(0.02)$ \\
\hline C17:0anteiso & 1,838 & 0.50 & 22 & 0.11 & $0.11_{(0.06)}$ & $0.06_{(0.03)}$ & $0.44(0.03)$ \\
\hline C18:0 & 1,898 & 8.73 & 16 & 1.40 & $0.24_{(0.07)}$ & $0.19_{(0.06)}$ & $0.19_{(0.02)}$ \\
\hline C18:1trans10 & 1,849 & 0.22 & 34 & 0.07 & $0.19_{(0.08)}$ & $0.08(0.03)$ & $0.56_{(0.02)}$ \\
\hline C18:1trans11 & 1,888 & 0.77 & 27 & 0.21 & $0.28(0.09)$ & $0.11(0.04)$ & $0.60(0.02)$ \\
\hline C18:1trans10+11 & 1,882 & 1.00 & 23 & 0.24 & $0.30_{(0.09)}$ & $0.13_{(0.04)}$ & $0.58_{(0.02)}$ \\
\hline C18:1cis11 & 1,898 & 0.41 & 26 & 0.10 & $0.20_{(0.08)}$ & $0.11(0.05)$ & $0.44(0.03)$ \\
\hline C18:1cis13 & 1,883 & 0.08 & 20 & 0.02 & $0.29(0.08)$ & $0.17_{(0.05)}$ & $0.41_{(0.03)}$ \\
\hline
\end{tabular}

${ }^{1}$ Based on morning milk samples and uncorrected.

${ }^{2}$ After adjustment by model 1.

${ }^{3}$ Fat and protein corrected milk $(\mathrm{FPCM})=$ milk $($ in $\mathrm{kg}) *(0.337+(0.116 *$ fat percentage $)+(0.06$ * protein percentage)).

4 Methane1 $=24.60+8.74 * C 17: 0$ anteiso $-1.97 * C 18: 1$ trans $10+11-9.09 * C 18: 1$ cis $11+$ $5.07 *$ C18:1cis 13 .

${ }^{5}$ Methane2 $=28.60-1.13 * \mathrm{C} 4: 0+0.36 * \mathrm{C} 18: 0-2.57 * \mathrm{C} 18: 1$ trans $10+11-9.29 * \mathrm{C} 18: 1$ cis 11 .

${ }^{6}$ Methane3 $=27.13-3.04 * \mathrm{C} 4: 0+2.71 * \mathrm{C} 6: 0-1.63 * \mathrm{C} 18: 1$ trans $10+11$.

rumen as the result of digesting feed in the rumen (Ellis et al., 2008). Certain FA are released directly from the feed and absorbed in the blood. VFA and FA from the blood can be used in the mammary gland for the production of milk fat. Microorganisms present in the rumen and rumen conditions affect the amount and composition of VFA that are produced and absorbed, the amount and composition of absorbed FA, and the amount of methane produced (Vlaeminck et al., 2006; Ellis et al., 2008). Therefore, the composition of milk fat has been suggested to be related 
to methane production in the rumen. Correlations between milk FA and predicted methane production were established successfully (Chilliard et al. 2009; Dijkstra et al. 2011; McCartney et al., 2013), confirming this hypothesis.

Methane prediction equations may not be universal and might be valid only when applied to datasets obtained at similar conditions as the dataset from which the prediction equations are derived. The prediction equations for this study were derived from the dataset of Dijkstra et al. (2011). The use of these prediction equations on our dataset was considered appropriate as conditions and breeds were similar in both datasets. More particular, both studies were based on the Dutch Holstein-Friesian breed and cows in both studies were fed common Dutch diets of mixed grass silage and corn silage. No actual methane data was available to verify that this similarity in conditions justifies the use of methane prediction equations on other datasets.

Methane prediction equations have generally been developed on datasets containing relatively small numbers of observations and limited ranges of dietary treatments. It is further expected that the validation $\mathrm{R}^{2}$ of the methane prediction equations will be lower than the $R^{2}$ reported based on the dataset from which the prediction equation was derived. The decreased $R^{2}$ is expected to reduce the ability to identify low methane producing dairy cows and might affect the genetic parameters of the predicted methane production. The effect of a $\mathrm{R}^{2}$ lower than one on the genetic parameters depends on the values of the genetic parameters in the part that is not explained by the methane prediction equation. When the values of the genetic parameters in the unexplained part are similar to the values of the genetic parameters in the explained part, a small effect is anticipated. The difference between genetic parameters in the explained part and the unexplained part can only be evaluated in datasets containing both measured and predicted methane production for large number of cows.

The coefficient of variation (CV) of predicted methane yields ranged from $4 \%$ for Methane3 to $6 \%$ for Methane1 and Methane2, which is slightly lower than the CV of $8 \%$ reported by Dijkstra et al. (2011). Milk production traits and individual FA had higher $\mathrm{CV}$, ranging from $7 \%$ for $\mathrm{C} 6: 0$ to $34 \%$ for C18:1trans10. Studies measuring methane production in cows have reported different $\mathrm{CV}$ depending on the measurement method. For example, Chagunda et al. (2013) reported a CV that ranged between $10 \%$ for the methane production of two cows in climate respiration chambers to $46 \%$ for methane measured with a laser on two cows. A low CV could cause difficulties in quantifying genetic variance. 


\subsubsection{Genetic parameters of predicted methane yields}

The heritabilities of the predicted methane yields ranged from 0.12 for Methane 1 to 0.44 for Methane3, and the proportion of variance explained by herd ranged from 0.31 for Methane3 to 0.55 for Methane1. The heritabilities of the individual FA ranged from 0.11 for $\mathrm{C} 17: 0$ anteiso to 0.46 for $\mathrm{C} 6: 0$, and the proportion of variance explained by herd ranged from 0.15 for $\mathrm{C} 6: 0$ to 0.60 for C18:1trans11. Lassen and Løvendahl (2013) reported $a h^{2}$ of 0.21 for the ratio between methane and carbon dioxide measured in an automatic milking system on 683 dairy cows. Pinares-Patiño et al. (2013) measured methane yield (in $\mathrm{g} / \mathrm{kg} \mathrm{DMI}$ ) of 1,225 sheep in climate respiration chambers and reported $a h^{2}$ of 0.13 . De Haas et al. (2011) predicted methane production (g/d) based on feed intake and diet composition for 548 cows, reporting a $\mathrm{h}^{2}$ of 0.35 , whereas predicted methane production corrected for fat and protein corrected milk had a $\mathrm{h}^{2}$ of 0.58 . Actual and predicted methane production shows heritable variation in the literature and in our study; therefore, methane production can be targeted by breeding strategies.

In conclusion, the results show that methane yields predicted based on milk FA $(\mathrm{g} / \mathrm{kg}$ $\mathrm{DMI} ; \mathrm{R}^{2}: 0.73-0.63$ ) are heritable traits, with heritabilities ranging between 0.12 and 0.44 . Breeding can, thus, be used to decrease methane production predicted based on milk fatty acids.

\subsection{Acknowledgements}

Milk fatty acid profiles were obtained from the Dutch Milk Genomics Initiative, funded by Wageningen University, the Dutch Dairy Association (NZO), CRV, and the Dutch Technology Foundation STW.

\subsection{References}

Bouwman, A. C., H. Bovenhuis, M. H. P. W. Visker, and J. A. M. van Arendonk. 2011. Genome-wide association of milk fatty acids in Dutch dairy cattle. BMC Genet. 12:43.

Buddle, B. M., M. Denis, G. T. Attwood, E. Altermann, P. H. Janssen, R. S. Ronimus, C. S. Pinares-Patiño, S. Muetzel, and D. Neil Wedlock. 2011. Strategies to reduce methane emissions from farmed ruminants grazing on pasture. Vet. J. 188(1):1117.

Chagunda, M. G. G., D. Ross, J. Rooke, T. Yan, J. L. Douglas, L. Poret, N. R. McEwan, P. Teeranavattanakul, and D. J. Roberts. 2013. Measurement of enteric methane 
from ruminants using a hand-held laser methane detector. Acta Agric. Scan. A: Anim. Sci. 63(2):68-75.

Chilliard, Y., C. Martin, J. Rouel, and M. Doreau. 2009. Milk fatty acids in dairy cows fed whole crude linseed, extruded linseed, or linseed oil, and their relationship with methane output. J. Dairy Sci. 92(10):5199-5211.

De Haas, Y., J. J. Windig, M. P. L. Calus, J. Dijkstra, M. de Haan, A. Bannink, and R. F. Veerkamp. 2011. Genetic parameters for predicted methane production and potential for reducing enteric emissions through genomic selection. J. Dairy Sci. 94(12):6122-6134.

Dijkstra, J., S. M. van Zijderveld, J. A. Apajalahti, A. Bannink, W. J. J. Gerrits, J. R. Newbold, H. B. Perdok, and H. Berends. 2011. Relationships between methane production and milk fatty acid profiles in dairy cattle. Anim. Feed Sci. and Technol. 166-167:590-595.

Ellis, J., J. Dijkstra, E. Kebreab, A. Bannink, N. Odongo, B. McBride, and J. France. 2008. Aspects of rumen microbiology central to mechanistic modelling of methane production in cattle. J. Agric. Sci. 146(02):213-233.

FAOSTAT. 2012. FAOSTAT Emission Database. Accessed Jan. 9, 2014. www.faostat.fao.org.

Forster, P., V. Ramaswamy, P. Artaxo, T. Berntsen, R. Betts, D.W. Fahey, J. Haywood, J. Lean, D.C. Lowe, G. Myhre, J. Nganga, R. Prinn, G. Raga, M. Schulz and R. Van Dorland. 2007. Changes in Atmospheric Constituents and in Radiative Forcing. In: Climate Change 2007: The Physical Science Basis. Contribution of Working Group I to the Fourth Assessment Report of the Intergovermental Panel on Climate Change. S. Solomon, D. Qin, M. Manning, Z. Chen, M. Marquis, K.B. Averyt, M.Tignor and H.L. Miller, ed. Cambridge University Press, Cambridge, United Kingdom and New York, NY, USA.

Gilmour, A. R., B.J. Gogel, B.R. Cullis, and R. Thompsom. 2006. ASReml User Guide Release 2.0. VSN International Ltd, Hemel Hempstead, HP1 1ES, UK.

Heringstad, B., D. Gianola, Y.M. Chang, J. Ødegård, and G. Klemetsdal. 2006. Genetic Associations Between Clinical Mastitis and Somatic Cell Score in Early First-Lactation Cows. J. Dairy Sci. 89(6):2236-2244.

Hristov, A. N., T. Ott, J. Tricarico, A. Rotz, G. Waghorn, A. Adesogan, J. Dijkstra, F. Montes, J. Oh, E. Kebreab, S. J. Oosting, P. J. Gerber, B. Henderson, H. P. S. Makkar, and J. Firkins. 2013. SPECIAL TOPICS - Mitigation of methane and nitrous oxide emissions from animal operations: III. A review of animal management mitigation options. J. Anim. Sci. 91(11):5095 - 5113. 
Lassen, J., and P. Løvendahl. 2013. Heritability for enteric methane emission from Danish Holstein cows using a non-invasive FTIR method. Adv. Anim. Biosci. 4(2):280.

McCartney, C. A., I. D. Bull, and R. J. Dewhurst. 2013. Chemical markers for rumen methanogens and methanogenesis. Animal 7(Suppl. 2):409-417.

Mohammed, R., S. M. McGinn, and K. A. Beauchemin. 2011. Prediction of enteric methane output from milk fatty acid concentrations and rumen fermentation parameters in dairy cows fed sunflower, flax, or canola seeds. J. Dairy Sci. 94(12):6057-6068.

Patra, A. K. 2012. Enteric methane mitigation technologies for ruminant livestock: A synthesis of current research and future directions. Environ. Monit. Assess. 184(4):1929-1952.

Pinares-Patiño, C. S., S. M. Hickey, E. A. Young, K. G. Dodds, S. MacLean, G. Molano, E. Sandoval, H. Kjestrup, R. Harland, C. Hunt, N. K. Pickering, and J. C. McEwan. 2013. Heritability estimates of methane emissions from sheep. Animal 7 (Suppl 2):316-321.

St-Pierre, N.R. 2001. Invited Review: Integrating Quantitative Findings from Multiple Studies Using Mixed Model Methodology. J. Dairy Sci. 84(4):741-755.

Stoop, W. M., J. A. M. Van Arendonk, J. M. L. Heck, H. J. F. Van Valenberg, and H. Bovenhuis. 2008. Genetic parameters for major milk fatty acids and milk production traits of dutch Holstein-Friesians. J. Dairy Sci. 91(1):385-394.

Van Lingen, H. J., L. A. Crompton, W. H. Hendriks, C. K. Reynolds, and J. Dijkstra. 2014. Meta-analysis of relationships between enteric methane yield and milk fatty acid profile in dairy cattle. J. Dairy Sci. 97(11):7115-7132.

Vlaeminck, B., V. Fievez, A. R. J. Cabrita, A. J. M. Fonseca, and R. J. Dewhurst. 2006. Factors affecting odd- and branched-chain fatty acids in milk: A review. Anim. Feed Sci. Technol. 131(3-4):389-417. 


\section{Genetic Background of Methane Emission by Dutch Holstein Friesian Cows Measured with Infrared Sensors in Automatic Milking Systems}

S. van Engelen ${ }^{1,2}$, H. Bovenhuis ${ }^{2}$, P.P.J. van der Tol ${ }^{3}$, and M.H.P.W. Visker ${ }^{1,2}$

${ }^{1}$ Top Institute Food and Nutrition, P.O. Box 557, 6700 AN, Wageningen, the Netherlands; ${ }^{2}$ Wageningen University \& Research Animal Breeding and Genomics, P.O. Box 338, 6700 AH, Wageningen, the Netherlands; ' ${ }^{2}$ Lely Industries NV, Cornelis van der Lelylaan 1, 3147 PB Maassluis, the Netherlands Journal of Dairy Science (Accepted) 


\begin{abstract}
International environmental agreements have led to the need to reduce methane emission by dairy cows. Reduction could be achieved through selective breeding. The aim of this study was to quantify the genetic variation of methane emission by Dutch Holstein Friesian cows measured using infrared sensors installed in automatic milking systems (AMS). Measurements of methane $\left(\mathbf{C H}_{4}\right)$ and carbon dioxide $\left(\mathbf{C O}_{2}\right)$ on 1508 Dutch Holstein Friesian cows located on 11 commercial dairy farms were available. Phenotypes per AMS visit were the mean of $\mathrm{CH}_{4}\left(\mathrm{CH}_{4}\right.$ mean), mean of $\mathrm{CO}_{2}$ ( $\mathrm{CO}_{2}$ mean), $\mathrm{CH}_{4}$ mean divided by $\mathrm{CO}_{2}$ mean (Ratiomean), and their $\log _{10^{-}}$ transformations $\mathrm{CH}_{4} \mathbf{l o g}, \mathrm{CO}_{2} \mathbf{l o g}$, and Ratiolog. The repeatabilities of the $\log _{10-}$ transformated methane phenotypes were 0.27 for $\mathrm{CH}_{4} \log , 0.31$ for $\mathrm{CO}_{2} \log$, and 0.14 for Ratiolog. The heritabilities of these phenotypes were 0.11 for $\mathrm{CH}_{4} \log , 0.12$ for $\mathrm{CO}_{2} \mathrm{log}$, and 0.03 for Ratiolog. These results indicate that measurements taken using infrared sensors in AMS are repeatable and heritable and, thus, could be used for selection for lower $\mathrm{CH}_{4}$ emission. Furthermore, it is important to account for farm, AMS, day of measurement, time of day, and lactation stage when estimating genetic parameters for methane phenotypes. Selection based on $\mathrm{CH}_{4} \mathrm{log}$ instead of Ratiolog would be expected to give a greater reduction of $\mathrm{CH}_{4}$ emission by dairy cows.
\end{abstract}

Key words: methane emission, dairy cow, AMS, non-dispersive infrared sensor 


\subsection{Introduction}

Agriculture contributes $24 \%$ of the total global greenhouse gas emissions (IPCC, 2014). The single largest pollution source within agriculture is enteric fermentation, i.e., the breakdown of feed in the rumen that results in the production of methane $\left(\mathrm{CH}_{4}\right)$ (Gerber et al., 2013). Approximately $8 \%$ of the worldwide agricultural greenhouse gas emissions originate from enteric $\mathrm{CH}_{4}$ emissions by dairy cows (FAOSTAT, 2012;FAO, 2014), showing the impact of dairy production on global warming. In December 2015, agreements were made in Paris between 195 countries to tackle climate change and keep global warming firmly below $2^{\circ} \mathrm{C}$ (UNCCC, 2015). These agreements have further emphasized the importance of the reduction of $\mathrm{CH}_{4}$ emission by dairy cows.

Reduction of $\mathrm{CH}_{4}$ emission by dairy cows can be achieved through a combination of mitigation strategies comprising dietary, microbial, management, and breeding strategies (Cottle et al., 2011;Hristov et al., 2013). Selective breeding has the advantage of giving a cumulative, permanent, and long-term reduction of $\mathrm{CH}_{4}$ emission. An example of breeding for reduced $\mathrm{CH}_{4}$ is the reduction of $13 \%$ of $\mathrm{CH}_{4}$ per $\mathrm{kg}$ of milk in Dutch dairy cattle that has been realized from 1990 to 2010 by selection for higher milk production (Vellinga et al., 2011). A further reduction of $\mathrm{CH}_{4}$ emission through selective breeding is wanted and requires quantification of possible genetic variation in $\mathrm{CH}_{4}$ emission.

To quantify possible genetic variation in $\mathrm{CH}_{4}$ emission, $\mathrm{CH}_{4}$ emission needs to be measured on large numbers of individual cows. One of the measurement methods could be infrared sensors installed in automatic milking systems (AMS). The infrared sensor samples the breath of the cows present in the AMS and measures $\mathrm{CH}_{4}$ and carbon dioxide $\left(\mathrm{CO}_{2}\right)$ concentration continuously. An advantage of this system is that cows visit the AMS several times per day and these repeated visits ensure repeated measurements of the same cow over the day and over time (Garnsworthy et al., 2012a). Furthermore, sensors can easily be moved from one AMS to another and, thus, provide the opportunity to measure individual $\mathrm{CH}_{4}$ emission on large numbers of cows.

Previous studies have shown that $\mathrm{CH}_{4}$ measurements based on infrared sensors in AMS are repeatable. Lassen et al. (2012) summarized $\mathrm{CH}_{4}$ measurements per AMS visit by taking the mean of $\mathrm{CH}_{4}$, the mean of $\mathrm{CO}_{2}$ and the mean of the ratio between $\mathrm{CH}_{4}$ and $\mathrm{CO}_{2}$. Repeatabilities ranged between 0.22 and 0.46 for 50 Holstein cows and 43 Jersey cows. Bell et al. (2014b) found a repeatability of 0.74 for mean of $\mathrm{CH}_{4}$ per AMS visit for 36 Holstein-Friesian cows. These repeatabilities illustrate that infrared 
sensors in AMS could provide the repeatable measurements on individual cows that are needed to quantify possible genetic variation in $\mathrm{CH}_{4}$ emission.

These $\mathrm{CH}_{4}$ phenotypes can be influenced by farm conditions (Bell et al., 2014a), hour of the day (Garnsworthy et al., 2012b), and week of lactation (Lassen et al., 2016); therefore, these effects were studied. Farm conditions can impact $\mathrm{CH}_{4}$ emission via the differences in feed regimes between farms (Bell et al., 2014a;Hammond et al., 2016). Hour of the day can influence $\mathrm{CH}_{4}$ emission as cow behavior, time after feeding, and ambient conditions change throughout the day (Garnsworthy et al., 2012b;Lassen et al., 2012;Bell et al., 2014b). Week of lactation can affect $\mathrm{CH}_{4}$ emission as the amount and composition of feed varies throughout lactation (Garnsworthy et al., 2012b;Bell et al., 2014a; Lassen and Løvendahl, 2016).

Repeated measurements obtained from infrared sensors can be used to estimate the variation in $\mathrm{CH}_{4}$ emission between cows. Lassen and Løvendahl (2016) found genetic variation in $\mathrm{CH}_{4}$ emission that was summarized in several phenotypes. The heritabilities ranged between 0.16 and 0.21 , providing support for the use of $\mathrm{CH}_{4}$ concentrations measured using infrared sensors in AMS to decrease $\mathrm{CH}_{4}$ emission through selective breeding.

The aim of this study was to quantify the genetic variation of $\mathrm{CH}_{4}$ emission by Dutch dairy cows measured using infrared sensors installed in AMS. The dataset comprised of $\mathrm{CH}_{4}$ and $\mathrm{CO}_{2}$ measurements taken with infrared sensors on Dutch Holstein Friesian cows located on commercial dairy farms. Measurements were summarized into different $\mathrm{CH}_{4}$ phenotypes per AMS visit and repeatability and heritability were calculated for these phenotypes.

\subsection{Materials and Methods}

\subsubsection{Ethical statement}

This research was accredited by the animal experimentation committee of Wageningen University and Research and the central committee animal trials under application number 2013085 and trial code 2013097.

\subsubsection{Methane sensor}

Methane phenotypes were measured using sensors. These sensors were tested in climate respiration chambers (CRC) before they were installed on commercial farms. In this test, $\mathrm{CH}_{4}$ emissions of 20 individual Holstein Friesian cows were recorded in $\mathrm{CRC}$ for 3 consecutive days and, simultaneously, by the sensor. In the $\mathrm{CRC}, \mathrm{CH}_{4}$ and $\mathrm{CO}_{2}$ were measured every $12.5 \mathrm{~min}$ as described by Heetkamp et al. (2015). The 
sensors were gas analyzers (SenseAir $\mathrm{LPL} \mathrm{CH} / \mathrm{CO}_{2}$, Rise Acreo, Stockholm, Sweden) that were installed in line with the cow's nostrils when standing and facing forward. Air was drawn through the instrument at $1 \mathrm{l} / \mathrm{min} ; \mathrm{CH}_{4}$ and $\mathrm{CO}_{2}$ concentrations were measured continuously using a non-dispersive infrared (NDIR) technique, and logged twice per second. Phenotypes were defined as follows: $\mathrm{CH}_{4}$ production (l/d) from $\mathrm{CRC} ; \mathrm{CH}_{4}$ concentration (ppm) from sensor; and $\mathrm{CH}_{4}: \mathrm{CO}_{2}$ ratio from sensor.

\subsubsection{Data}

$\mathrm{CH}_{4}$ and $\mathrm{CO}_{2}$ concentrations (ppm) were measured on 1508 primiparous and multiparous dairy cows from 11 commercial farms in the Netherlands. On nine of these farms, cows were fed in the morning, whereas on one farm cows were fed in the evening. In addition, some farms had automatic feed pushers that compiled the feed continuously during the day, and one farm had an automatic feeder that fed the cows freshly mixed feed up to 30 times a day. Furthermore, cows on some farms could graze during the day whereas cows on other farms were kept indoors. More than $85 \%$ of the cows were at least $7 / 8$ Holstein Friesian. Measurements were taken during milking in automatic milking systems (AMS; Lely Astronaut A4, Lely Industries NV, Maassluis, the Netherlands) using NDIR sensors. A total of four sensors were used to collect all data by installing them consecutively in different AMS. Measurements were taken in a total of 23 AMS, one to four AMS per farm, between November 2013 and March 2016. The data from these sensors were linked to the data from the AMS to obtain the identification numbers (ID) of the cows and, subsequently, additional animal information, such as week of lactation. The data of the sensors were aligned to the AMS visits as both were recorded on different devices. The alignment between these devices was based on the pattern of AMS visits, i.e., duration and order of AMS visits and the time between the AMS visits. This pattern was aligned in such a way that $\mathrm{CH}_{4}$ and $\mathrm{CO}_{2}$ concentrations were highest during AMS visits and lowest in between AMS visits. After alignment, the ID of the cows were used to link sensor data to data from the cooperative cattle improvement organization CRV (Arnhem, the Netherlands) to obtain the pedigree. The pedigree was traced back two generations, resulting in 4,214 animals in the pedigree.

\subsubsection{Data editing}

Data from the sensors and AMS were edited based on several conditions. The first condition was that only data from days with sensor measurements for at least $30 \%$ of the day were kept. Days with less than $30 \%$ data were mostly without data or the data present were fragmentary and these days were, therefore, discarded. The number of days with measurements ranged from ten up to 81 per AMS. The second 
condition was that AMS visits should last at least 90 seconds and AMS visits shorter than 90 seconds were removed from the dataset. Removing AMS visits shorter than 90 seconds ensured that most AMS visits that did not result in a milking, and would, thus, not provide a steady measurement, were removed from the dataset. The third condition was that the ID of the cow visiting the AMS should be known. AMS visits without cow ID were removed from the dataset, as these could not be linked to the pedigree. The fourth condition was that week of lactation of the cow visiting the AMS should be known and cows should be between one and 60 weeks in lactation. The fifth condition was that AMS visits with missing $\mathrm{CH}_{4}$ phenotypes (see phenotypes) or missing model effects (see model 1 ) were removed from the dataset. The sixth and last condition was that each cow should have at least four AMS visits. After editing, a total of 129,900 AMS visits on 1,508 dairy cows that had on average 86 AMS visits (range: 4-295 AMS visits) were available for analysis. The number of cows ranged between 62 and 224 per farm.

AMS visits that had a standardized residual effect $>3.5$ based on model 1 for $\mathrm{CH}_{4}$ mean, $\mathrm{CH}_{4} \log$, $\mathrm{CO}_{2}$ mean, $\mathrm{CO}_{2} \mathrm{log}$, Ratiomean or Ratiolog were considered outliers and were removed. After removal of the outliers, the dataset consisted of 123,369 AMS visits from 1,508 dairy cows. This dataset was used to estimate the variance components and genetic parameters.

\subsubsection{Phenotypes}

The $\mathrm{CH}_{4}$ and $\mathrm{CO}_{2}$ measurements were summarized per AMS visit into six phenotypes. To correct for the background levels of $\mathrm{CH}_{4}$ and $\mathrm{CO}_{2}$ in the barn, offsets for $\mathrm{CH}_{4}$ and $\mathrm{CO}_{2}$ were calculated per AMS visit. The background levels of $\mathrm{CH}_{4}$ were assumed to be 0 ppm and the offset for $\mathrm{CH}_{4}$ was the mean of the 10 lowest values for $\mathrm{CH}_{4}$ in a specific AMS visit. As the background levels of $\mathrm{CO}_{2}$ were assumed to be $400 \mathrm{ppm}$, the offset for $\mathrm{CO}_{2}$ was the mean of the lowest 10 values for $\mathrm{CO}_{2}$ minus 400 . The $\mathrm{CH}_{4}$ offset was subtracted from the individual (twice per second) $\mathrm{CH}_{4}$ measurements during a specific AMS visit and the $\mathrm{CO}_{2}$ offset was subtracted from the individual $\mathrm{CO}_{2}$ measurements. After adjustment for the offsets, the methane phenotypes were calculated. The first phenotype is the mean of $\mathrm{CH}_{4}$ per AMS visit $\left(\mathrm{CH}_{4}\right.$ mean). The second phenotype is the mean of $\mathrm{CO}_{2}$ per $\mathrm{AMS}$ visit $\left(\mathrm{CO}_{2}\right.$ mean). The third phenotype is based on the ratio $\left(\mathrm{CH}_{4} / \mathrm{CO}_{2}\right)$ per AMS visit and is calculated as the mean of $\mathrm{CH}_{4}$ divided by the mean $\mathrm{CO}_{2}$ per AMS visit (Ratiomean). The residuals of the traits based on model 1 were not normally distributed. For example, the residuals of $\mathrm{CH}_{4}$ mean showed a thicker and longer right tail (Kurtosis=3.24). Therefore, phenotypes were $\log _{10}$-transformated and after transformation residuals became normally distributed 
(Kurtosis of $\log _{10}$-transformed $\mathrm{CH}_{4}$ mean $=0.55$ ). These $\log _{10}$-transformations resulted in the fourth phenotype $\mathrm{CH}_{4} \log \left(\log _{10}\left(\mathrm{CH}_{4}\right.\right.$ mean)), fifth phenotype $\mathrm{CO}_{2} \mathbf{l o g}$ $\left(\log _{10}\left(\mathrm{CO}_{2}\right.\right.$ mean $\left.)\right)$, and sixth phenotype Ratiolog ( $\log _{10}$ (Ratiomean)). Furthermore, milk yield in kg per AMS visit was included as a general trait.

\subsubsection{Data analysis}

Variance components of the phenotypes were estimated with ASReml 4.1 (Gilmour et al., 2015) using the following model:

$Y_{i j k l m}=m u+$ DayAMS $_{i}+$ Lactationweek $_{j}+$ Hour*Farm $_{k}+$ Animal $_{l}+$ Permanent $_{m}+$ e $_{i j k l m}$ (model 1)

Where $\mathrm{Y}_{\mathrm{ijk}} \mathrm{m}$ is the dependent variable $\left(\mathrm{CH}_{4}\right.$ mean, $\mathrm{CO}_{2}$ mean, Ratiomean, $\mathrm{CH}_{4}$ log, $\mathrm{CO}_{2} \log$, Ratiolog or milk yield); $\mathrm{mu}$ is the mean; DayAMS $\mathrm{S}_{i}$ is the combined effect of day of measurement, farm of measurement, AMS of measurement and sensor of measurement (991 levels); Lactationweek $\mathrm{k}_{\mathrm{j}}$ is the fixed effect of week of lactation (60 levels); Hour*Farm ${ }_{k}$ is the fixed interaction of hour of the day (24 levels) and farm of measurement (11 levels); Animal, is the random additive genetic effect of animal ( $\mathrm{N}\left(0, \mathbf{A} \sigma^{2}\right.$ Animal) $)$ with additive genetic relationship matrix $\mathbf{A}$ and additive genetic variance $\sigma^{2}{ }_{\text {Animal; }}$ Permanent $t_{m}$ is the random permanent environmental effect $(\sim N(0$, $\left(\sigma^{2}\right.$ Permanent)) with identity matrix I and permanent environmental variance $\sigma^{2}$ Permanent; and $e_{i j k l m}$ is the random error effect $\left(\sim N\left(0, I \sigma^{2}\right.\right.$ Error $)$ ) with identity matrix I and residual variance $\sigma^{2}$ Error.

\subsubsection{Measurement period}

For analysis, all data available for each cow were used, ranging from 1 to 81 days per cow. To study the effect of length of measurement period a subset of the data was used consisting of data from one AMS on one farm during 50 consecutive days from December 2015 to February 2016. The measurement period lengths that were tested were $3,5,10,20$, and 30 consecutive days. For each of these lengths, five individual datasets with that length in consecutive days were created by random sampling from the dataset of 50 days (e.g., five datasets containing 30 consecutive days). Datasets of the same measurement period length were sometimes partially overlapping. Repeatabilities were calculated for each measurement period dataset, and repeatabilities and their standard errors were averaged over the five datasets for each measurement period length. 


\subsubsection{Genetic parameters}

The repeatability was calculated as follows:

$$
\text { Repeatability }=\frac{\sigma_{\text {Animal }}^{2}+\sigma_{\text {Permanent }}^{2}}{\sigma_{\text {Animal }}^{2}+\sigma_{\text {Permanent }}^{2}+\sigma_{\text {Error }}^{2}}
$$

with additive genetic variance $\sigma^{2}$ Animal, permanent environmental variance $\sigma^{2}$ Permanent and residual variance $\sigma^{2}$ Error. The heritability $\left(\mathbf{h}^{2}\right)$ was calculated as follows:

$$
h^{2}=\frac{\sigma_{\text {Animal }}^{2}}{\sigma_{\text {Animal }}^{2}+\sigma_{\text {Permanent }}^{2}+\sigma_{\text {Error }}^{2}}
$$

We presented the descriptive statistics on all six phenotypes, but the genetic parameters of only the $\log _{10}$-transformed phenotypes were shown. As the residuals of the untransformed phenotypes were not normally distributed, this could affect the results found for these genetic parameters. Effects of the model parameters were presented on the untransformed phenotypes as these effects are then easier to interpret.

The accuracy of the breeding value for $\mathrm{CH}_{4}$ emission for a cow was calculated as: $\sqrt{\frac{m h^{2}}{(m-1) t+1}}$ where $\mathrm{m}$ is the number of repeated sensor measurements in an AMS, $\mathrm{h}^{2}$ is the heritability, and $t$ is the repeatability. The accuracy of breeding value for $\mathrm{CH}_{4}$ for a bull with half-sib daughters was calculated as: $\sqrt{\frac{n x^{2}}{(n-1) x^{2}+4}}$ where $\mathrm{n}$ is the number of half-sib daughters and $x$ is the accuracy of the breeding value of the daughters with 25 repeated sensor measurements each.

\subsection{Results}

\subsubsection{Methane sensor test}

During the test, the repeatabilities of $\mathrm{CH}_{4}$ production $(\mathrm{l} / \mathrm{d}), \mathrm{CH}_{4}$ concentration (ppm) and $\mathrm{CH}_{4}: \mathrm{CO}_{2}$ ratio were calculated using data averaged per cow per day. Repeatability of $\mathrm{CH}_{4}$ production obtained from $\mathrm{CRC}$ measurements was 0.87 (s.e.=0.04), repeatability of $\mathrm{CH}_{4}$ concentration obtained from sensor measurements was 0.90 (s.e. $=0.04$ ) and repeatability of $\mathrm{CH}_{4}: \mathrm{CO}_{2}$ ratio obtained from sensor measurements was 0.94 (s.e.=0.02). The correlation between $\mathrm{CH}_{4}$ production obtained from $\mathrm{CRC}$ and $\mathrm{CH}_{4}$ concentration obtained from sensor was 0.71 (s.e. $=0.10$ ). 
The correlation between $\mathrm{CH}_{4}$ production obtained from $\mathrm{CRC}$ and $\mathrm{CH}_{4}: \mathrm{CO}_{2}$ ratio obtained from sensor was 0.49 (s.e.=0.18).

\subsubsection{Descriptive statistics}

Descriptive statistics on the six methane phenotypes and on milk production per AMS visit are represented in Table 3.1. After the $\log _{10}$-transformation, the means and standard deviations of $\mathrm{CH}_{4}$ mean and $\mathrm{CO}_{2}$ mean decreased, whereas the mean and standard deviation increased in an absolute sense for Ratiomean. A milk yield of $0 \mathrm{~kg}$ for 619 AMS visits illustrates that during these AMS visits the cows were not milked by the AMS. These AMS visits were still present in the dataset, despite removing AMS visits shorter than 90 seconds. We considered any AMS visit longer than 90 seconds suitable for $\mathrm{CH}_{4}$ and $\mathrm{CO}_{2}$ measurements, irrespective if the cow was being milked during that visit.

\subsubsection{Effect of hour of the day on methane emission}

In general, the effect of hour of the day on $\mathrm{CH}_{4}$ mean, as obtained from model 1 , was lower during the night and higher during the day. This general pattern showed variation between farms, as demonstrated by farms $A$ and $B$ in Figure 3.1. Farm A showed two distinct peaks in $\mathrm{CH}_{4}$ mean during the day: the first peak around $9 \mathrm{AM}$ and the second peak around 8 PM. Farm B showed a strong increase in $\mathrm{CH}_{4}$ mean during the day compared with the night. Both types of patterns were present in the dataset, but most farms had a pattern similar to that of farm $A$.

Table 3.1 Descriptive statistics of phenotypes on methane $\left(\mathrm{CH}_{4}\right)$ and carbon dioxide $\left(\mathrm{CO}_{2}\right)$ measured with non-dispersive infrared (NDIR) sensors in automatic milking systems (AMS) on 1,508 Dutch dairy cows (123,369 AMS visits)

\begin{tabular}{lcccc}
\hline Trait & Mean & SD $^{1}$ & Minimum & Maximum \\
\hline CH4mean $(\mathrm{ppm})$ & 254 & 230 & 11 & 2073 \\
${\text { CH4log }(p p m)^{2}}^{2}$ & 2.25 & 0.37 & 1.04 & 3.32 \\
CO2mean (ppm) & 1443 & 681 & 408 & 9054 \\
CO2log (ppm) ${ }^{2}$ & 3.11 & 0.20 & 2.61 & 3.96 \\
Ratiomean & 0.17 & 0.12 & 0.01 & 0.87 \\
Ratiolog $^{2}$ & -0.87 & 0.27 & -1.92 & -0.06 \\
${\text { Milk }(k g)^{3}}^{3}$ & 10.8 & 3.4 & 0.00 & 36.50 \\
\hline
\end{tabular}

${ }^{1}$ Standard deviation.

${ }^{2} \log _{10}$-transformed phenotypes.

${ }^{3}$ Milk production per AMS visit. 


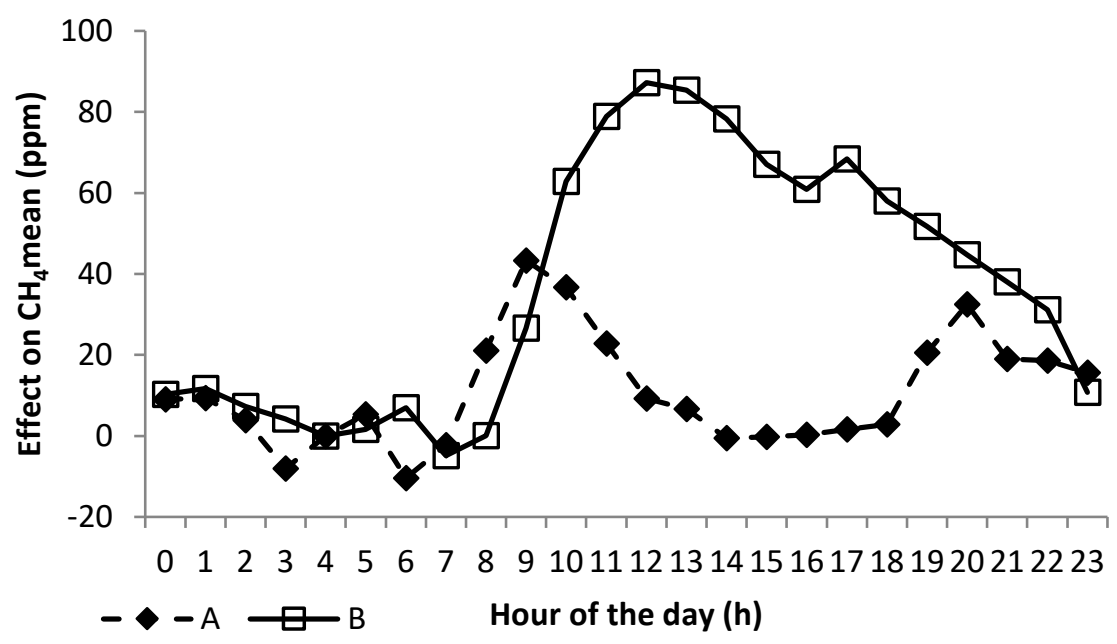

Figure 3.1 Effect of hour of the day on $\mathrm{CH}_{4}$ mean (ppm) measured with non-dispersive infrared (NDIR) sensors in automatic milking systems (AMS) on 1,508 Dutch dairy cows. The figure shows two representative farms ( $A=5,554$ AMS visits; $B=20,458$ AMS visits). The effect of hour 4 was set to zero for both farms to enable comparison and the other effects are expressed relative to hour 4 .

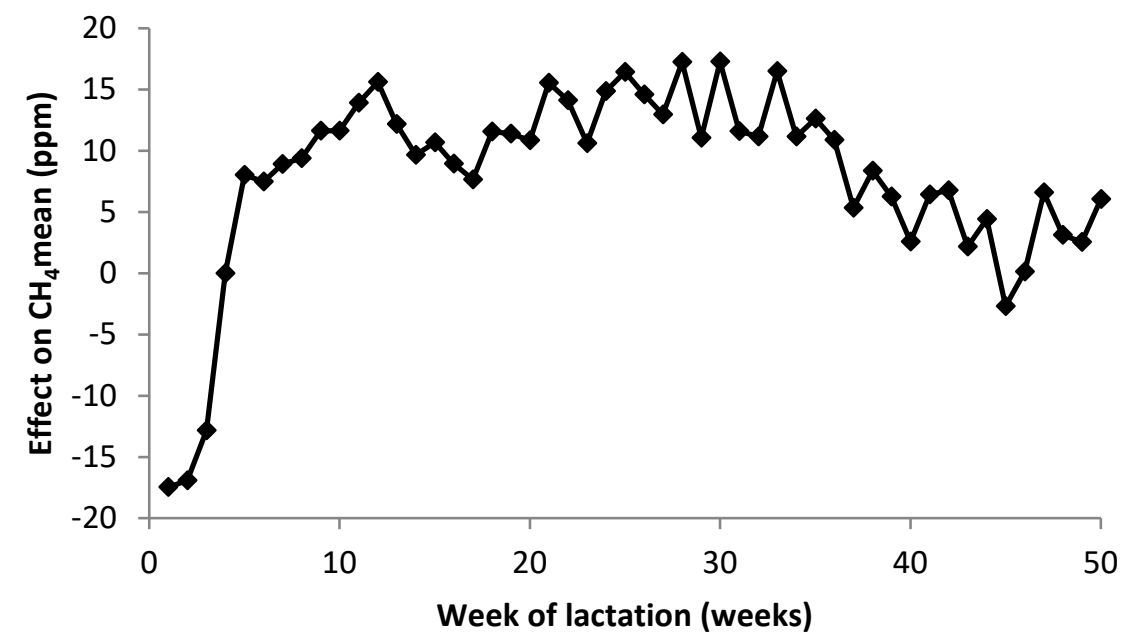

Figure 3.2 Effect of week of lactation on $\mathrm{CH}_{4}$ mean (ppm) measured with non-dispersive infrared (NDIR) sensors in automatic milking systems (AMS) on 1,508 Dutch dairy cows (123,369 AMS visits). The effect of week 4 of lactation was set to zero and the other effects are expressed relative to week 4 . 


\subsubsection{Effect of week of lactation on methane emission}

The effect of week of lactation on $\mathrm{CH}_{4}$ mean, as obtained from model 1 , for the first 50 weeks of lactation is presented in Figure 3.2. The effect of week of lactation on $\mathrm{CH}_{4}$ mean increased rapidly during the first 12 weeks of lactation. After this strong increase, the effect of week of lactation on $\mathrm{CH}_{4}$ mean remained relatively constant until 35 weeks in lactation and decreased gradually thereafter. Between weeks 12 and 35 , the effect of lactation week accounted for $3-7 \%$ of the variation in the mean of $\mathrm{CH} 4$ mean.

\subsubsection{Genetic parameters for methane emission}

Repeatabilities and heritabilities of the $\log _{10}$-transformated methane phenotypes and milk production are presented in Table 3.2. The repeatabilities ranged between 0.14 and 0.31 for the methane phenotypes, were similar for $\mathrm{CH}_{4} \log$ and $\mathrm{CO}_{2} \mathrm{log}$, and were lower for Ratiolog. The heritabilities were lower than the repeatabilities and ranged between 0.03 and 0.12 for the methane phenotypes. Heritabilities were similar for $\mathrm{CH}_{4} \log$ and $\mathrm{CO}_{2} \log$, and were lower for Ratiolog. Milk yield per AMS visit had a higher repeatability (0.45) and heritability (0.17) than the methane phenotypes. Standard errors of the repeatabilities and heritabilities were between 0.005 and 0.03 .

The accuracy of the breeding value for $\mathrm{CH}_{4}$ emission expressed as $\mathrm{CH}_{4}$ log for a cow based on 25 repeated sensor measurements in an AMS was 0.61. For a bull with 25 daughters, where each daughter has 25 repeated sensor measurements, the accuracy of the breeding value for $\mathrm{CH}_{4}$ emission was 0.85 .

Table 3.2 Repeatabilities and heritabilities of phenotypes on methane $\left(\mathrm{CH}_{4}\right)$ and carbon dioxide $\left(\mathrm{CO}_{2}\right)$ measured with non-dispersive infrared (NDIR) sensors in automatic milking systems (AMS) on 1,508 Dutch dairy cows (123,369 AMS visits) ${ }^{1}$

\begin{tabular}{lcc}
\hline Trait & repeatability & heritability \\
\hline $\mathrm{CH}_{4} \log (\mathrm{ppm})^{2}$ & $0.27_{(0.008)}$ & $0.11_{(0.02)}$ \\
$\mathrm{CO}_{2} \log (\mathrm{ppm})^{2}$ & $0.31_{(0.009)}$ & $0.12_{(0.02)}$ \\
Ratiolog ${ }^{2}$ & $0.14_{(0.005)}$ & $0.03_{(0.01)}$ \\
Milk $(\mathrm{kg})^{3}$ & $0.45_{(0.010)}$ & $0.17_{(0.03)}$ \\
\hline ble contains the repeatability (repeatability $=\sigma^{2}$ Animal $+\sigma^{2}$ Permanent $/ \sigma^{2}$ Animal $+\sigma^{2}$ Permanent \\
and the heritability (heritability $=\sigma^{2}$ Animal $/ \sigma^{2}$ Animal $+\sigma^{2}$ Permanent $+\sigma^{2}$ Error $)$ with their \\
live standard errors in parentheses. \\
ransformed phenotypes. \\
poduction per AMS visit.
\end{tabular}




\subsubsection{Effect of measurement period}

The average repeatabilities and standard error of each measurement period length are presented in Table 3.3. All three methane phenotypes showed higher repeatabilities in measurement periods longer than 5 days compared with shorter measurement periods. Measurement periods longer than 10 days did not lead to further improvements of the repeatabilities. Standard errors decreased with increasing measurement period length, but the largest decrease occurred with the increase in measurement period from 3 to 5 days. Furthermore, repeatabilities of the measurement period of 10 days were not significantly different from the repeatabilities of the dataset with all observations from that specific AMS.

\subsection{Discussion}

The aim of this study was to quantify the genetic variation in methane phenotypes measured with NDIR sensors in AMS. Methane phenotypes based on sensor measurements of $\mathrm{CH}_{4}$ and $\mathrm{CO}_{2}$ on Dutch dairy cows were both repeatable and heritable. The repeatabilities of these phenotypes ranged between 0.14 and 0.31 . The heritabilities of these phenotypes ranged between 0.03 and 0.12 , indicating that there is genetic variation in these phenotypes.

Table 3.3 The average repeatability of phenotypes on methane $\left(\mathrm{CH}_{4}\right)$ and carbon dioxide $\left(\mathrm{CO}_{2}\right)$ measured with non-dispersive infrared (NDIR) sensors in automatic milking systems (AMS) on Dutch dairy cows over different measurement period lengths ${ }^{1,2}$

\begin{tabular}{lcccc}
\hline Measurement period & $\mathrm{N}$ & $\mathrm{CH}_{4} \log ^{3}$ & $\mathrm{CO}_{2} \log ^{3}$ & Ratiolog ${ }^{3}$ \\
\hline Total AMS period & 8,851 & $0.19_{(0.029)}$ & $0.16_{(0.026)}$ & $0.19_{(0.026)}$ \\
3 days & 376 & $0.12_{(0.075)}$ & $0.12_{(0.062)}$ & $0.14_{(0.079)}$ \\
5 days & 650 & $0.15_{(0.055)}$ & $0.12_{(0.044)}$ & $0.15_{(0.054)}$ \\
10 days & 1,295 & $0.22_{(0.049)}$ & $0.17_{(0.043)}$ & $0.22_{(0.048)}$ \\
20 days & 2,567 & $0.23_{(0.040)}$ & $0.18_{(0.034)}$ & $0.23_{(0.038)}$ \\
30 days & 3,827 & $0.23_{(0.037)}$ & $0.18_{(0.031)}$ & $0.22_{(0.034)}$ \\
50 days & 6,296 & $0.22_{(0.032)}$ & $0.16_{(0.026)}$ & $0.21_{(0.030)}$ \\
\hline
\end{tabular}

${ }_{1}^{1}$ Per measurement period length 5 random samples were taken from the dataset of 50 consecutive days, and numbers reported are the average over these 5 random samples. Total AMS period consists of all data from the one AMS (73 days) of which the dataset of 50 consecutive days was obtained.

2 The table contains the measurement period in days, the average number of AMS visit per measurement period $(\mathrm{N})$, and the average repeatability per methane phenotype (repeatability $=\sigma^{2}$ Animal $+\sigma^{2}$ Permanent $/ \sigma^{2}$ Animal $+\sigma^{2}$ Permanent $+\sigma^{2}$ Error $)$ with their respective average standard error (s.e.) in parentheses.

${ }^{3} \log _{10}$-transformed phenotypes. 


\subsubsection{Methane sensor test}

High repeatability of $\mathrm{CH}_{4}$ production obtained from $\mathrm{CRC}$ measurements and of $\mathrm{CH}_{4}$ concentration obtained from sensors agree with the literature (Bell et al., 2014b;Donoghue et al., 2016). The high repeatabilities found in the present study demonstrate high consistency between subsequent measurements on the same animal, implying high precision of measurement and suggesting consistent differences between animals. High repeatabilities and moderate correlations demonstrate the potential of the sensor method for the collection of phenotypes on $\mathrm{CH}_{4}$ emission for large numbers of individual animals. Repeatabilities are expected to be lower when installed in AMS because of more variable conditions on the farm. This limitation is most likely compensated by the ability to perform large-scale collection of data on commercial dairy farms. This facilitates repeated measures on a single animal and recording large numbers of animals, both contributing to the accuracy of estimated breeding values.

\subsubsection{Methane phenotypes}

Phenotypes used in this study were measured in parts per million (ppm). In the literature concentration measurements (in ppm) have been transformed to $\mathrm{CH}_{4}$ production (g/day) using a dilution factor or using $\mathrm{CO}_{2}$ production (Madsen et al., 2010;Garnsworthy et al., 2012a; Lassen and Løvendahl, 2016). These transformations, however, are based on several assumptions, like a constant $\mathrm{CO}_{2}$ production of a cow throughout the day, that may not always be met. $\mathrm{The}^{\mathrm{CH}_{4}}$ production that is obtained after transformation is affected by the accuracy of these assumptions. For breeding, absolute values are not needed, as it focusses on the relative differences between animals to select the best animals.

Phenotypes similar to those used in our study were also used in other studies (e.g. Madsen et al. 2010; Lassen et al. 2012; Bell et al. 2014b). The absolute values of such similar phenotypes, however, have not been published except for Ratiomean, i.e., the mean of the ratio between $\mathrm{CH}_{4}$ and $\mathrm{CO}_{2}$. We included Ratiomean in our study because it was reported in other studies and can be used to quantify methane production (Madsen et al., 2010). The absolute value of Ratiomean in our study was considerably higher than the one reported by Lassen et al. (2012), i.e., 0.17 vs. 0.065 . The reason for this difference is unclear as the absolute values of the underlying traits to Ratiomean, i.e., $\mathrm{CH}_{4}$ mean and $\mathrm{CO}_{2}$ mean, were not reported by Lassen et al. (2012). Breeding, however, does not depend on absolute values, and, therefore, it is expected that the difference in absolute value of Ratiolog compared with the literature would not affect the direction of selection if Ratiolog would be used for selection. 


\subsubsection{Milk yield}

Selective breeding for milk yield has led to substantial genetic progress over time. Heritability for milk yield per AMS visit in our study was 0.17 (s.e. $=0.03$ ). This heritability is slightly lower than the heritability of 0.24 reported (Mulder et al., 2004) for milk yield per day recorded in AMS. The heritability of $\mathrm{CH}_{4} \log$ was 0.11 (s.e.=0.02), which is comparable with the heritability of milk yield per AMS visit. This indicates that there is potential for a reduction in methane emission through selective breeding when using sensor measurements in AMS.

\subsubsection{Effect of DayAMS}

The DayAMS effect that was used in the model includes the effects of the day, farm, AMS, and sensor of measurement. These effects could not be disentangled in our study, because most measurements took place on one farm at a time, with a single sensor installed per AMS. To study the impact of the DayAMS effect on the methane phenotypes, an additional analysis was performed in which DayAMS was included in model 1 as a random effect instead of as a fixed effect. This analysis showed that the percentage of total variation that was explained by the DayAMS effect was $56 \%$ for $\mathrm{CH}_{4} \log , 27 \%$ for $\mathrm{CO}_{2} \log$, and $82 \%$ for Ratiolog. These results indicate that the phenotypes were largely influenced by the DayAMS effect, and illustrates that accounting for the effects of day of measurement, farm, AMS, and sensor is important when analyzing methane phenotypes. Farm conditions that are known to influence $\mathrm{CH}_{4}$ measurements are season, air flow, and barn management (Wu et al., 2016). The large effect of DayAMS agrees with the other studies that acknowledge the impact of farm of measurement and farm conditions on methane measurements (Bell et al., 2014a;Hammond et al., 2016).

\subsubsection{Effect of hour of the day on methane emission}

Hour of the day had a significant effect in our analysis with a p-value below 0.001 when DayAMS was included in model 1 as random. The size of the effect is relatively small compared with the effect of DayAMS. This is in line with previous studies that reported diurnal variation in methane emission, mainly driven by the time of feeding of the cows (Garnsworthy et al., 2012b;Lassen et al., 2012;Bell et al., 2014b). To deal with the rather different feeding strategies of the 11 farms in our study (see material and methods), a farm by hour of the day interaction was included in the model instead of a single hour of the day effect. Not only the moment of feeding differed between the farms, but also the amount of times the cows were fed and the possibility of grazing. These diverse strategies resulted in hour of the day effects per farm that were different for each farm. Therefore, inclusion of the interaction 
between hour of the day and farm instead of a single hour of the day effect into the model was preferred to deal with these diverse feeding strategies.

\subsubsection{Effect of week of lactation on methane emission}

Week of lactation had a significant effect in the model with a p-value below 0.001 when DayAMS was included in model 1 as random. The size of the effect is relatively small compared with the effect of DayAMS. As feed composition and intake usually changes throughout lactation, week of lactation can affect $\mathrm{CH}_{4}$ emission (Garnsworthy et al., 2012b;Bell et al., 2014a; Lassen and Løvendahl, 2016). Previous studies also reported effects of lactation stage on methane emission measured in AMS (Garnsworthy et al., 2012b;Bell et al., 2014a;Lassen and Løvendahl, 2016). Similar to our study, these studies found an increase in methane emissions during the first weeks of lactation. The highest level of methane emission was found at around 10 weeks of lactation by Lassen and Løvendahl (2016), at 20 weeks of lactation by Garnsworthy et al. (2012b), and at 12 weeks of lactation in our study. After the initial increase in methane emission per week of lactation, either a stable level of methane emission until 50 weeks in lactation was reported (Bell et al., 2014a), or a decrease in methane emission per week of lactation was reported (Garnsworthy et al., 2012b; Lassen and Løvendahl, 2016). The extent of this decrease varied between $20 \%$ of the peak methane emission at 50 weeks of lactation (Garnsworthy et al., 2012b) and $80 \%$ of the peak methane emission at 44 weeks of lactation (Lassen and Løvendahl, 2016). In our study, methane emission decreased with about $33 \%$ of the peak methane emission at 50 weeks of lactation. The pattern found in our study is comparable with the patterns found in literature and the found differences in patterns might be explained by many different factors such as the used phenotypes. Our study used $\mathrm{CH}_{4}$ mean in ppm as phenotype whereas the other studies used methane in $\mathrm{g} /$ day that was either from the integral area under the peaks of methane emission (Garnsworthy et al., 2012b) or by the ratio between $\mathrm{CH}_{4}$ and $\mathrm{CO}_{2}$ in relation to heat-producing units (Lassen and Løvendahl, 2016). Based on the results of our study and of the literature, inclusion of lactation stage into the model to analyze methane emission is recommended.

\subsubsection{Repeatabilities of methane phenotypes}

Selective breeding requires a repeatable phenotype for methane emission and methane phenotypes measured in AMS using infrared sensors could be suitable phenotypes. In this study, repeatabilities of the $\log _{10}$-transformed methane phenotypes ranged between 0.14 and 0.31 . Other studies have reported repeatabilities of $\mathrm{CH}_{4}$ measured in AMS that ranged between 0.34 for the mean of 
$\mathrm{CH}_{4}$ and 0.86 for the mean of $\mathrm{CO}_{2}$ (Lassen et al., 2012;Bell et al., 2014b). In general, the repeatabilities found in other studies were higher than the repeatabilities found in our study. Both studies of Lassen and Bell used a model that corrects for diet effects and this might explain the higher repeatabilities found in these studies compared with our study. Repeatabilities found in our study and other studies do confirm that methane measurements by infrared sensors in AMS provide repeatable phenotypes.

\subsubsection{Effect of measurement period}

Measurement period has influenced the repeatabilities found in our study, and other studies have chosen different measurement periods. Bell et al. (2014b) measured $\mathrm{CH}_{4}$ and $\mathrm{CO}_{2}$ for a 35-day period whereas Lassen et al. (2012) measured for a 3-day period. The results obtained from our study indicate that repeatabilities (and their standard errors) remained stable in measurement periods of at least 10 consecutive days. In other words, the value of additional repeated measurements beyond 10 days of measurements on the same individual was close to zero. Although Lassen et al. (2012) used a shorter measurement period than our study, their reported standard errors are small (s.e. $=0.003-0.006)$. This indicates that the repeatability reported will likely not be affected by increasing the measurement period.

\subsubsection{Genetic parameters for methane emission}

The heritabilities of the $\log _{10}$-transformed phenotypes in this study were 0.11 for $\mathrm{CH}_{4}$ log, 0.12 for $\mathrm{CO}_{2} \log$, and 0.03 for Ratiolog. Lassen and Løvendahl (2016) measured methane using infrared sensors in AMS on 3,121 Holstein cows and calculated heritabilities of methane emission. Methane emission calculated using the ratio between $\mathrm{CH}_{4}$ and $\mathrm{CO}_{2}$ (in ppm) gave a heritability of 0.16 and both $\mathrm{CH}_{4}$ in $\mathrm{g} /$ day and $\mathrm{CH}_{4}$ in $\mathrm{g} / \mathrm{kg}$ fat and protein corrected milk gave a heritability of 0.21 . These heritabilities were slightly higher compared with the heritabilities of $\mathrm{CH}_{4} \log$ and $\mathrm{CO}_{2} \log$ in our study. The heritability of Ratiolog of our study is considerably lower compared with the other heritabilities. Lassen et al. (2012) used the ratio between $\mathrm{CH}_{4}$ and $\mathrm{CO}_{2}$ to create a more stable phenotype that was less influenced by the position of the head of the cow to the sensor. In our study, however, we found that Ratiolog had relatively more total variation and less genetic variation than $\mathrm{CH}_{4}$ log and $\mathrm{CO}_{2} \log$. Therefore, based on the results of our study, the use of $\mathrm{CH}_{4}$ log for selection instead of Ratiolog would be expected to give a greater reduction of methane emission by dairy cows. 
The heritability of the phenotypes showed that there is genetic variation present in $\mathrm{CH}_{4}$ and $\mathrm{CO}_{2}$ measured using infrared sensors in AMS, indicating that these phenotypes could be used in selective breeding. The reduction in methane emission that could be achieved through selective breeding depends on the genetic variance of methane emission, the intensity of selection, the accuracy of selection, and the relationship between methane emission and the other breeding goal traits. The accuracies of breeding values for methane emission for cows and bulls were 0.61 and 0.85 , respectively. This illustrates that fairly accurate estimates of breeding values for selective breeding can be obtained based on repeated methane measurements on a limited number of daughters per bull.

\subsection{Conclusions}

$\mathrm{CH}_{4} \log , \mathrm{CO}_{2} \log$, and Ratiolog were all repeatable and heritable, but Ratiolog had a lower repeatability and heritability than the other two traits. It is recommended to measure $\mathrm{CH}_{4}$ and $\mathrm{CO}_{2}$ on at least 10 consecutive days to maximize repeatabilities of the methane phenotypes. It is important to account for farm, AMS, day of measurement, time of day, and lactation stage when estimating genetic parameters for methane phenotypes. The use of $\mathrm{CH}_{4} \log$ for selection instead of Ratiolog would be expected to give a greater reduction of methane emission by dairy cows.

\subsection{Acknowledgments}

The authors would like to acknowledge the 11 farmers for their input and collaboration with the project and Jan Kortmann for his technical assistance.

\subsection{References}

Bell, M. J., S. L. Potterton, J. Craigon, N. Saunders, R. H. Wilcox, M. Hunter, J. R. Goodman, and P. C. Garnsworthy. 2014a. Variation in enteric methane emissions among cows on commercial dairy farms. Animal 8(9):1540-1546.

Bell, M. J., N. Saunders, R. H. Wilcox, E. M. Homer, J. R. Goodman, J. Craigon, and P. C. Garnsworthy. 2014b. Methane emissions among individual dairy cows during milking quantified by eructation peaks or ratio with carbon dioxide. J. Dairy Sci. 97(10):6536-6546.

Cottle, D. J., J. V. Nolan, and S. G. Wiedemann. 2011. Ruminant enteric methane mitigation: A review. Anim Prod Sci 51(6):491-514. 
Donoghue, K. A., T. Bird-Gardiner, P. F. Arthur, R. M. Herd, and R. S. Hegarty. 2016. Repeatability of methane emission measurements in australian beef cattle. Anim Prod Sci 56(3):213-217.

FAO. 2014. Food and agriculture statistical yearbook 2014 europe and central asia, budapest, hungary.

FAOSTAT. 2012. Faostat emission database, accessed feb. 26, 2016. Http://www.Faostat3.Fao.Org.

Garnsworthy, P. C., J. Craigon, J. H. Hernandez-Medrano, and N. Saunders. 2012a. On-farm methane measurements during milking correlate with total methane production by individual dairy cows. J. Dairy Sci. 95(6):3166-3180.

Garnsworthy, P. C., J. Craigon, J. H. Hernandez-Medrano, and N. Saunders. 2012b. Variation among individual dairy cows in methane measurements made on farm during milking. J. Dairy Sci. 95(6):3181-3189.

Gerber, P. J., H. Steinfeld, B. Henderson, A. Mottet, C. Opio, J. Dijkman, A. Falcucci and G. Tempio. 2013. Tackling climate change through livestock - a global assessment of emissions and mitigation opportunities. in Food and Agriculture Organization of the United Nations. FAO, Rome.

Gilmour, A. R., B. J. Gogel, B. R. Cullis, S. J. a. Welham, and R. Thompson. 2015. Asreml user guide release 4.1 structural specification. VSN International Ltd, Hemel Hempstead, UK.

Hammond, K. J., L. A. Crompton, A. Bannink, J. Dijkstra, D. R. Yáñez-Ruiz, P. O’Kiely, E. Kebreab, M. A. Eugène, Z. Yu, K. J. Shingfield, A. Schwarm, A. N. Hristov, and C. K. Reynolds. 2016. Review of current in vivo measurement techniques for quantifying enteric methane emission from ruminants. Anim. Feed Sci. and Technol. 219:13-30.

Heetkamp, M. J. W., S. J. J. Alferink, T. Zandstra, P. Hendriks, H. v. d. Brand, and W. J. J. Gerrits. 2015. Design of climate respiration chambers, adjustable to the metabolic mass of subjects. Pages 35-56 in Indirect calorimetry. Wageningen Academic Publishers, Wageningen.

Hristov, A. N., T. Ott, J. Tricarico, A. Rotz, G. Waghorn, A. Adesogan, J. Dijkstra, F. Montes, J. Oh, E. Kebreab, S. J. Oosting, P. J. Gerber, B. Henderson, H. P. S. Makkar, and J. Firkins. 2013. Special topics -mitigation of methane and nitrous oxide emissions from animal operations: lii. A review of animal management mitigation options. J. Anim. Sci. 91(11):5095 - 5113.

IPCC. 2014. Climate change 2014: Synthesis report. Contribution of working groups i, ii and iii to the fifth assessment report of the intergovermental panel on climate change, ed. R.K. Pachauri and I.A. Meyer. Geneva, Switzerland. 
Lassen, J. and P. Løvendahl. 2016. Heritability estimates for enteric methane emissions from holstein cattle measured using noninvasive methods. J. Dairy Sci. 99(3):1959-1967.

Lassen, J., P. Lovendahl, and J. Madsen. 2012. Accuracy of noninvasive breath methane measurements using fourier transform infrared methods on individual cows. J. Dairy Sci. 95(2):890-898.

Lassen, J., N. A. Poulsen, M. K. Larsen, and A. J. Buitenhuis. 2016. Genetic and genomic relationship between methane production measured in breath and fatty acid content in milk samples from danish holsteins. Anim Prod Sci 56(3):298-303.

Madsen, J., B. S. Bjerg, T. Hvelplund, M. R. Weisbjerg, and P. Lund. 2010. Methane and carbon dioxide ratio in excreted air for quantification of the methane production from ruminants. Livest Sci 129(1-3):223-227.

Mulder, H. A., A. F. Groen, G. De Jong, and P. Bijma. 2004. Genotype $\times$ environment interaction for yield and somatic cell score with automatic and conventional milking systems. J. Dairy Sci. 87(5):1487-1495.

UNCCC. 2015. United nations conference on climate change, accessed feb. 262016. Http://www.Cop21.Gouv.Fr/en/.

Vellinga, T. V., A. Bannink, M. C. J. Smits, A. Van den Pol-Van Dasselaar, and I. Pinxterhuis. 2011. Intensive dairy production systems in an urban landscape, the dutch situation. Livest Sci 139(1-2):122-134.

Wu, L., P. W. G. Groot Koerkamp, and N. W. M. Ogink. 2016. Temporal and spatial variation of methane concentrations around lying cubicles in dairy barns. Biosyst Eng 151:464-478. 



\title{
4
}

\section{Genetic Background of Milk Mid Infrared predicted Methane Emission and Relationship with Sensor Measured Methane Emission in Dutch Dairy Cows}

\author{
S. van Engelen ${ }^{1,2}$, H. Bovenhuis ${ }^{2}$, and M.H.P.W. Visker ${ }^{1,2}$ \\ ${ }^{1}$ Top Institute Food and Nutrition, P.O. Box 557, 6700 AN, Wageningen, the \\ Netherlands; ${ }^{2}$ Wageningen University \& Research Animal Breeding and Genomics, \\ P.O. Box 338, $6700 \mathrm{AH}$, Wageningen, the Netherlands \\ Journal of Dairy Science (Submitted)
}




\begin{abstract}
Dairy cows produce methane $\left(\mathrm{CH}_{4}\right)$, a greenhouse gas that needs to be mitigated to reduce the impact of dairy farming on global warming. Mitigation of $\mathrm{CH}_{4}$ emission by dairy cows might be achieved via breeding. The aim of this study was to estimate genetic parameters of milk mid-infrared (MIR) predicted $\mathrm{CH}_{4}$ emissions and their relationship with $\mathrm{CH}_{4}$ measured with sensors in automatic milking systems (AMS). For this purpose milk production and $\mathrm{CH}_{4}$ data on 1,302 cows from 11 commercial dairy farms in the Netherlands were available. These cows had three milk MIR predicted $\mathrm{CH}_{4}$ phenotypes: $\mathrm{CH}_{4}$ production (g/day), $\mathrm{CH}_{4}$ yield (g/kg DMI), and $\mathrm{CH}_{4}$ intensity ( $\mathrm{g} / \mathrm{kg}$ fat and protein corrected milk) and three sensor measured phenotypes: mean of $\mathrm{CH}_{4}$ per AMS visit $\left(\mathrm{CH}_{4} \mathbf{l o g}\right)$, mean of carbon dioxide $\left(\mathrm{CO}_{2}\right)$ per AMS visit $\left(\mathrm{CO}_{2} \mathrm{log}\right.$ ), and mean of $\mathrm{CH}_{4}$ divided by the mean of $\mathrm{CO}_{2}$ (Ratiolog). The heritabilities of the milk MIR predicted $\mathrm{CH}_{4}$ phenotypes were 0.17 for $\mathrm{CH}_{4}$ production, 0.21 for $\mathrm{CH}_{4}$ yield, and 0.18 for $\mathrm{CH}_{4}$ intensity. Correlations between milk MIR predicted $\mathrm{CH}_{4}$ phenotypes and sensor measured phenotypes were weak with phenotypic correlations ranging between 0.03 and 0.16 . This indicates that milk MIR predicted $\mathrm{CH}_{4}$ phenotypes provide information that is independent of sensor measured phenotypes. Combining information from the two types of $\mathrm{CH}_{4}$ phenotypes could be a useful next step. Furthermore, the prediction of milk MIR predicted and sensor measured phenotypes with test-day milk yield, and percentages of fat, protein, and lactose resulted in coefficients of determination ranging between 0.01 and 0.63 . This indicates that both milk MIR predicted $\mathrm{CH}_{4}$ phenotypes and sensor measured phenotypes contain information that is not fully captured by information that is currently available on milk yield and composition.
\end{abstract}

Key words: Methane emission, dairy cow, milk mid-infrared, genetic variation 


\subsection{Introduction}

Methane $\left(\mathrm{CH}_{4}\right)$ is a greenhouse gas of which the atmospheric concentration has risen significantly since pre-industrial time and which is expected to continue to increase the coming years (Boucher et al., 2009). Methane produced by agriculture contributes $53 \%$ of the total $\mathrm{CH}_{4}$ emissions in the Netherlands (Van der Maas et al., 2009). The single largest source of $\mathrm{CH}_{4}$ emissions by agriculture is enteric fermentation, production of $\mathrm{CH}_{4}$ in the rumen of ruminants, which accounts for more than $40 \%$ of the agricultural greenhouse gas emissions in the Netherlands (FAOSTAT, 2014).

Reduction of $\mathrm{CH}_{4}$ emissions by dairy cows is needed to reduce the impact of agriculture on global warming. The demand for animal food products is expected to increase with the expected growth of the human population to 9 billion people by 2050 (United Nations, 2015). Therefore, a reduction in dairy production is not anticipated and the mitigation of $\mathrm{CH}_{4}$ emission per dairy cow is required.

Mitigation of $\mathrm{CH}_{4}$ emission by dairy cows might be achieved through selective breeding. Current breeding strategies result in an increased $\mathrm{CH}_{4}$ emission per cow per year, but decreased $\mathrm{CH}_{4}$ emission per $\mathrm{kg}$ of milk as a result of improved production and longevity (Van der Maas et al., 2009; Bannink et al., 2011). A further reduction of $\mathrm{CH}_{4}$ emission could be achieved by actual breeding for lower $\mathrm{CH}_{4}$ emitting dairy cows. Breeding for lower $\mathrm{CH}_{4}$ emitting dairy cows, however, relies on the availability of $\mathrm{CH}_{4}$ emission phenotypes that are heritable and can be measured on large numbers of animals.

Milk mid-infrared (MIR) spectra are routinely collected via milk production recording and have been suggested for predicting $\mathrm{CH}_{4}$ emission (Dehareng et al., 2012; Vanlierde et al., 2015; Van Gastelen et al., Wageningen University \& Research, Wageningen, personal communication). The three prediction equations developed by Van Gastelen and colleagues were used in our study, because breed and diet of the cows in the study of Van Gastelen and colleagues were similar to those in our study.

Another method for obtaining large scale $\mathrm{CH}_{4}$ phenotypes is based on sensors in automatic milking systems (AMS). Previous studies using sensors to measure $\mathrm{CH}_{4}$ emission on different Holstein populations found repeatabilities between 0.14 and 0.86 for $\mathrm{CH}_{4}$ phenotypes (Lassen et al., 2012; Bell et al., 2014; Van Engelen et al., Accepted) and heritabilities between 0.03 and 0.21 (Lassen and Løvendahl, 2016; Van Engelen et al., Accepted). 
Selective breeding based on both types of $\mathrm{CH}_{4}$ phenotypes might be possible, though no scientific consensus has been reached on which phenotype to use for breeding for reduced $\mathrm{CH}_{4}$ emission (Robinson and Oddy, 2016; de Haas et al., 2017). Moreover, no comparison between $\mathrm{CH}_{4}$ measured with sensors and $\mathrm{CH}_{4}$ predicted with milk MIR spectra has been made. Therefore, we would like to know whether $\mathrm{CH}_{4}$ predicted via milk MIR is similar to or different from $\mathrm{CH}_{4}$ measured with sensors in AMS. In this study we estimated the genetic parameters for milk MIR predicted $\mathrm{CH}_{4}$ emissions, and explored the relationships between milk MIR predicted $\mathrm{CH}_{4}$ emissions and $\mathrm{CH}_{4}$ measured with sensors in AMS. Data on milk MIR predicted $\mathrm{CH}_{4}$ emissions were available on more than 1,400 Dutch dairy cows and were obtained from milk samples taken during routine milk recording. Most of these cows also had data on $\mathrm{CH}_{4}$ and carbon dioxide $\left(\mathrm{CO}_{2}\right)$ measurements taken with sensors in AMS. Genetic variation in milk MIR predicted $\mathrm{CH}_{4}$ emissions was estimated and phenotypic and genetic correlations with sensor measured phenotypes were calculated.

\subsection{Materials and Methods}

\subsubsection{Data}

\subsubsection{Milk MIR and milk production data}

Milk samples were collected during routine milk production recording (MPR) from all lactating cows on 11 commercial Dutch dairy farms. Some farms were sampled twice resulting in 17 MPR for these 11 farms. Milk samples were analysed with midinfrared (MIR) spectroscopy using MilkoScan FT 6000 equipment (Foss Analytical A/S, Hillerød, Denmark) by Qlip B.V. (Zutphen, the Netherlands). A total of 2,378 observations were available for this study with milk MIR spectra and milk production traits including milk yield, and fat, protein, and lactose percentages of 1,412 dairy cows.

\subsubsection{Methane predicted based on milk MIR}

Three predictions for $\mathrm{CH}_{4}$ based on milk MIR spectra were used in this study. These milk MIR $\mathrm{CH}_{4}$ predictions were developed by Van Gastelen et al. (Wageningen University \& Research, Wageningen, personal communication), and a detailed description of the data and methods can be found there. In short, data for development of the milk MIR $\mathrm{CH}_{4}$ predictions consisted of $218 \mathrm{CH}_{4}$ emission records obtained in climate respiration chambers (CRC) from 8 studies that fed diets with at least $70 \%$ roughage. Milk samples corresponding to the $218 \mathrm{CH}_{4}$ emission records were analyzed with MIR, and MIR spectra were used to develop three $\mathrm{CH}_{4}$ prediction 
equations via regression models. The three resulting methane prediction equations predicted $\mathrm{CH}_{4}$ in grams per day $\left(\mathrm{CH}_{4}\right.$ production), $\mathrm{CH}_{4}$ in grams per $\mathrm{kg}$ of dry matter intake ( $\mathrm{CH}_{4}$ yield), and $\mathrm{CH}_{4}$ in grams per $\mathrm{kg}$ of fat and protein corrected milk $\left(\mathrm{CH}_{4}\right.$ intensity). For the latter prediction equation fat and protein corrected milk was calculated as $(0.337+0.116 *$ fat $(\mathrm{g} / 100 \mathrm{~g}$ milk $)+0.06 *$ protein $(\mathrm{g} / 100 \mathrm{~g}$ milk $)) *$ milk yield $(\mathrm{kg} / \mathrm{d})$. The cross validated coefficient of determination $\left(\mathbf{R}^{\mathbf{2}} \mathrm{cv}\right)$ was 0.30 for $\mathrm{CH}_{4}$ production, 0.19 for $\mathrm{CH}_{4}$ yield, and 0.49 for $\mathrm{CH}_{4}$ intensity (Van Gastelen et al., Wageningen University \& Research, Wageningen, personal communication). These three prediction equations were applied to the 2,378 milk MIR spectra that were available for this study, resulting in three milk MIR predicted $\mathrm{CH}_{4}$ phenotypes per observation.

\subsubsection{Editing of milk MIR data}

The milk MIR dataset was edited in four steps. The first step was the removal of observations with extreme values for either predicted $\mathrm{CH}_{4}$ emissions or the milk production traits. For each of the 17 MPR, the mean and standard deviation (sd) was calculated for predicted $\mathrm{CH}_{4}$ emissions and the milk production traits. Observations were considered to contain extreme values when the values of predicted $\mathrm{CH}_{4}$ emissions or milk production traits were outside the range of the mean $\pm 4 *$ sd. Of the 2,378 observations, 32 observations contained extreme values and were removed. The second step was to summarize multiple observations for each cow per MPR into a single observation per MPR. In total, 410 cows were sampled twice ( 820 observations) and 11 cows were sampled three times (33 observations) per MPR. A weighted average based on milk yield was calculated for predicted $\mathrm{CH}_{4}$ emissions and the milk production traits to obtain a single observation per cow per MPR. The third step was to add week of lactation to the dataset and remove observations with unknown week of lactation or with week of lactation above 60. Data on calving dates were made available by the cooperative cattle improvement organization CRV (Arnhem, the Netherlands) and matched to the Milk MIR data to calculate the week of lactation at the time of the MPR. In total, 63 cows were removed from the dataset during this step. The fourth step was the reduction of the dataset to 1 observation per cow as the dataset contained too few repeated observations to be of added value in the statistical analysis. Most cows had 1 observation, but some cows had 2 observations as they took part in two MPR. For these cows, 1 of the 2 observations was randomly selected and removed from the dataset. The edited milk MIR dataset consisted of 1,302 observations on 1,302 cows (dataset 1 ) and was used to calculate the heritabilities of milk MIR phenotypes and their mutual correlations. 


\subsubsection{Methane measured with sensors}

We also measured the dairy cows on the same 11 dairy farms that yielded the milk MIR data with non-dispersive infrared sensors in AMS. A detailed description of this data and the methods are given by Van Engelen et al. (Accepted). In short, sensors were installed in $23 \mathrm{AMS}$ located at 11 farms and measured $\mathrm{CH}_{4}$ and $\mathrm{CO}_{2}$ concentrations twice per second. Measurements were summarized per AMS visit by the mean of $\mathrm{CH}_{4}\left(\mathrm{CH}_{4}\right.$ mean), the mean of $\mathrm{CO}_{2}\left(\mathrm{CO}_{2}\right.$ mean), and the mean of the ratio between $\mathrm{CH}_{4}$ and $\mathrm{CO}_{2}$ (Ratiomean). A $\log _{10}$-transformation was applied to these phenotypes, resulting in $\mathbf{C H}_{4} \log \left(\log _{10}\left(\mathrm{CH}_{4}\right.\right.$ mean $\left.)\right)$, $\mathbf{C O} 2 \log \left(\log _{10}\left(\mathrm{CO}_{2}\right.\right.$ mean $\left.)\right)$, and Ratiolog $\left(\log _{10}(\right.$ Ratiomean)). Data on 123,369 AMS visits with sensor measured phenotypes from 1,508 dairy cows were available.

\subsubsection{Dataset for correlations between milk MIR data and sensor data} All sensor observations of a cow between two weeks before and two weeks after the MPR were selected for calculation of correlations between sensor measured phenotypes and milk MIR data (milk $\mathrm{MIR} \mathrm{CH}_{4}$ phenotypes and milk production traits). The selected sensor observations (on average 39) were averaged and three sensor measured phenotypes were constructed: mean of $\mathrm{CH}_{4} \log \left(\mathbf{m} \mathrm{CH}_{4} \log \right)$, mean of $\mathrm{CO}_{2} \log$ ( $\mathrm{mCO}_{2} \log$ ), and mean of Ratiolog (mRatiolog). Only cows with both sensor measurements in the month surrounding the MPR and MIR predicted $\mathrm{CH}_{4}$ phenotypes were included in this dataset (dataset 2). Dataset 2 consisted of 1,225 observations on 1,225 dairy cows and was used to calculate correlations between milk MIR phenotypes and sensor measured phenotypes. As milk yield had missing observations, correlations with milk yield were calculated on a dataset consisting of 1,097 observations.

\subsubsection{Genetic parameters}

\subsubsection{Heritability}

Variance components of milk MIR phenotypes in dataset 1 (milk MIR predicted $\mathrm{CH}_{4}$ phenotypes and milk production traits) were estimated with ASReml 4.1 (Gilmour et al., 2015) using the following model:

$Y_{i j k}=m u+$ Lactationweek $_{i}+M P R_{j}+$ Animal $_{k}+e_{i j k} \quad($ model 1)

where $Y_{i j k}$ is the dependent variable; $m u$ is the mean of the dataset; Lactationweek is the fixed effect of week of lactation at the time of the MPR (60 levels); MPR is the fixed effect of the date of the milk production recording (17 levels; farm is nested within MPR); Animal $l_{k}$ is the random additive genetic effect of animal ( N $\left(0, A \sigma^{2} A\right)$ ) 
with additive genetic relationship matrix $\mathbf{A}$ and additive genetic variance $\sigma^{2}$ (the pedigree was traced back two generations, resulting in 4,231 animals in the pedigree, and was obtained from CRV); and $e_{i j k}$ is the random error effect $(\sim \mathrm{N}(0$, $\left.I \sigma^{2} E\right)$ ) with identity matrix $I$ and residual variance $\sigma^{2} \mathrm{E}$.

The heritability $\left(\mathrm{h}^{2}\right)$ of the milk MIR phenotypes was calculated as follows:

$$
h^{2}=\frac{\sigma_{A}^{2}}{\sigma_{A}^{2}+\sigma_{E}^{2}}
$$

where $\sigma^{2} \mathrm{~A}$ is the additive genetic variance and $\sigma^{2} \mathrm{E}$ is the residual variance.

\subsubsection{Correlation}

To calculate the correlations among the milk MIR phenotypes a bivariate model was used with effects as in model 1 on dataset 1 . Another bivariate model was used to calculate the correlations between milk MIR phenotypes and sensor measured phenotypes in dataset 2 . The fixed effects for milk MIR phenotypes were those of model 1 whereas the fixed effects for sensor measured phenotypes were farm of measurement (11 levels) and week of lactation (59 levels). Variance components of milk MIR phenotypes and sensor measured phenotypes were estimated with ASReml 4.1.

The phenotypic correlations $\left(r_{p}\right)$ among milk MIR predicted $\mathrm{CH}_{4}$ phenotypes and between milk MIR phenotypes and sensor measured phenotypes were calculated as follows:

$$
r_{p}=\frac{\sigma_{P 1, P 2}}{\sqrt{\left(\sigma_{P 1}^{2} * \sigma_{P 2}^{2}\right)}}
$$

where $\sigma_{\mathrm{P} 1, \mathrm{P} 2}$ is the phenotypic covariance between trait 1 and trait 2 , and $\sigma^{2} \mathrm{P} 1$ and $\sigma^{2} \mathrm{P} 2$ are the phenotypic variances of trait 1 and trait 2 . The genetic correlations $\left(\mathbf{r}_{\mathbf{g}}\right)$ among the milk MIR predicted $\mathrm{CH}_{4}$ phenotypes and between milk MIR phenotypes and sensor measured phenotypes were calculated as follows:

$$
r_{g}=\frac{\sigma_{A 1, A 2}}{\sqrt{\left(\sigma_{A 1}^{2} * \sigma_{A 2}^{2}\right)}}
$$

where $\sigma_{\mathrm{A} 1, \mathrm{~A} 2}$ is the additive genetic covariance between trait 1 and trait 2 , and $\sigma^{2} \mathrm{~A} 1$ and $\sigma^{2}{ }_{A}$ are the additive genetic variances of trait 1 and trait 2 . 


\subsubsection{Variation in $\mathrm{CH}_{4}$ phenotypes explained by milk yield and composition}

Routinely recorded traits like milk yield and fat, protein, and lactose percentage might provide information that could be used to predict $\mathrm{CH}_{4}$ emission. It is of interest to investigate to what extent the two types of $\mathrm{CH}_{4}$ phenotypes used in this study contain information that is not contained by routinely recorded traits. To investigate this, we estimated how much variation in the $\mathrm{CH}_{4}$ phenotypes was explained by the milk production traits. Variation in milk MIR predicted $\mathrm{CH}_{4}$ phenotypes and sensor measured phenotypes explained by milk yield, and percentages of fat, protein, and lactose were estimated using the least squares method of the PROC GLM procedure in SAS ${ }^{\oplus} 9.3$ (SAS Institute Inc., 2011). The amount of variation explained by these production traits was calculated on dataset 2 with complete observations $(1,097$ observations) and expressed as the coefficient of determination $\left(\mathbf{R}^{2}\right)$.

\subsection{Results and Discussion}

\subsubsection{Descriptive statistics}

Descriptive statistics and heritabilities of milk MIR predicted $\mathrm{CH}_{4}$ phenotypes and production traits are presented in Table 4.1. Test-day milk yield had an average of $29.7 \mathrm{~kg}$ in dataset 1 which is slightly higher than the Dutch average of $27.3 \mathrm{~kg}$ (CRV, 2016). The slightly higher milk yield might be explained by the nature of these farms, since the 11 dairy farms part of our study are innovative farms with a focus on higher performance. Fat and protein percentages were on average $4.37 \%$ and $3.57 \%$, respectively. These percentages are similar to the Dutch national average of $4.38 \%$ for fat percentage and 3.55\% for protein percentage in 2016 (CRV, 2016). Predicted $\mathrm{CH}_{4}$ emissions found in our study were on average $372.4 \mathrm{~g} /$ day, $22.1 \mathrm{~g} / \mathrm{kg} \mathrm{DMI}$, and $15.0 \mathrm{~g} / \mathrm{kg}$ FPCM . These averages are in line with literature (Dijkstra et al., 2016) and with the dataset on which the milk MIR predictions were developed (Van Gastelen et al., Wageningen University \& Research, Wageningen, personal communication). These numbers suggest that our data is a good representation of the Dutch dairy population.

\subsubsection{Heritabilities of milk MIR phenotypes}

Heritabilities of milk MIR predicted $\mathrm{CH}_{4}$ phenotypes were 0.17 for $\mathrm{CH}_{4}$ production, 0.21 for $\mathrm{CH}_{4}$ yield, and 0.18 for $\mathrm{CH}_{4}$ intensity with standard errors (s.e.) of 0.07. To the best of our knowledge, heritabilities of milk MIR predicted $\mathrm{CH}_{4}$ emission have not been reported before. Heritabilities of $\mathrm{CH}_{4}$ production based on milk fatty acids that were predicted from milk MIR spectra ranged between 0.22 and 0.40 (Kandel et al., 
2015). Furthermore, heritabilities ranging between 0.12 and 0.44 were found for $\mathrm{CH}_{4}$ yield predicted based on milk fatty acids that were measured by gas chromatography (van Engelen et al., 2015). Moreover, data of sensor measured phenotypes used in this study had heritabilities between 0.03 and 0.12 (Van Engelen et al., Accepted). Thus, heritabilities of milk MIR predicted $\mathrm{CH}_{4}$ phenotypes estimated in the current study are in line with these heritabilities reported in literature.

Table 4.1 Descriptive statistics and heritabilities of predicted methane $\left(\mathrm{CH}_{4}\right)$ phenotypes and production traits based on 1,302 milk mid-infrared (MIR) spectra of 1,302 Dutch dairy cows. Milk MIR predicted $\mathrm{CH}_{4}$ phenotypes are expressed as grams of methane per day $\left(\mathrm{CH}_{4}\right.$ production), grams of methane per $\mathrm{kg}$ of dry matter intake $\left(\mathrm{CH}_{4}\right.$ yield), and grams of methane per $\mathrm{kg}$ of fat and protein corrected milk $\left(\mathrm{CH}_{4} \text { intensity }\right)^{1,2}$

\begin{tabular}{lccccc}
\hline Trait & $\mathrm{N}$ & mean & $\mathrm{CV}(\%)$ & $\sigma_{\mathrm{p}}^{2}$ & $\mathrm{~h}^{2}$ \\
\hline Methane phenotypes & & & & & \\
$\mathrm{CH}_{4}$ production (g/day) & 1,302 & 372.4 & 7 & 342.86 & $0.17_{(0.07)}$ \\
$\mathrm{CH}_{4}$ yield (g/kg DMI) & 1,302 & 22.1 & 5 & 0.95 & $0.21_{(0.07)}$ \\
$\mathrm{CH}_{4}$ intensity (g/kg FPCM) & 1,302 & 15.0 & 12 & 1.62 & $0.18_{(0.07)}$ \\
Production traits & & & & & \\
$\quad$ Milk (kg) & 1,176 & 29.7 & 31 & 44.24 & $0.36_{(0.07)}$ \\
Fat percentage & 1,302 & 4.37 & 20 & 0.54 & $0.39_{(0.08)}$ \\
Protein percentage & 1,302 & 3.57 & 12 & 0.08 & $0.33_{(0.08)}$ \\
Lactose percentage & 1,302 & 4.56 & 4 & 0.03 & $0.37_{(0.07)}$ \\
\hline
\end{tabular}

${ }^{1}$ This table contains the number of animals $(\mathrm{N})$, mean, coefficient of variation $\left(\mathrm{CV} ; \mathrm{CV}=100^{*}\right.$ $(\sigma / \mu))$, phenotypic variance $\left(\sigma^{2} \mathrm{p}\right)$, and the heritability $\left(h^{2} ; h^{2}=\sigma^{2}{ }_{A} / \sigma^{2}{ }_{A}+\sigma_{E}^{2}\right)$ with the respective standard error in parentheses.

${ }^{2}$ Fat and protein corrected milk (FPCM) was calculated as FPCM $=$ milk (in kg) $*(0.337+(0.116$

$*$ fat percentage $)+(0.06 *$ protein percentage $))$.

Heritabilities of milk production traits ranged between 0.33 and 0.39 (s.e. $=0.07$ 0.08). Heritabilities reported by Mulder et al. (2004) were comparable to those in this study, whereas heritabilities reported by Stoop et al. (2007) were slightly higher. Mulder et al. (2004) found lower heritabilities for AMS compared to conventional milking systems. The heritabilities reported by Stoop et al. (2007) were recorded in conventional milking systems and this might explain the higher heritabilities found by Stoop et al. (2007) compared to our study. Furthermore, both Mulder et al. (2004) and Stoop et al. (2007) used data of first parity cows whereas in our study cows of multiple parities were included. This might impact the heritabilities estimated, though the heritabilities in the current study were in line with literature. 


\subsubsection{Correlations among milk MIR predicted $\mathrm{CH}_{4}$ phenotypes and between milk MIR predicted and sensor measured phenotypes}

The correlations among the milk MIR predicted $\mathrm{CH}_{4}$ phenotypes and between milk MIR predicted and sensor measured phenotypes are presented in Table 4.2. The correlations among milk MIR predicted $\mathrm{CH}_{4}$ phenotypes showed that on the one hand $\mathrm{CH}_{4}$ production and $\mathrm{CH}_{4}$ yield were highly correlated $\left(\mathrm{r}_{\mathrm{p}}=0.73 ; \mathrm{r}_{\mathrm{g}}=0.63\right) . \mathrm{CH}_{4}$ intensity, on the other hand, showed weak correlations with $\mathrm{CH}_{4}$ production and $\mathrm{CH}_{4}$ yield. These correlations among milk MIR predicted $\mathrm{CH}_{4}$ phenotypes show that $\mathrm{CH}_{4}$ production and $\mathrm{CH}_{4}$ yield are related, whereas $\mathrm{CH}_{4}$ intensity is a different trait than $\mathrm{CH}_{4}$ production and yield. Direct relationships between the three milk MIR predicted $\mathrm{CH}_{4}$ phenotypes have not been explored before. In beef and dairy cattle, correlation between the three $\mathrm{CH}_{4}$ phenotypes measured in climate respiration chambers (CRC) or with sensors in AMS were found to be ranging between 0.07 and 0.96 (Donoghue et al., 2016; Lassen and Løvendahl, 2016; De Haas et al., 2017). Our correlations are in range of these correlations, but the distinction between $\mathrm{CH}_{4}$ intensity versus $\mathrm{CH}_{4}$ production and $\mathrm{CH}_{4}$ yield has not been reported in literature.

Phenotypic correlations between milk MIR predicted $\mathrm{CH}_{4}$ phenotypes and sensor measured phenotypes were weak, and range between 0.03 and 0.16 (s.e. $=0.03$ ). Genetic correlations had large standard errors $(0.27-0.87)$, especially the correlations with mRatiolog $(0.55-0.87)$. The large s.e. were likely due to the relatively small datasets that were used in this study for estimation of phenotypic and genetic correlations. The two datasets used for the correlations ranged between 1,302 and 1,097 observations and cows. Therefore, the main focus of our study is on the phenotypic correlations instead of the genetic correlations.

Genetic correlations of $\mathrm{CH}_{4}$ intensity with $\mathrm{mCH}_{4} \log$ and $\mathrm{mCO}_{2} \log$ were stronger than correlations of $\mathrm{CH}_{4}$ production and $\mathrm{CH}_{4}$ yield. Correlations between milk MIR predicted $\mathrm{CH}_{4}$ phenotypes and sensor measured phenotypes have not been reported before. The results from the current study suggest that sensor measured phenotypes are weakly correlated to milk MIR predicted $\mathrm{CH}_{4}$ phenotypes.

\subsubsection{Correlations between $\mathrm{CH}_{4}$ phenotypes and milk production traits}

The correlations between the two types of $\mathrm{CH}_{4}$ phenotypes and the milk production traits are presented in Table 4.2. Genetic correlations estimated in this study had large s.e. $(0.11-0.48)$ and were, therefore, mostly not significantly different from zero. For example, the genetic correlations of test-day milk yield with $\mathrm{mCH}_{4} \log$ and $\mathrm{mRatiolog}$ were high, though their large s.e. result in a large range of possible values of these correlations. To determine when genetic correlations differ significantly 


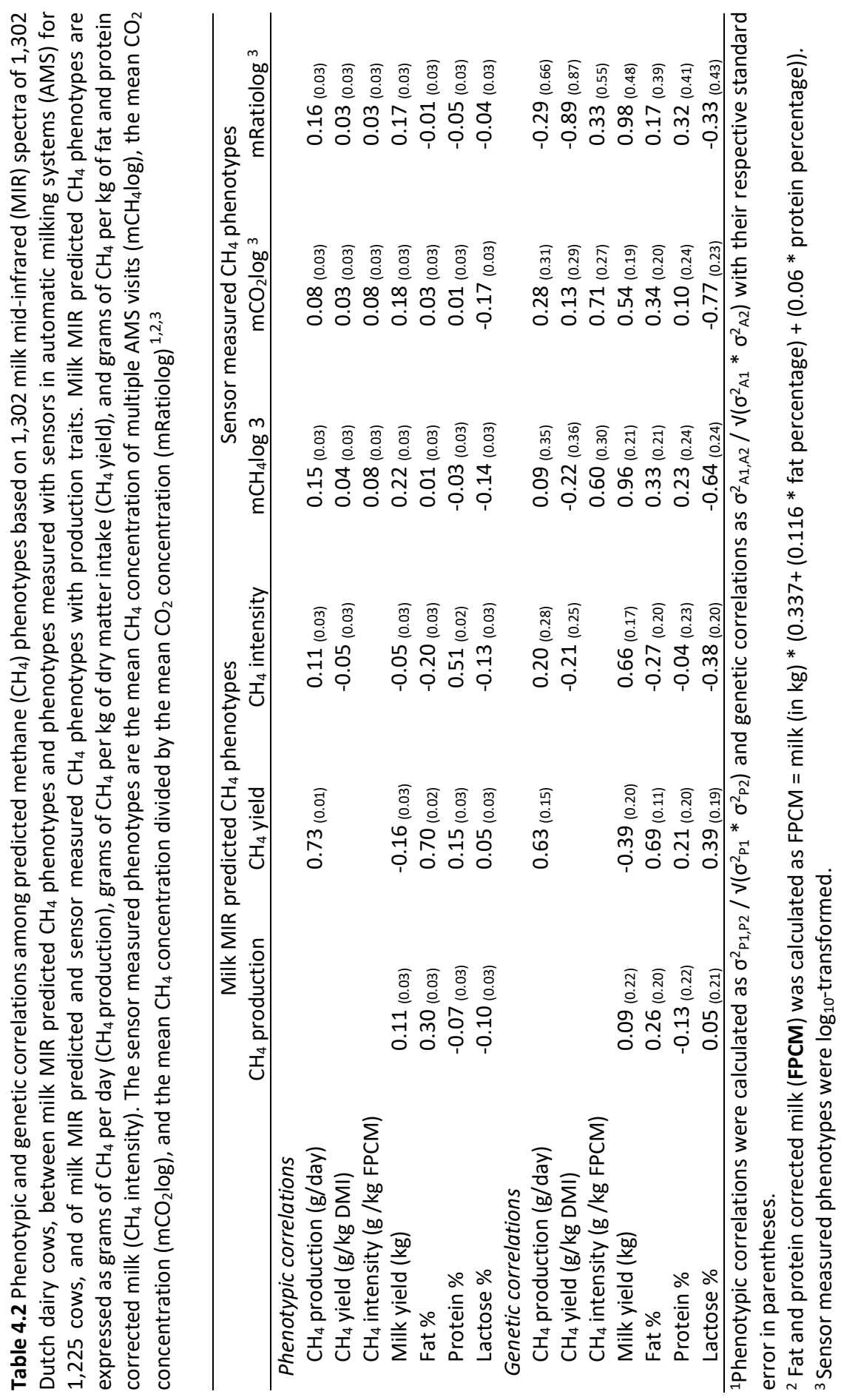


from the estimate, we used a log-Likelihood ratio test. Genetic correlations ranging from -0.1 to 1 did not differ significantly from our estimate ( $p$-value $=0.95$ ). This strongly indicates that these genetic correlations could change when analyses are conducted on larger datasets.

Most of the phenotypic correlations between milk MIR predicted $\mathrm{CH}_{4}$ phenotypes and milk production traits were not significantly different from zero. Nine out of the 12 correlations were weak, with correlations ranging between -0.20 and 0.15 (s.e. = $0.02-0.03$ ). Moderate to strong correlations were found for both $\mathrm{CH}_{4}$ production and $\mathrm{CH}_{4}$ yield with fat percentage ( $r=0.30$ and 0.70 , respectively), and between $\mathrm{CH}_{4}$ intensity and protein percentage $(r=0.51)$. The phenotypic correlations between sensor measured phenotypes and milk production traits were mostly not significantly different from zero and weak, ranging between -0.17 and 0.22 (s.e. = 0.03). The weak correlations between $\mathrm{CH}_{4}$ phenotypes and production traits suggest that both types of $\mathrm{CH}_{4}$ phenotypes contain new information that is not already captured by routinely collected milk production traits.

Correlations between $\mathrm{CH}_{4}$ phenotypes and milk production traits have been reported in literature and vary between studies (Garnsworthy et al., 2012; Moraes et al., 2014; Van Lingen et al., 2014). Milk yield was found to be significantly correlated with $\mathrm{CH}_{4}$ emission measured with sensors in AMS (Garnsworthy et al., 2012a, b). Fat percentage was found to be a key explanatory variable for $\mathrm{CH}_{4}$ emission in lactating dairy cows by Moraes et al. (2014). In the study of Van Lingen and colleagues, however, fat yield was not included in the prediction equations for $\mathrm{CH}_{4}$ yield and $\mathrm{CH}_{4}$ intensity (van Lingen et al., 2014). Moreover, the review by Negussie et al. (2017) reported that the relationships between $\mathrm{CH}_{4}$ emission on the one hand and milk production and major milk components on the other hand vary substantially over the different studies.

\subsubsection{Variation in methane emission explained by milk yield and fat, protein, and lactose percentages}

The amount of variation in the two types of $\mathrm{CH}_{4}$ phenotypes that is explained by milk yield and the percentages of fat, protein, and lactose is presented in Table 4.3. These milk production traits represent information that is currently available from all cows that participate in the MPR. The variation that is not explained by these production traits $\left(1-R^{2}\right)$ is indicative for the additional information provided by the $\mathrm{CH}_{4}$ phenotypes. The amount of variation explained by the milk production traits was moderate for $\mathrm{CH}_{4}$ yield and $\mathrm{CH}_{4}$ intensity $\left(\mathrm{R}^{2}=0.45\right.$ and 0.63 , respectively), whereas the $\mathrm{R}^{2}$ for $\mathrm{CH}_{4}$ production and sensor measured phenotypes were low $(0.01-0.13)$. 
This demonstrates that currently available information on milk yield and composition does not explain the variation in sensor measured $\mathrm{CH}_{4}$ production and sensor measured phenotypes, but does explains part of the variation in $\mathrm{CH}_{4}$ yield and $\mathrm{CH}_{4}$ intensity. As stated above, milk yield and composition are correlated with $\mathrm{CH}_{4}$ emission, but correlations vary between different studies. Furthermore, the amount of variation in $\mathrm{CH}_{4}$ emission explained by milk yield and composition was found to be limited (Negussie et al., 2017). The higher $\mathrm{R}^{2}$ of milk MIR predicted $\mathrm{CH}_{4}$ phenotypes compared to sensor measured phenotypes might reflect the relationship between milk yield and composition and milk predicted $\mathrm{CH}_{4}$ emission. Milk yield and composition are used to predict this $\mathrm{CH}_{4}$ phenotype. The results of the current study and literature show that the $\mathrm{CH}_{4}$ phenotypes contain new information that is not yet captured by existing information on milk yield and major milk components.

Table 4.3 Predicted methane $\left(\mathrm{CH}_{4}\right)$ phenotypes based on 1,302 milk mid-infrared (MIR) spectra of 1,302 Dutch dairy cows and phenotypes measured with sensors in automatic milking systems (AMS) for 1,225 cows, as predicted with complete test-day milk yield, and percentages of fat, protein, and lactose (1,097 observations). Milk MIR predicted $\mathrm{CH}_{4}$ phenotypes are expressed as grams of $\mathrm{CH}_{4}$ per day $\left(\mathrm{CH}_{4}\right.$ production), grams of $\mathrm{CH}_{4}$ per $\mathrm{kg}$ of dry matter intake $\left(\mathrm{CH}_{4}\right.$ yield), and grams of $\mathrm{CH}_{4}$ per $\mathrm{kg}$ of fat and protein corrected milk $\left(\mathrm{CH}_{4}\right.$ intensity). The sensor measured phenotypes are the mean $\mathrm{CH}_{4}$ concentration of multiple AMS visits $\left(\mathrm{mCH}_{4} \mathrm{log}\right)$, the mean $\mathrm{CO}_{2}$ concentration $\left(\mathrm{mCO}_{2} \mathrm{log}\right)$, and the mean $\mathrm{CH}_{4}$ concentration divided by the mean $\mathrm{CO}_{2}$ concentration (mRatiolog) $1,2,3$

\begin{tabular}{ll}
\hline Methane phenotypes & $\mathrm{R}^{2}$ \\
\hline Milk MIR predicted $\mathrm{CH}_{4}$ phenotypes & \\
$\mathrm{CH}_{4}$ production & 0.13 \\
$\mathrm{CH}_{4}$ yield & 0.45 \\
$\mathrm{CH}_{4}$ intensity & 0.63 \\
Sensor measured phenotypes & \\
$\mathrm{mCH}_{4} \log$ & 0.02 \\
$\mathrm{mCO}_{2} \log$ & 0.05 \\
mRatiolog & 0.01 \\
\hline
\end{tabular}

${ }^{1}$ Coefficient of determination $\left(R^{2}\right)$ as determined via the least squares method of the PROC GLM procedure in SAS 9.3.

2 Fat and protein corrected milk (FPCM) was calculated as FPCM $=$ milk (in $\mathrm{kg}) *(0.337+(0.116$

* fat percentage $)+(0.06 *$ protein percentage $))$.

${ }^{3}$ Sensor measured phenotypes were $\log _{10}$-transformed.

\subsubsection{Milk MIR predicted $\mathrm{CH}_{4}$ phenotypes versus sensor measured phenotypes}

The two types of $\mathrm{CH}_{4}$ phenotypes used in this study are proxies of true $\mathrm{CH}_{4}$ emission and have low correlations with each other. The golden standard to determine $\mathrm{CH}_{4}$ emission by dairy cows is the $\mathrm{CRC}$. Sensor measured $\mathrm{CH}_{4}$ had a $\mathrm{R}^{2}$ with $\mathrm{CH}_{4}$ measured 
in CRC of 0.25 for 20 Dutch dairy cows (Van Engelen et al., Accepted). Milk MIR predicted $\mathrm{CH}_{4}$ phenotypes had a $\mathrm{R}^{2}$ cv with $\mathrm{CH}_{4}$ measured in $\mathrm{CRC}$ between 0.19 and 0.49 for 218 Dutch dairy cows (Van Gastelen et al., Wageningen University \& Research, Wageningen, personal communication). The low correlations found between both types of $\mathrm{CH}_{4}$ phenotypes might be because of these modest $\mathrm{R}^{2}$ of both types of phenotypes with $\mathrm{CH}_{4}$ measured in $\mathrm{CRC}$. The higher the $\mathrm{R}^{2}$ of the two types of $\mathrm{CH}_{4}$ phenotypes with $\mathrm{CRC} \mathrm{CH}_{4}$, the higher the correlation between the two types of phenotypes will be. The $\mathrm{R}^{2}$ of both types of $\mathrm{CH}_{4}$ phenotypes with $\mathrm{CRC} \mathrm{CH}_{4}$ is expected to be lower in practice, where conditions are more variable than in CRC.

The low correlations between sensor measured phenotypes and milk MIR predicted $\mathrm{CH}_{4}$ phenotypes indicate that each type of $\mathrm{CH}_{4}$ phenotype provides independent information on true $\mathrm{CH}_{4}$ emission. In addition, both types of $\mathrm{CH}_{4}$ phenotypes have their own advantages and disadvantages. Sensor measured phenotypes are a direct method for measuring $\mathrm{CH}_{4}$ emission in the expelled air of dairy cows. They are, however, influenced by the environmental factors in the barn and the behavior of the cow during sensor measurements (Lassen et al., 2012). For example, selecting for cows with low $\mathrm{CH}_{4}$ emission based on sensor measurements in AMS could lead to selection of cows that are more restless instead of truly low-emitting (Lassen et al., 2012, Hammond et al., 2016). Milk MIR $\mathrm{CH}_{4}$ prediction equations are easy to apply to the milk MIR spectra that are currently routinely collected for MPR. The performance of MIR spectra to predict $\mathrm{CH}_{4}$ is limited as important components in the milk for prediction of $\mathrm{CH}_{4}$ (like low concentration fatty acids) cannot be detected by MIR (van Gastelen and Dijkstra, 2016). Combining the information from the two types of $\mathrm{CH}_{4}$ phenotypes could be a useful next step, as suggested by Negussie et al. (2017). Combining proxies could overcome some of their shortcomings and is useful when proxies contain information that is independent of each other (Negussie et al., 2017).

\subsection{Conclusions}

Methane emission phenotypes predicted via milk MIR spectra are heritable and weakly correlated with $\mathrm{CH}_{4}$ measured via sensors in AMS. This low correlation indicates that both types of $\mathrm{CH}_{4}$ phenotypes are independent information sources on $\mathrm{CH}_{4}$ emission. Combining the information from the two types of $\mathrm{CH}_{4}$ phenotypes could be a useful next step. Milk MIR predicted $\mathrm{CH}_{4}$ phenotypes and sensor measured phenotypes contain information that is not fully captured by currently available information on milk yield and composition. 


\subsection{Acknowledgements}

The authors would like to acknowledge the 11 farmers for their input and collaboration with the project.

\subsection{References}

Bannink, A., M. W. van Schijndel, and J. Dijkstra. 2011. A model of enteric fermentation in dairy cows to estimate methane emission for the Dutch National Inventory Report using the IPCC Tier 3 approach. Anim. Feed Sci. and Technol. 166167:603-618.

Bell, M. J., N. Saunders, R. H. Wilcox, E. M. Homer, J. R. Goodman, J. Craigon, and P. C. Garnsworthy. 2014. Methane emissions among individual dairy cows during milking quantified by eructation peaks or ratio with carbon dioxide. J. Dairy Sci. 97(10):6536-6546.

Boucher, O., P. Friedlingstein, B. Collins, and K. P. Shine. 2009. The indirect global warming potential and global temperature change potential due to methane oxidation. Environ Res Lett 4(4):044007.

CRV. 2016. Jaarstatistieken Vol. 2017.

de Haas, Y., M. Pszczola, H. Soyeurt, E. Wall, and J. Lassen. 2017. Invited review: Phenotypes to genetically reduce greenhouse gas emissions in dairying. J. Dairy Sci. 100(2):855-870.

Dehareng, F., C. Delfosse, E. Froidmont, H. Soyeurt, C. Martin, N. Gengler, A. Vanlierde, and P. Dardenne. 2012. Potential use of milk mid-infrared spectra to predict individual methane emission of dairy cows. Animal 6(10):1694-1701.

Dijkstra, J., S. Van Gastelen, E. C. Antunes-Fernandes, D. Warner, B. Hatew, G. Klop, S. C. Podesta, H. J. Van Lingen, K. A. Hettinga, and A. Bannink. 2016. Relationships between milk fatty acid profiles and enteric methane production in dairy cattle fed grass- or grass silage-based diets. Anim Prod Sci 56(3):541-548.

Donoghue, K. A., T. Bird-Gardiner, P. F. Arthur, R. M. Herd, and R. F. Hegarty. 2016. Genetic and phenotypic variance and covariance components for methane emission and postweaning traits in Angus cattle12. J. Anim. Sci. 94(4):1438-1445.

FAOSTAT. 2014. FAOSTAT Emission Database, Accessed Mar. 8, 2017. Http://www.faostat3.fao.org.

Garnsworthy, P. C., J. Craigon, J. H. Hernandez-Medrano, and N. Saunders. 2012a. On-farm methane measurements during milking correlate with total methane production by individual dairy cows. J. Dairy Sci. 95(6):3166-3180. 
Garnsworthy, P. C., J. Craigon, J. H. Hernandez-Medrano, and N. Saunders. 2012b. Variation among individual dairy cows in methane measurements made on farm during milking. J. Dairy Sci. 95(6):3181-3189.

Gilmour, A. R., B. J. Gogel, B. R. Cullis, S. J. a. Welham, and R. Thompson. 2015. ASReml User Guide Release 4.1 Structural Specification. VSN International Ltd, Hemel Hempstead, UK.

Hammond, K. J., L. A. Crompton, A. Bannink, J. Dijkstra, D. R. Yáñez-Ruiz, P. O’Kiely, E. Kebreab, M. A. Eugène, Z. Yu, K. J. Shingfield, A. Schwarm, A. N. Hristov, and C. K. Reynolds. 2016. Review of current in vivo measurement techniques for quantifying enteric methane emission from ruminants. Anim. Feed Sci. and Technol. 219:13-30.

Kandel, P. B., N. Gengler, and H. Soyeurt. 2015. Assessing variability of literature based methane indicator traits in a large dairy cow population. Biotechnology, Agronomy and Society and Environment 19(1):11-19.

Lassen, J. and P. Løvendahl. 2016. Heritability estimates for enteric methane emissions from Holstein cattle measured using noninvasive methods. J. Dairy Sci. 99(3):1959-1967.

Lassen, J., P. Lovendahl, and J. Madsen. 2012. Accuracy of noninvasive breath methane measurements using Fourier transform infrared methods on individual cows. J. Dairy Sci. 95(2):890-898.

Moraes, L. E., A. B. Strathe, J. G. Fadel, D. P. Casper, and E. Kebreab. 2014. Prediction of enteric methane emissions from cattle. Glob Chang Biol 20(7):2140-2148.

Mulder, H. A., A. F. Groen, G. De Jong, and P. Bijma. 2004. Genotype $\times$ Environment Interaction for Yield and Somatic Cell Score with Automatic and Conventional Milking Systems. J. Dairy Sci. 87(5):1487-1495.

Negussie, E., Y. de Haas, F. Dehareng, R. J. Dewhurst, J. Dijkstra, N. Gengler, D. P. Morgavi, H. Soyeurt, S. van Gastelen, T. Yan, and F. Biscarini. 2017. Invited review: Large-scale indirect measurements for enteric methane emissions in dairy cattle: A review of proxies and their potential for use in management and breeding decisions. J. Dairy Sci. 100(4):2433-2453.

Robinson, D. L. and V. H. Oddy. 2016. Benefits of including methane measurements in selection strategies. J. Anim. Sci. 94(9):3624-3635.

SAS Institute Inc. 2011. SAS Institute Inc., Cary, NC.

Stoop, W. M., H. Bovenhuis, and J. A. M. Van Arendonk. 2007. Genetic parameters for milk urea nitrogen in relation to milk production traits. J. Dairy Sci. 90(4):19811986. 
United Nations. 2015. World Population Prospects: The 2015 Revision, Key Findings and Advance Tables. Working Paper No. ESA/P/WP.241.

Van der Maas, C. W. M., P.W.H.G. Coenen, P.J. Zijlema, L.J. Brandes, K. Baas, G. van den Berghe, G.J. van den Born, B. Guis, G. Geilenkirchen, R. te Molder, D.S. Nijdam, J.G.J. Olivier, C.J. Peek, M.W. van Schijndel, and S. M. v. d. Sluis. 2009. Greenhouse Gas Emissions in the Netherlands 1990-2007: National Inventory Report 2009. Page 210.

Van Engelen, S., H. Bovenhuis, J. Dijkstra, J. A. M. van Arendonk, and M. H. P. W. Visker. 2015. Short communication: Genetic study of methane production predicted from milk fat composition in dairy cows. J. Dairy Sci. 98(11):8223-8226.

Van Engelen, S., H. Bovenhuis, P.P.J. van der Tol, and M.H.P.W. Visker. Genetic Background of Methane Emission by Dutch Holstein Friesian cows measured with Infrared Sensors in Automatic Milking Systems. J. Dairy Sci. Accepted.

Van Gastelen, S. and J. Dijkstra. 2016. Prediction of methane emission from lactating dairy cows using milk fatty acids and mid-infrared spectroscopy. J. Sci. Food Agric. 96:3963-3968.

Van Lingen, H. J., L. A. Crompton, W. H. Hendriks, C. K. Reynolds, and J. Dijkstra. 2014. Meta-analysis of relationships between enteric methane yield and milk fatty acid profile in dairy cattle. J. Dairy Sci. 97(11):7115-7132.

Vanlierde, A., M. L. Vanrobays, F. Dehareng, E. Froidmont, H. Soyeurt, S. McParland, E. Lewis, M. H. Deighton, F. Grandl, M. Kreuzer, B. Gredler, P. Dardenne, and N. Gengler. 2015. Hot topic: Innovative lactation-stage-dependent prediction of methane emissions from milk mid-infrared spectra. J. Dairy Sci. 98(8):5740-5747. 



\title{
Correlations of Milk Mid Infrared predicted and Sensor Measured Methane Emission with Production and Fertility Traits in Dutch Dairy Cows
}

\author{
S. van Engelen ${ }^{1,2}$, H. Bovenhuis ${ }^{2}$, and M.H.P.W. Visker ${ }^{1,2}$ \\ ${ }^{1}$ Top Institute Food and Nutrition, P.O. Box 557, 6700 AN, Wageningen, the \\ Netherlands; ${ }^{2}$ Wageningen University \& Research Animal Breeding and Genomics, \\ P.O. Box 338, $6700 \mathrm{AH}$, Wageningen, the Netherlands \\ Journal of Dairy Science (Ready for submission)
}




\begin{abstract}
Dairy cows produce methane $\left(\mathbf{C H}_{4}\right)$, a greenhouse gas that is $\mathbf{2 8}$ times more harmful than carbon dioxide. The heritable variation in $\mathrm{CH}_{4}$ provides opportunities in breeding for lower $\mathrm{CH}_{4}$ emission by dairy cows. Inclusion of $\mathrm{CH}_{4}$ emission into the breeding goal for dairy cows in order to reduce $\mathrm{CH}_{4}$ emission could affect selection response of other breeding goal traits. The aim of this study was to estimate the correlations between $\mathrm{CH}_{4}$ emission indicators and test-day production and fertility traits. $\mathrm{CH}_{4}$ emission was either measured with breath sensors in automatic milking systems or predicted based on milk mid-infrared spectra. Most genetic correlations between $\mathrm{CH}_{4}$ emission and test-day production traits and fertility traits were either weak or moderate. Moderate correlations were found between sensor measured $\mathrm{CH}_{4}$ phenotypes and the yields of milk, fat, protein, and lactose. Furthermore, moderate correlations between milk MIR predicted $\mathrm{CH}_{4}$ phenotypes and percentages of fat and lactose were found. Correlations with somatic cell score, urea, and fertility traits were weak. Selective breeding for lower $\mathrm{CH}_{4}$ emission might result in a change in milk composition when selecting for reduced $\mathrm{CH}_{4}$ emission, but the change is expected to be small.
\end{abstract}

Key words: methane emission, dairy cow, milk production trait, fertility trait 


\subsection{Introduction}

Agriculture contributes significantly to greenhouse gas emissions, and enteric production of methane $\left(\mathrm{CH}_{4}\right)$ by ruminants is the single largest source of agricultural emissions (FAO, 2014;IPCC, 2014). Methane has a global warming potential that is 28 times that of carbon dioxide $\left(\mathbf{C O}_{2}\right)$ on a time span of 100 years (IPCC, 2014). Lactating dairy cows on a roughage based diet emit 300 to 400 grams of $\mathrm{CH}_{4}$ per day (Dijkstra et al., 2016; Van Gastelen et al., 2017). Moreover, the dairy industry is responsible for $2.9 \%$ of the total anthropogenic greenhouse gas emissions worldwide (Gerber et al., 2013). A reduction of greenhouse gas emissions by dairy cows is therefore necessary.

The heritable variation in $\mathrm{CH}_{4}$ emission provides opportunities to breed for lower $\mathrm{CH}_{4}$ emission in dairy cows (Lassen and Løvendahl, 2016; Van Engelen et al., Accepted, Submitted). Incorporating $\mathrm{CH}_{4}$ emission into the breeding goal, however, could result in unfavourable responses in other breeding goal traits. Therefore, the relationship between $\mathrm{CH}_{4}$ emission and other breeding goal traits needs to be studied. Although $\mathrm{CH}_{4}$ emission is not part of the current breeding goal, $\mathrm{CH}_{4}$ emission did change as a correlated response to current breeding strategies. The $\mathrm{CH}_{4}$ emission per dairy cow per year was $17 \%$ higher in 2008 as compared with 1990 . Methane emission per $\mathrm{kg}$ of fat and protein corrected milk (FPCM) over the same period decreased with $13 \%$, because FPCM per day increased with 5.7 kg (Bannink et al. 2011; Van Middelaar et al. 2014).

The aim of this study was to estimate correlations between $\mathrm{CH}_{4}$ emission and testday production and fertility traits. Data on $\mathrm{CH}_{4}$ emission measured with sensors in automatic milking systems (AMS) and predicted via milk mid-infrared (MIR) spectra were available on more than 1,300 cows. On these cows and cows related to these cows had information available on test-day milk production traits, including somatic cell score and urea, and fertility traits. Phenotypic and genetic correlations between $\mathrm{CH}_{4}$ emission and test-day milk production parameters, and genetic correlations between $\mathrm{CH}_{4}$ emission and fertility parameters were estimated.

\subsection{Material and Methods}

\subsubsection{Data}

Data on methane $\left(\mathrm{CH}_{4}\right)$ measured with breath sensors in automatic milking systems (AMS) on 1,508 dairy cows from 11 commercial dairy farms were available. Most of these cows $(1,302)$ also had data available on milk production recording (MPR) which 
were used to determine milk mid-infrared (MIR) predicted $\mathrm{CH}_{4}$ emission. In addition to these data, cows with $\mathrm{CH}_{4}$ emission, their sires and dams, and offspring of these sires and dams had information on test-day production and fertility traits available. Test-day and fertility data were made available by cooperative cattle improvement organisation CRV (Arnhem, the Netherlands). Test-day production data consisted of nearly 1.6 million records on more than 113,000 dairy cows and fertility data of approximately 250,000 records on more than 117,000 dairy cows. Detailed description on the data available is given below.

\subsubsection{Sensor measured $\mathrm{CH}_{4}$ data}

Sensor measured $\mathrm{CH}_{4}$ data contained measurements of $\mathrm{CH}_{4}$ and carbon dioxide $\left(\mathrm{CO}_{2}\right)$ measured with non-dispersive infrared sensors in AMS. Detailed description of the data is given by Van Engelen et al. (accepted). In short, sensors were installed on 11 commercial Dutch dairy farms and $\mathrm{CH}_{4}$ and $\mathrm{CO}_{2}$ measurements were taken twice per second during automatic milking. These measurements were summarized per AMS visit, resulting in three sensor phenotypes: mean of $\mathrm{CH}_{4}\left(\mathrm{CH}_{4}\right.$ mean), mean of $\mathrm{CO}_{2}$ ( $\mathrm{CO}_{2}$ mean), and mean of the ratio between $\mathrm{CH}_{4}$ and $\mathrm{CO}_{2}$ (Ratiomean). As the residuals of these three phenotypes were not normally distributed, a $\log _{10^{-}}$ transformation was applied to these phenotypes, resulting in $\mathbf{C H}_{4}$ log $\left(\log _{10}\left(\mathrm{CH}_{4}\right.\right.$ mean $\left.)\right), \mathrm{CO}_{2} \log \left(\log _{10}\left(\mathrm{CO}_{2}\right.\right.$ mean $\left.)\right)$, and Ratiolog $\left(\log _{10}\right.$ (Ratiomean)). Data on 123,369 AMS visits from November 2013 till March 2016 with sensor measured $\mathrm{CH}_{4}$ phenotypes from 1,508 dairy cows were available.

\subsubsection{Milk MIR predicted $\mathrm{CH}_{4}$ data}

Detailed description of the milk MIR predicted $\mathrm{CH}_{4}$ data is given in Van Engelen et al. (submitted). In short, milk samples were collected during MPR of all lactating cows on the same 11 dairy farms that are part of the sensor measured dataset. These milk samples were collected while the sensors were installed on the farms and were analysed by Qlip B.V. (Zutphen, the Netherlands) with MIR exactly like regular MPR samples. Three prediction equations were developed by Van Gastelen et al. (2017) and applied to the MIR spectra to create three $\mathrm{CH}_{4}$ phenotypes: $\mathrm{CH}_{4}$ production (in $\mathrm{g} /$ day), $\mathbf{C H}_{4}$ yield (in g/kg dry matter intake (DMI)), and $\mathbf{C H}_{4}$ intensity (in g/kg FPCM). The milk MIR predicted $\mathrm{CH}_{4}$ dataset consisted of 1,302 observations of milk MIR predicted $\mathrm{CH}_{4}$ phenotypes for 1,302 cows.

\subsubsection{Test-day production data}

Test-day production data consisted of nine milk production traits per observation, resulting in nearly 1.6 million observations on more than 113,000 dairy cows. Part of 
these cows also had sensor measured and milk MIR predicted $\mathrm{CH}_{4}$. The multiple testday observations per cow could be of the same parity as well as from different parities. The test-day milk production traits were milk yield, somatic cell count, urea, and the percentages of fat, protein, and lactose. Yields of fat, protein, and lactose were calculated by taking their respective percentages and multiplying those with milk yield. Somatic cell count was transformed to a somatic cell score (SCS):

SCS $=1000+100 *\left(\log _{2}(\right.$ somatic cell count $\left./ 1000)\right)$.

\subsubsection{Fertility data}

Fertility data consisted of four fertility traits per lactation during the first three lactations on more than 117,000 dairy cows. Part of these cows also had sensor measured and milk MIR predicted $\mathrm{CH}_{4}$. Not all cows had all four fertility traits for all three lactations. The four fertility parameters used in the current study were number of inseminations, non-return at 56 days, interval between calving and first insemination, and calving interval.

\subsubsection{Data editing}

Editing of sensor measured $\mathrm{CH}_{4}$ data and milk MIR predicted $\mathrm{CH}_{4}$ data has been described by Van Engelen et al. (Accepted, Submitted). For each of the test-day production and fertility traits extreme values were identified. Extreme values were defined as those outside the range mean \pm 4 *standard deviation and these were set to missing. Observations that contained only missing values were removed from the datasets. Farms with less than 30 cows were removed from the datasets for test-day production and fertility traits. The number of observations per trait after editing is presented in Table 5.1.

\subsubsection{Sensor measured $\mathrm{CH}_{4}$ data - production and fertility traits}

The test-day milk production and fertility datasets were combined with sensor measured $\mathrm{CH}_{4}$ data to calculate correlations between these traits and sensor measured $\mathrm{CH}_{4}$ emission. Sensor measured $\mathrm{CH}_{4}$ observations were combined with test-day milk production observations of the same parity. For each sensor $\mathrm{CH}_{4}$ observation, the test-day production observation closest to the sensor $\mathrm{CH}_{4}$ observation was selected by calculating the difference in days between the observations. When a specific test-day production observation was linked to multiple sensor $\mathrm{CH}_{4}$ observations, only the test-day production observation with the smallest difference in days was kept and the others were set to missing. The time between the test-day production observations and the sensor $\mathrm{CH}_{4}$ observations was 
on average 1.38 days (range: -119 to 105 days). Sensor measured $\mathrm{CH}_{4}$ observations were combined with fertility observations of only the first parity. First parity data was chosen because most observations were available for the first parity and first parity data were not influenced by selection of cows from the first to the second lactation. The fertility observation of a cow was linked to one of the observations of sensor measured $\mathrm{CH}_{4}$ emission of that cow.

Sensor measured $\mathrm{CH}_{4}$ data were now combined into two datasets: one combined with test-day production data and one combined with fertility data. These two combined datasets each consisted of 123,369 observations on 1,508 cows, because sensor measured $\mathrm{CH}_{4}$ observations without production or fertility traits were kept in the datasets. Production or fertility traits that were not available in these combined datasets were set to missing.

\subsubsection{Milk MIR predicted $\mathrm{CH}_{4}$ data - production and fertility traits}

The test-day production and fertility datasets were combined with milk MIR predicted $\mathrm{CH}_{4}$ data to calculate correlations between these traits and milk MIR predicted $\mathrm{CH}_{4}$ emission. The milk MIR predicted $\mathrm{CH}_{4}$ observations were combined with the test-day production observations of the same MPR. The single milk MIR predicted $\mathrm{CH}_{4}$ observation per cow was combined with fertility observation of the first parity of that cow. These two combined datasets each consisted of 1,302 observations on 1,302 cows, because milk MIR predicted $\mathrm{CH}_{4}$ observations without production or fertility traits were kept in the datasets. Production or fertility traits that were not available in these combined datasets were set to missing.

\subsubsection{Data analysis}

Models used for analysis of sensor measured $\mathrm{CH}_{4}$ and milk MIR predicted $\mathrm{CH}_{4}$ data were the models used previously (Van Engelen et al., accepted, submitted). Variance components of test-day milk production and fertility traits and their correlations with sensor measured $\mathrm{CH}_{4}$ phenotypes and milk MIR predicted $\mathrm{CH}_{4}$ phenotypes were estimated with ASReml 4.1 (Gilmour et al., 2015).

\subsubsection{Test-day production traits}

Variance components of test-day milk production traits were estimated on a dataset with $1,561,597$ observations of 112,398 cows using the following model:

$\mathrm{Y}_{\mathrm{ijklmno}}=\mathrm{mu}+\mathrm{UBN}_{\mathrm{i}}+$ Parcat $_{\mathrm{j}}+$ Lactationweek $_{\mathrm{k}}+$ Year $_{\mathrm{I}}+$ Season $_{\mathrm{m}}+$ Permanent $_{\mathrm{n}}+$ Animalo $+\mathrm{e}_{\mathrm{ijk} \mathrm{mno}}($ model 1$)$ 
where $Y_{i j k l m n o}$ is the dependent variable; $m u$ is the mean of the dataset; $U B N_{i}$ is the fixed effect of farm at first parity (728 levels); Parcat is $_{\mathrm{j}}$ the fixed effect of category

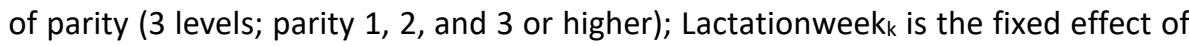
week of lactation (60 levels); Yearı is the fixed effect of year of calving ( 7 levels; 2010 - 2016); Season $n_{m}$ is the fixed effect of season of calving (4 levels; December February, March - May, June - August, and September - November); Permanent $t_{n}$ is the random permanent environmental effect of animal $\left(\sim N\left(0, I \sigma^{2} \mathrm{PE}\right)\right)$ with incidence matrix I and phenotypic variance $\sigma^{2} \mathrm{PE}$; Animalo is the random additive genetic effect of animal ( $\mathrm{N}\left(0, \mathbf{A} \sigma^{2} \mathrm{~A}\right)$ ) with additive genetic relationship matrix $\mathbf{A}$ and additive genetic variance $\sigma_{\mathrm{A}}{ }_{\mathrm{A}}$ (the pedigree contained 411,864 animals); and $\mathrm{e}_{\mathrm{ijk}} \mathrm{mno}$ is the random error effect $\left(\sim \mathrm{N}\left(0, I \sigma^{2} \mathrm{E}\right)\right.$ ) with incidence matrix I and residual variance $\sigma^{2} \mathrm{E}$.

\subsubsection{Fertility traits}

Variance components of the fertility traits were estimated on a dataset with 239,812 observations of 109,496 cows using the following model:

$\begin{aligned} Y_{i j k l m n}= & m u+U N_{i}+\text { Parity }_{j}+\text { Year }_{k}+\text { Season }_{1}+\text { Permanent }_{m}+\text { Animal }_{n}+\text { e }_{i j k l m n} \\ & (\text { model } 2)\end{aligned}$

where $Y_{i j k l m n}$ is the dependent variable; mu is the mean of the dataset; $U B N_{i}$ is the fixed effect of farm at first parity (731 levels); Parity is the fixed effect of parity ( 3 levels; parity 1, 2 and 3); Year $\mathrm{k}$ is the fixed effect of year of calving (10 levels; before 2007, 2007 - 2014, after 2014); Season। is the fixed effect of season of calving (4 levels; December - February, March - May, June - August, and September November); Permanent $t_{m}$ is the random permanent environmental effect of animal $\left(\sim N\left(0, I \sigma^{2} \mathrm{PE}\right)\right.$ ) with incidence matrix $\mathbf{I}$ and phenotypic variance $\sigma^{2}{ }_{\mathrm{PE}}$; Animal $\mathrm{I}_{\mathrm{n}}$ is the random additive genetic effect of animal $\left(\sim N\left(0, A \sigma^{2} A\right)\right)$ with additive genetic relationship matrix $\mathbf{A}$ and additive genetic variance $\sigma^{2}$ (the pedigree contained 411,864 animals); and $e_{i j k l m n}$ is the random error effect $\left(\sim N\left(0, I \sigma^{2} E\right)\right)$ with incidence matrix $I$ and residual variance $\sigma^{2} \mathrm{E}$.

\subsubsection{Genetic parameters}

Repeatabilities of the test-day production and fertility traits were calculated as follows:

$$
\text { Repeatability }=\frac{\sigma_{A}^{2}+\sigma_{P E}^{2}}{\sigma_{A}^{2}+\sigma_{P E}^{2}+\sigma_{E}^{2}}
$$


where $\sigma^{2} \mathrm{~A}$ is the additive genetic variance, $\sigma^{2} \mathrm{PE}$ is the permanent environmental variance, and $\sigma^{2} E$ is the residual variation. The heritabilities $\left(\mathbf{h}^{2}\right)$ of the test-day production and fertility traits were as follows:

$$
h^{2}=\frac{\sigma_{A}^{2}}{\sigma_{A}^{2}+\sigma_{P E}^{2}+\sigma_{E}^{2}}
$$

where $\sigma^{2}$ is the additive genetic variance, $\sigma^{2} \mathrm{PE}$ is the permanent environmental variance, and $\sigma^{2} \mathrm{E}$ is the residual variation.

\subsubsection{Correlations of $\mathrm{CH}_{4}$ phenotypes with production and fertility traits} Bivariate analyses were used to calculate the correlations of, on the one hand, sensor measured $\mathrm{CH}_{4}$ phenotypes and milk MIR predicted $\mathrm{CH}_{4}$ phenotypes, and, on the other hand, test-day milk production and fertility traits. Fixed effects for test-day milk production were the same as in model 1 and for fertility traits the same as in model 2. The permanent environmental effect was removed from these two models for the bivariate analyses. Fixed effects for sensor measured $\mathrm{CH}_{4}$ phenotypes were farm of measurement (11 levels) and week of lactation (59 levels). Fixed effects for milk MIR predicted $\mathrm{CH}_{4}$ phenotypes were week of lactation (60 levels) and MPR (17 levels).

Phenotypic correlations $\left(\boldsymbol{r}_{\mathbf{p}}\right)$ of sensor measured $\mathrm{CH}_{4}$ phenotypes and milk MIR predicted $\mathrm{CH}_{4}$ phenotypes with test-day milk production traits were calculated. Phenotypic correlations with fertility traits were not calculated as phenotypic correlations require observations taken at the same time and this was not the case for fertility traits. The rp were calculated as follows:

$$
r_{p}=\frac{\sigma_{P 1, P 2}}{\sqrt{\left(\sigma_{P 1}^{2} * \sigma_{P 2}^{2}\right)}}
$$

where $\sigma_{\mathrm{P} 1, \mathrm{P} 2}$ is the phenotypic covariance between trait 1 and trait 2 , and $\sigma^{2} \mathrm{P}_{1}$ and $\sigma^{2}$ P2 are the phenotypic variances of trait 1 and 2 . The genetic correlations $\left(\mathbf{r}_{\mathrm{A}}\right)$ of $\mathrm{CH}_{4}$ phenotypes (sensor measured and milk MIR predicted) with test-day milk production and fertility traits were calculated as follows:

$$
r_{A}=\frac{\sigma_{A 1, A 2}}{\sqrt{\left(\sigma_{A 1}^{2} * \sigma_{A 2}^{2}\right)}}
$$


where $\sigma_{\mathrm{A} 1, \mathrm{~A} 2}$ is the genetic covariance between trait 1 and trait 2 , and $\sigma^{2} \mathrm{~A} 1$ and $\sigma^{2} \mathrm{~A} 2$ are the genetic variances of trait 1 and 2 .

\subsection{Results}

\subsubsection{Repeatabilities and heritabilities}

The repeatabilities and heritabilities of the test-day milk production and fertility traits are presented in Table 5.1. Repeatabilities for milk production traits ranged between 0.18 and 0.52 , and were higher than repeatabilities of fertility traits, which ranged between 0.04 and 0.17 . The standard errors (s.e.) of the repeatabilities were small (0.001 - 0.004). Like the repeatabilities, heritabilities for test-day milk production traits were higher ranging between 0.10 and 0.43 than heritabilities for fertility heritabilities ranging between 0.02 and 0.09 . The s.e. of the heritabilities were also low (0.002 - 0.007).

Table 5.1 Descriptive statistics and genetic parameters of test-day milk production and fertility traits $^{1,2}$

\begin{tabular}{|c|c|c|c|c|c|}
\hline Traits & $\mathrm{N}$ & Mean & SD & Repeatability & Heritability \\
\hline \multicolumn{6}{|l|}{ Test-day production traits } \\
\hline Milk yield (kg) & $1,561,011$ & 28.9 & 9.4 & $0.42(0.002)$ & $0.18(0.005)$ \\
\hline Fat percentage & $1,545,020$ & 4.43 & 0.71 & $0.52(0.002)$ & $0.43(0.005)$ \\
\hline Fat yield (kg) & $1,545,459$ & 1.25 & 0.37 & $0.34(0.002)$ & $0.14(0.004)$ \\
\hline Protein percentage & $1,544,059$ & 3.63 & 0.40 & $0.52(0.002)$ & $0.42(0.005)$ \\
\hline Protein yield (kg) & $1,546,685$ & 1.03 & 0.29 & $0.39(0.002)$ & $0.12(0.005)$ \\
\hline Lactose percentage & $1,541,066$ & 4.54 & 0.19 & $0.50_{(0.002)}$ & $0.37(0.005)$ \\
\hline Lactose yield (kg) & $1,546,603$ & 1.32 & 0.44 & $0.41_{(0.002)}$ & $0.17(0.005)$ \\
\hline Somatic cell score & $1,540,937$ & 1,605 & 177 & $0.37(0.002)$ & $0.10_{(0.004)}$ \\
\hline $\begin{array}{l}\text { Urea }(\mathrm{mg} / 100 \mathrm{~g} \text { milk}) \\
\text { Fertility traits }\end{array}$ & $1,484,254$ & 22.0 & 5.9 & $0.18(0.001)$ & $0.13(0.003)$ \\
\hline Number of inseminations & 235,248 & 2.0 & 1.4 & $0.08(0.003)$ & $0.02(0.003)$ \\
\hline Non return at 56 days & 203,921 & 57.9 & 49.4 & $0.04(0.003)$ & $0.02(0.002)$ \\
\hline $\begin{array}{l}\text { Calf insemination interval } \\
\text { (days) }\end{array}$ & 217,576 & 81.9 & 30.5 & $0.17(0.003)$ & $0.09(0.006)$ \\
\hline Between calf interval (days) & 155,219 & 400.8 & 61.7 & $0.17_{(0.004)}$ & $0.07_{(0.007)}$ \\
\hline
\end{tabular}

${ }_{1}$ Descriptive statistics shown in this table are number of observations $(\mathrm{N})$, mean, standard deviation (SD) of each trait.

${ }^{2}$ Genetic parameters shown in this table are repeatability calculated as $\left(\sigma^{2}{ }_{\mathrm{A}}+\sigma^{2} \mathrm{PE}\right) /\left(\sigma^{2}{ }_{\mathrm{A}}+\sigma^{2} \mathrm{PE}\right.$ $\left.+\sigma^{2} \mathrm{E}\right)$ and heritability $\left(\mathrm{h}^{2}\right)$ calculated as $\sigma_{\mathrm{A}}^{2} /\left(\sigma^{2} \mathrm{~A}+\sigma^{2} \mathrm{PE}+\sigma^{2} \mathrm{E}\right)$ with the respective standard error in parentheses. 


\subsubsection{Phenotypic correlations between methane phenotypes and test- day production traits}

The phenotypic correlations $\left(\mathbf{r}_{\mathrm{p}}\right)$ between $\mathrm{CH}_{4}$ phenotypes (sensor measured and milk MIR predicted) and test-day production traits are presented in table 5.2. Most of these correlations were weak, with some exceptions. Correlations of test-day milk production traits with sensor measured $\mathrm{CH}_{4}$ phenotypes were weak, ranging between -0.06 and 0.10 (s.e. $=0.01-0.04$ ). Correlations of test-day milk production traits with milk MIR predicted $\mathrm{CH}_{4}$ phenotypes were also weak to moderate $\left(r_{p}=-\right.$ $0.34-0.64$, s.e. $=0.02-0.03$ ). Correlations between $\mathrm{CH}_{4}$ phenotypes and SCS and urea were, thus, also weak. The strongest correlations were found between $\mathrm{CH}_{4}$ yield and fat percentage $\left(r_{p}=0.64\right), \mathrm{CH}_{4}$ intensity and fat yield $\left(r_{p}=-0.34\right)$, and $\mathrm{CH}_{4}$ intensity and protein percentage $\left(r_{p}=0.52\right)$.

\subsubsection{Genetic correlations of methane phenotypes with test-day production and fertility traits}

The genetic correlations $\left(r_{A}\right)$ of $\mathrm{CH}_{4}$ phenotypes (sensor measured and milk MIR predicted) with test-day production and fertility traits are presented in Table 5.3. Genetic correlations of sensor measured $\mathrm{CH}_{4}$ phenotypes and milk MIR predicted $\mathrm{CH}_{4}$ emission with test-day production traits were weak to moderate $\left(\mathrm{r}_{\mathrm{g}}=-0.47-\right.$ 0.65 , s.e. $=0.06-0.45)$. Correlations of $\mathrm{CH}_{4}$ phenotypes with SCS ranged between 0.61 and -0.04 (s.e. $=0.06-0.38$ ) and correlations with urea ranged between -0.12 and 0.44 (s.e. $=0.08-0.53$ ). Correlations with sensor measured $\mathrm{CH}_{4}$ phenotypes outside the range of -0.30 to 0.30 with s.e. lower than 0.20 were found for $\mathrm{CH}_{4}$ log and Ratiolog with milk yield $\left(\mathrm{r}_{\mathrm{A}}=0.32\right.$ and 0.51$)$, for $\mathrm{CH}_{4} \log$ and Ratiolog with fat yield ( $r_{A}=0.37$ and 0.65$)$, for $\mathrm{CH}_{4} \log$ and Ratiolog with protein yield ( $r_{A}=0.34$ and 0.53 ), and for $\mathrm{CH}_{4} \log$ and Ratiolog with lactose yield ( $\mathrm{r}_{\mathrm{A}}=0.32$ and 0.53$)$. Correlations with milk MIR predicted $\mathrm{CH}_{4}$ phenotypes outside the set range were found for $\mathrm{CH}_{4}$ yield with fat percentage $\left(r_{A}=0.63\right)$, and for $\mathrm{CH}_{4}$ yield with lactose percentage $\left(r_{A}=0.50\right)$. Genetic correlations between sensor measured $\mathrm{CH}_{4}$ phenotypes and fertility traits were weak to moderate ranging from -0.32 to 0.38 (s.e. $=0.12-0.68$ ). Genetic correlations with milk MIR predicted $\mathrm{CH}_{4}$ phenotypes were not reported as their s.e. were large ranging between 0.25 and 17.73. Genetic correlation between sensor $\mathrm{CH}_{4}$ phenotypes and fertility traits outside the range of -0.30 to 0.30 with s.e. lower than 0.20 was found for Ratiolog with calf-insemination interval $\left(r_{A}=0.38\right)$. 


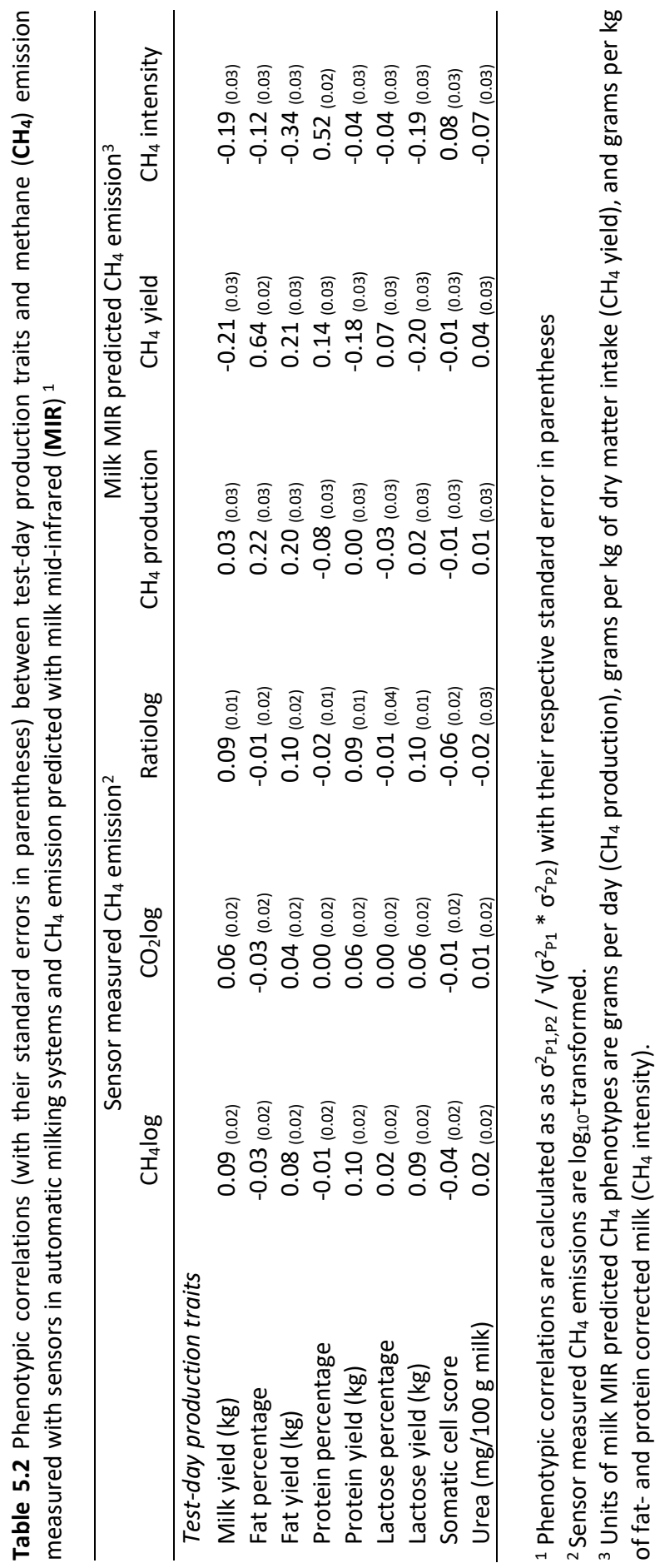




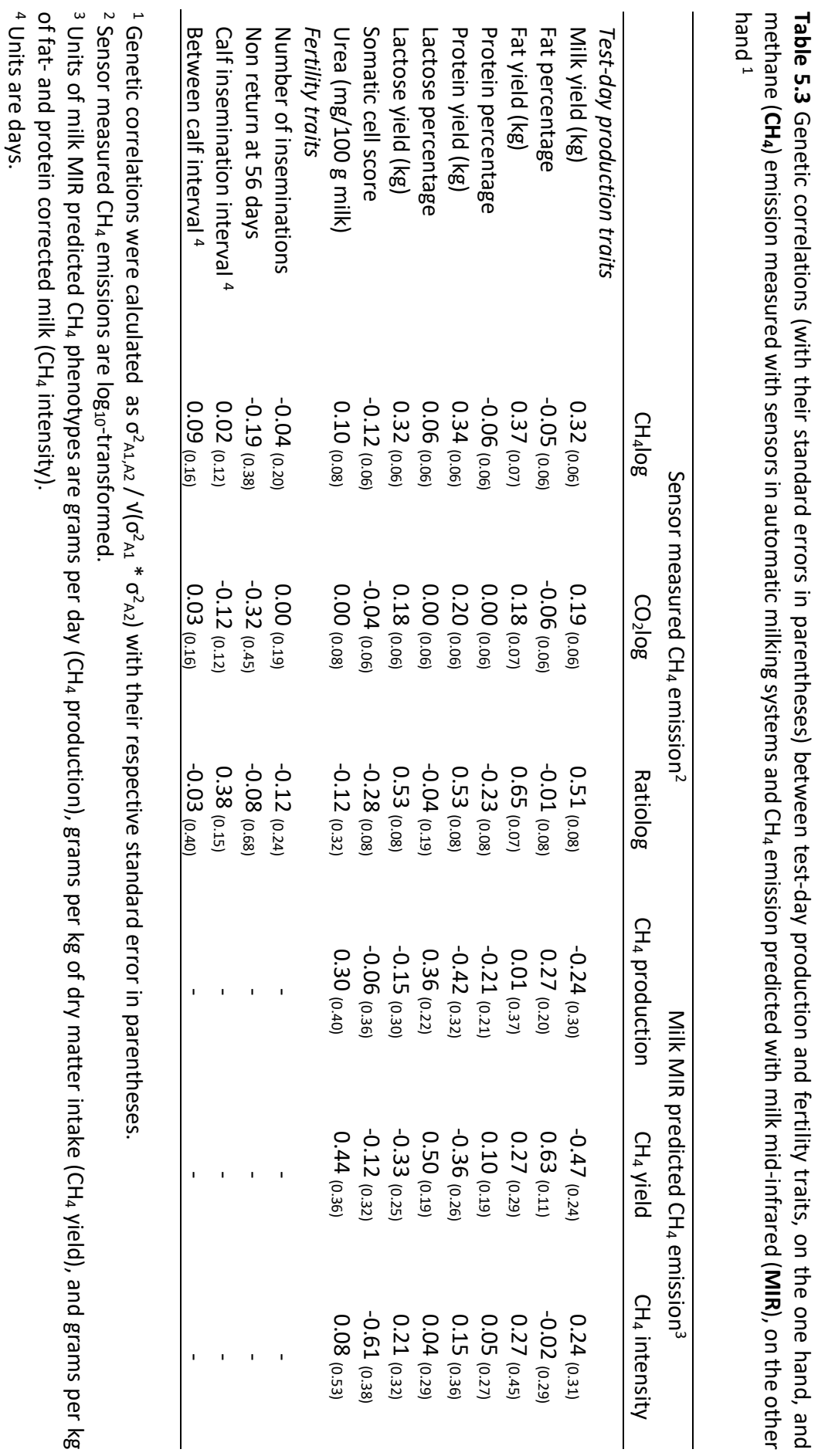




\subsection{Discussion}

\subsubsection{Repeatability and heritability}

To our knowledge, repeatabilities of the production and fertility traits have not been reported in literature, but their heritabilities have been reported (Stoop et al., 2008;CRV, 2015a;b). The production traits showed lower heritabilities for yields than for percentages. Furthermore, these heritabilities were lower than reported in literature and this might be explained by the fact that farm was added to the model as fixed and not as random. In the study of Stoop et al. (2008), herd was found to explain substantial variation in milk production traits. The found difference in heritabilities between yields and percentages are in line with literature (Stoop et al., 2008;CRV, 2015a). Fertility traits were reported to have in general lower heritabilities compared to the production traits. The heritabilities for fertility traits in our study ranged between 0.02 and 0.09 , and are in line with the range of heritabilities of 0.016 to 0.099 reported in literature (CRV, 2015b). Agreement with literature indicates that the datasets used for this study were a good representation of the Dutch dairy population.

\subsubsection{Phenotypic and genetic correlations between methane phenotypes and test-day production traits}

The phenotypic correlations between $\mathrm{CH}_{4}$ phenotypes and test-day production traits were weaker than the genetic correlations estimated in this study. Weaker phenotypic correlations compared to genetic correlations were also found by Kandel et al. (2017) for milk MIR predicted $\mathrm{CH}_{4}$ emission and milk, fat and protein yield. The phenotypic correlations had smaller s.e. $(0.01-0.04)$ than the genetic correlations $(0.06-0.53)$. These large standard errors of genetic correlations are due to the relatively small datasets for $\mathrm{CH}_{4}$ phenotypes that were used to estimate these correlations on.

Phenotypic correlations of $\mathrm{CH}_{4}$ phenotypes with fertility traits were not estimated in this study. Phenotypic correlations require that observations on both phenotypes are taken close in time. Methane phenotypes can be linked to a short time-span of several days whereas fertility traits cannot as they occur over a longer time period. For example, calving interval describes the fertility of a cow over a long period of time and, thus, cannot be linked to $1 \mathrm{CH}_{4}$ phenotype.

A relationship between $\mathrm{CH}_{4}$ emission and milk yield is anticipated. Cows that produce more milk are expected to have a higher feed intake, and a higher feed intake is expected to result in a higher $\mathrm{CH}_{4}$ production. Production of $\mathrm{CH}_{4}$ occurs namely during feed fermentation in the rumen and feed intake could, thus, be used to 
predict $\mathrm{CH}_{4}$ emission (De Haas et al., 2011). In our study, the genetic correlations between $\mathrm{CH}_{4}$ emission and milk yield were positive for sensor measured $\mathrm{CH}_{4}$ emission, and both positive and negative for milk MIR predicted $\mathrm{CH}_{4}$ emission. The correlations between sensor measured $\mathrm{CH}_{4}$ emission and milk yield are in line with the hypothesis that higher milk yield results in a higher $\mathrm{CH}_{4}$ emission. The negative genetic correlations with milk yield were with $\mathrm{CH}_{4}$ production and $\mathrm{CH}_{4}$ yield.

Neither correlation between milk yield and $\mathrm{CH}_{4}$ phenotypes was strong positive or negative. Milk yield has been used to predict $\mathrm{CH}_{4}$ emission, though the predictive power of milk yield was low (Ellis et al., 2010). Milk yield was also not part of the $\mathrm{CH}_{4}$ prediction equations for $\mathrm{CH}_{4}$ yield or $\mathrm{CH}_{4}$ intensity reported by Van Lingen et al. (2014). These studies are based on feeding trials and indicate that the expected relationship between $\mathrm{CH}_{4}$ emission and milk yield is positive, but might not be very strong. The strength of this relationship might be weaker as in feeding trials cows are feed restricted. Most genetic correlations reported in this study, however, follow this line as neither is strong positive or negative.

Moreover, the phenotype used for $\mathrm{CH}_{4}$ emission influences the relationship between milk yield and $\mathrm{CH}_{4}$ phenotypes. $\mathrm{CH}_{4}$ production is indeed expected to increase when milk yield increases, but $\mathrm{CH}_{4}$ yield and $\mathrm{CH}_{4}$ intensity are expected to decrease. Cows with higher milk yield are expected to not only have a higher feed intake, but also to be more efficient. High-productive cows are, thus, expected to need a smaller part of their daily intake for maintenance (Yan et al., 2010). Therefore, $\mathrm{CH}_{4}$ emission per day is expected to increase, but $\mathrm{CH}_{4}$ per $\mathrm{kg}$ of fat and protein corrected milk is expected to decrease. Furthermore, a higher intake could lead to a shorter rumen retention time which could lead to a lower $\mathrm{CH}_{4}$ production per unit of feed (Hegarty, 2004).

Genetic correlations of milk yield with milk MIR predicted $\mathrm{CH}_{4}$ production were reported by Kandel et al. (2017). The genetic correlation between $\mathrm{CH}_{4}$ production and milk yield was -0.19 and between log-transformed $\mathrm{CH}_{4}$ intensity and milk yield was -0.68 . The correlation between $\mathrm{CH}_{4}$ production and milk yield was, like in our study, negative, and might be caused by the feeding regime applied by the farmers. In the study of Kandel, cows with a milk yield above $30 \mathrm{~kg}$ were fed higher amounts of concentrates, and these concentrates are known to result in less $\mathrm{CH}_{4}$ production compared to roughage. In our dataset high productive cows were fed more concentrates compared to their low productive herd mates. This feeding practice will result in lower $\mathrm{CH}_{4}$ production and, thus, an even lower $\mathrm{CH}_{4}$ intensity for high productive cows. This might explain the negative correlation between milk yield and $\mathrm{CH}_{4}$ production found in this study. Based on these results and on literature, there 
are no indications that selective breeding for lower $\mathrm{CH}_{4}$ emission will have a large impact on milk production.

The relationship between $\mathrm{CH}_{4}$ emission and major milk components might be influenced by milk yield. Cows that had a higher genetic merit for milk yield had lower percentages for milk fat and protein compared with cows with a lower genetic merit (Bobe et al., 2007). Yields of fat and protein, however, were higher for high merit cows compared with low merit cows (Bobe et al., 2007). In this study, genetic correlations of sensor measured and milk MIR predicted $\mathrm{CH}_{4}$ phenotypes with major milk components (fat, protein and lactose) were found to be weak to moderate. Sensor measured $\mathrm{CH}_{4}$ emission showed mostly negative correlations with percentage traits and positive correlations with yield traits, in line with the hypothesis. Milk MIR predicted $\mathrm{CH}_{4}$ emission did not show negative correlations with percentage traits and positive correlations with yield traits, though these correlations were mostly weak and had large standard errors.

The relationships between $\mathrm{CH}_{4}$ emission and the major milk components fat and protein reported in literature were different for the individual studies and different $\mathrm{CH}_{4}$ phenotypes (Lassen and Løvendahl, 2016;Kandel et al., 2017;Negussie et al., 2017). Weak correlations of milk MIR predicted $\mathrm{CH}_{4}$ production with fat and protein yield were reported by Kandel et al. (2017). In the same study, moderately negative correlations between milk MIR predicted $\mathrm{CH}_{4}$ intensity ( $\mathrm{g} / \mathrm{kg}$ milk) with fat and protein yield were reported. Moderate to strong positive correlations of sensor measured $\mathrm{CH}_{4}$ phenotypes with fat and protein percentage were reported by Lassen and Løvendahl (2016). Some of the correlations reported in literature were in line with the hypothesis made in the previous paragraph whereas others were not in line. The hypothesis, however, is based on milk yield which is not strongly related to $\mathrm{CH}_{4}$ emission in this study. Moreover, the review by Negussie et al. (2017) indicated that major milk components are a weak proxy for $\mathrm{CH}_{4}$ emission and, thus, the correlation between them is expected to be weak. Moderate correlations, however, were found in this study between milk MIR predicted $\mathrm{CH}_{4}$ yield and percentages of fat and lactose, and between sensor measured $\mathrm{CH}_{4}$ emission and yield traits (yields of fat, protein and lactose). Although neither correlation is strong, selection for reduced $\mathrm{CH}_{4}$ emission might result in a lower content of fat and lactose, or a lower yield for fat, protein, and lactose.

\subsubsection{Genetic correlations between $\mathrm{CH}_{4}$ emission and somatic cell score}

Somatic cell score is a health parameter that is used to determine the presence of mastitis in lactating dairy cows. Mastitis is known to be the most costly production 
disease in cattle that is linked with treatment costs as well as a loss in milk yield (Veerkamp et al., 2012; Bell et al., 2013). Furthermore, cows with mastitis need to be replaced earlier than cows without mastitis (Cha et al., 2014), leading to a higher total $\mathrm{CH}_{4}$ production per herd. The correlations between $\mathrm{SCS}$ and $\mathrm{CH}_{4}$ emission found in this study were negative and weak to moderate.

The relationship between $\mathrm{CH}_{4}$ emission and SCS has not been studied before and might be via milk yield. Cows with a high milk yield have a higher risk for clinical mastitis (Nielsen, 2009). However, the relationship between SCS and milk yield varied within and across lactations (Jamrozik et al., 2010). These studies suggest that the expected relationship between $\mathrm{CH}_{4}$ emission and SCS is weak. The relationship between $\mathrm{CH}_{4}$ emission and $\mathrm{SCS}$ found in this study was in line with this hypothesis. The negative correlations between $\mathrm{CH}_{4}$ emission and SCS suggest an unfavourable response in SCS when selecting on $\mathrm{CH}_{4}$ emission. As the correlations were not strong and had large standard errors, selective breeding for reduced $\mathrm{CH}_{4}$ emission is expected not to result in a higher SCS or higher incidence of mastitis.

\subsubsection{Genetic correlations between $\mathrm{CH}_{4}$ emission and urea}

The urea content of milk is influenced by the protein content of the feed and by feed intake (Spek et al., 2013) and might, thus, be correlated to $\mathrm{CH}_{4}$ emission. Increased DMI might be linked with a higher nitrogen consumption, leading to an increased milk urea content. Reduction of milk urea content is wanted as it is linked to ammonia emissions (Spek, 2013). To our knowledge, no studies have investigated the relationship between milk urea content and $\mathrm{CH}_{4}$ emission. In this study the correlations between urea and $\mathrm{CH}_{4}$ emission were found to be weak. The expectation is that selective breeding for lower $\mathrm{CH}_{4}$ emission will have no impact on milk urea content.

\subsubsection{Genetic correlations between $\mathrm{CH}_{4}$ emission and fertility}

The direct relationship between sensor measured $\mathrm{CH}_{4}$ phenotypes and fertility traits has not been studied before. From a biological point of view, fertility might be linked with $\mathrm{CH}_{4}$ emission via milk production and feed intake. Cows that have a high milk yield are also expected to have a higher feed intake and, thereby, produce more $\mathrm{CH}_{4}$. High-productive cows are also reported to have a lower fertility (Windig et al., 2006). Weak correlations between milk yield and fertility traits were found in literature with a positive correlation between number of inseminations and milk yield (Berry et al., 2003). Furthermore, no relationship of $\mathrm{CH}_{4}$ yield and $\mathrm{CH}_{4}$ intensity with profitable lifetime index based on fertility traits was found (Dong et al., 2015). The correlations 
found in literature are confirmed in this study with the weak correlations ranging between -0.32 and 0.38 . These results indicate that selective breeding for lower $\mathrm{CH}_{4}$ emission is, thus, not expected to reduce fertility of dairy cows.

Genetic correlations between milk MIR predicted $\mathrm{CH}_{4}$ phenotypes and fertility traits could not be estimated accurately. The genetic correlations had large standard errors ranging between 0.25 and 17.71 . The large standard errors are due to the relatively small dataset that was used to estimate these genetic correlations on and the large number of missing values in the fertility dataset (see Table 5.1). Therefore, we decided not to show these genetic correlations.

\subsubsection{Breeding for lower $\mathrm{CH}_{4}$ emission}

In this study we estimated the correlations between $\mathrm{CH}_{4}$ emission and test-day production and fertility traits currently used as breeding goal traits for selective breeding in dairy cows. The current breeding goal reduces $\mathrm{CH}_{4}$ emission per $\mathrm{kg}$ of milk, but increases $\mathrm{CH}_{4}$ emission per cow per year (Bannink et al., 2011;van Middelaar et al., 2014). The effect of adding $\mathrm{CH}_{4}$ emission to the breeding goal will be influenced by the genetic correlations between $\mathrm{CH}_{4}$ emission and the other breeding goal traits. Most genetic correlations between $\mathrm{CH}_{4}$ emission and production and fertility traits were either weak or moderate. Moderate correlations between milk MIR predicted $\mathrm{CH}_{4}$ yield and percentages of fat and lactose, and between sensor measured $\mathrm{CH}_{4}$ emission and yield traits (yields of fat, protein and lactose) were found in this study. The percentage of fat and lactose and the yields of fat, protein and lactose might decrease when selecting for reduced $\mathrm{CH}_{4}$ emission. However, the potential change in milk composition is expected to be small because genetic correlations with $\mathrm{CH}_{4}$ emission are weak to moderate. Therefore, the results of this study show that inclusion of $\mathrm{CH}_{4}$ emission in the breeding goal is expected to have a minor negative impact on the other breeding goal traits.

\subsection{Conclusions}

The relationships between, on the one hand, sensor measured and milk MIR predicted $\mathrm{CH}_{4}$ emission and, on the other hand, test-day production and fertility parameters are weak to moderate. The results of this study suggests that the impact of adding $\mathrm{CH}_{4}$ emission to the breeding goal for dairy cows is expected to be small. 


\subsection{References}

Bannink, A., M. W. van Schijndel, and J. Dijkstra. 2011. A model of enteric fermentation in dairy cows to estimate methane emission for the Dutch national inventory report using the IPCC tier 3 approach. Anim. Feed Sci. and Technol. 166167:603-618.

Bell, M.J. R.J. Eckard, M. Haile-Mariam, and J.E. Pryce. 2013. The effect of changing cow production and fitness traits on net income and greenhouse gas emission from Australian dairy system. J. Dairy Sci. 96:7918-7931.

Berry, D. P., F. Buckley, P. Dillon, R. D. Evans, M. Rath, and R. F. Veerkamp. 2003. Genetic relationships among body condition score, body weight, milk yield, and fertility in dairy cows. J. Dairy Sci. 86(6):2193-2204.

Bobe, G. G.L. Lindberg, A.E. Freeman, and D.C. Beitz. 2007. Short communication: composition of milk protein and milk fatty acids is stable for cows differing in genetic merit for milk production. J. Dairy Sci. 90:3955-3960.

Cha, E., A.R. Kristensen, J.A. Hertl, Y.H. Schukken, L.W. Tauer, F.L. Welcome, and Y.T. Gröhn. 2014. Optimal insemination and replacement decisions to minimize the cost of pathogen-specific clinical mastitis in dairy cows. J. Dairy Sci. 97:2101-2117.

CRV. 2015a. Kengetallen e-7 fokwaardeschatting melkproductiekenmerken met testdagmodel.

CRV. 2015b. Kengetallen e-17 fokwaarde vruchtbaarheid.

De Haas, Y., J. J. Windig, M. P. L. Calus, J. Dijkstra, M. de Haan, A. Bannink, and R. F. Veerkamp. 2011. Genetic parameters for predicted methane production and potential for reducing enteric emissions through genomic selection. J. Dairy Sci. 94(12):6122-6134.

Dijkstra, J., S. Van Gastelen, E. C. Antunes-Fernandes, D. Warner, B. Hatew, G. Klop, S. C. Podesta, H. J. Van Lingen, K. A. Hettinga, and A. Bannink. 2016. Relationships between milk fatty acid profiles and enteric methane production in dairy cattle fed grass- or grass silage-based diets. Anim Prod Sci 56(3):541-548.

Dong, L. F., T. Yan, C. P. Ferris, D. A. McDowell, and A. Gordon. 2015. Is there a relationship between genetic merit and enteric methane emission rate of lactating Holstein-Friesian dairy cows? Animal 9(11):1807-1812.

Ellis, J. L., A. Bannink, J. France, E. Kebreab, and J. Dijkstra. 2010. Evaluation of enteric methane prediction equations for dairy cows used in whole farm models. Glob Chang Biol 16(12):3246-3256.

FAO. 2014. Food and agriculture statistical yearbook 2014 Europe and central Asia, Budapest, Hungary. 
Gerber, P. J., H. Steinfeld, B. Henderson, A. Mottet, C. Opio, J. Dijkman, A. Falcucci and G. Tempio. 2013. Tackling climate change through livestock - a global assessment of emissions and mitigation opportunities. in Food and Agriculture Organization of the United Nations. FAO, Rome.

Gilmour, A. R., B. J. Gogel, B. R. Cullis, S. J. a. Welham, and R. Thompson. 2015. Asreml user guide release 4.1 structural specification. VSN International Ltd, Hemel Hempstead, UK.

Hegarty, R. S. 2004. Genotype differences and their impact on digestive tract function of ruminants: A review. Aust J Exp Agric 44(5):459-467.

IPCC. 2014. Climate change 2014: Synthesis report. Contribution of working groups $\mathrm{i}$, ii and iii to the fifth assessment report of the intergovermental panel on climate change, ed. R.K. Pachauri and I.A. Meyer. Geneva, Switzerland.

Jamrozik. J., J. Bohmanova, and L.R. Schaeffer. 2010. Relationships between milk yield and somatic cell score in Canadian Holsteins from simultaneous and recursive random regression models. J. Dairy Sci. 93:1216-1233.

Kandel, P. B., M. L. Vanrobays, A. Vanlierde, F. Dehareng, E. Froidmont, N. Gengler, and $\mathrm{H}$. Soyeurt. 2017. Genetic parameters of mid-infrared methane predictions and their relationships with milk production traits in holstein cattle. J. Dairy Sci. 100(7):5578-5591.

Lassen, J. and P. Løvendahl. 2016. Heritability estimates for enteric methane emissions from holstein cattle measured using noninvasive methods. J. Dairy Sci. 99(3):1959-1967.

Negussie, E., Y. de Haas, F. Dehareng, R. J. Dewhurst, J. Dijkstra, N. Gengler, D. P. Morgavi, H. Soyeurt, S. van Gastelen, T. Yan, and F. Biscarini. 2017. Invited review: Large-scale indirect measurements for enteric methane emissions in dairy cattle: A review of proxies and their potential for use in management and breeding decisions. J. Dairy Sci. 100(4):2433-2453.

Nielsen, C. 2009. Economic impact of mastitis in dairy cows. PhD thesis. Swedish University of Agriculture, Uppsala, Sweden.

Spek, J. W. 2013. Variation of milk urea in dairy cattle. PhD thesis. Wageningen University, Wageningen, the Netherlands.

Spek, J. W., J. Dijkstra, G. Van Duinkerken, and A. Bannink. 2013. A review of factors influencing milk urea concentration and its relationship with urinary urea excretion in lactating dairy cattle. J. Agric. Sci 151(3):407-423.

Stoop, W. M., J. A. M. Van Arendonk, J. M. L. Heck, H. J. F. Van Valenberg, and H. Bovenhuis. 2008. Genetic parameters for major milk fatty acids and milk production traits of dutch holstein-friesians. J. Dairy Sci. 91(1):385-394. 
Van Engelen, S., H. Bovenhuis, P.P.J. van der Tol, and M.H.P.W. Visker. Genetic Background of Methane Emission by Dutch Holstein Friesian cows measured with Infrared Sensors in Automatic Milking Systems. J. Dairy Sci. Accepted.

Van Engelen, S., H. Bovenhuis, and M.H.P.W. Visker. Genetic Background of Milk Mid Infrared predicted Methane Emission and Relationship with Sensor Measured Methane Emission in Dutch Dairy Cows. J. Dairy Sci. Submitted.

Van Gastelen, S., H. Mollenhorst, E.C. Antunes-Fernandes, K.A. Hettinga, G. van Burgsteden, J. Dijkstra, and J.L.W. Rademaker. Predicting enteric methane emission of dairy cows with milk fatty acid profiles and milk Fourier-transform infrared spectra. J. Dairy Sci. Submitted.

Van Lingen, H. J., L. A. Crompton, W. H. Hendriks, C. K. Reynolds, and J. Dijkstra. 2014. Meta-analysis of relationships between enteric methane yield and milk fatty acid profile in dairy cattle. J. Dairy Sci. 97(11):7115-7132.

Van Middelaar, C. E., P. B. M. Berentsen, J. Dijkstra, J. A. M. van Arendonk, and I. J. M. de Boer. 2014. Methods to determine the relative value of genetic traits in dairy cows to reduce greenhouse gas emissions along the chain. J. Dairy Sci. 97(8):51915205.

Veerkamp. R.F., B. Beerda, and T. van der Lende. 2003. Effects of genetic selection for milk yield on energy balance, levels of hormones, and metabolites in lactating cattle, and possible links to reduced fertility. Livest. Prod. Sci. 83:257-275

Windig, J. J., M. P. L. Calus, B. Beerda, and R. F. Veerkamp. 2006. Genetic correlations between milk production and health and fertility depending on herd environment. J. Dairy Sci. 89(5):1765-1775. 


\section{6}

General discussion 



\subsection{Introduction}

The main aim of this thesis was to investigate whether there is genetic variation in methane $\left(\mathrm{CH}_{4}\right)$ emission by dairy cows. To estimate genetic variation in $\mathrm{CH}_{4}$ emission, a large number of records on $\mathrm{CH}_{4}$ emission of individual cows are needed. The 'golden standard' for measuring $\mathrm{CH}_{4}$ emission by dairy cows is the climate respiration chamber (CRC), a closed system in which the amount of gasses produced by cows can be measured precisely. The use of CRC, however, is labour intensive and costly (Johnson and Johnson, 1995; Storm, 2012) and can, therefore, not be used on large number of cows. Therefore, the use of CRC measurements to determine the genetic variation in $\mathrm{CH}_{4}$ emission is practically not feasible.

In this thesis, three different indicators for $\mathrm{CH}_{4}$ emission were used to quantify genetic variation in $\mathrm{CH}_{4}$ emission. The first indicator was $\mathrm{CH}_{4}$ emission predicted based on milk fatty acids (FA) which were measured using gas chromatography (chapter 2). Different FA based $\mathrm{CH}_{4}$ prediction equations were used and 12 to $44 \%$ of the variation was due to the genetic differences between cows. The second indicator was $\mathrm{CH}_{4}$ emission measured with breath sensors. The breath of cows was analysed during milking in an automatic milking system (AMS)(chapter 3). Genetics explained 3 to $12 \%$ of the total variation in this $\mathrm{CH}_{4}$ indicator. Data of these breath sensors will hereafter be called sensor data. The third indicator was $\mathrm{CH}_{4}$ emission predicted based on milk mid-infrared (MIR) spectroscopy (chapter 4). Of this indicator, between 17 and $21 \%$ of the total variation could be attributed to genetic factors. The correlations between sensor measured $\mathrm{CH}_{4}$ emission and milk MIR predicted $\mathrm{CH}_{4}$ emission were low, with phenotypic correlations ranging between 0.03 and 0.16. Correlations of sensor measured $\mathrm{CH}_{4}$ emission and milk MIR predicted $\mathrm{CH}_{4}$ emission with breeding goal traits (production and fertility traits) were low to medium (chapter 5). Phenotypic correlations between $\mathrm{CH}_{4}$ emission and production traits ranged between -0.34 and 0.64 . Genetic correlations between $\mathrm{CH}_{4}$ emission and production traits ranged between -0.61 and 0.65 , and genetic correlations between $\mathrm{CH}_{4}$ emission and fertility traits ranged between -0.32 and 0.38 .

The main aim of this general discussion is to get a better understanding of $\mathrm{CH}_{4}$ emission on a genomic level based on these three indicators and study their potential for selective breeding. The general discussion is structured in three parts. In the first part, the genetic background of $\mathrm{CH}_{4}$ emission indicators is studied based on genomewide association. In the second part, selection index theory is used to study selection to reduce $\mathrm{CH}_{4}$ emission based on sensor measured $\mathrm{CH}_{4}$ emission, milk MIR predicted $\mathrm{CH}_{4}$ emission and on the combination of these two sources of information. In the 
third part, possible consequences of selection for reduced $\mathrm{CH}_{4}$ emission for other breeding goal traits was evaluated.

\subsection{Genome-wide association studies}

In this thesis three indicators for $\mathrm{CH}_{4}$ emission have been investigated which can be used for selective breeding in order to reduce $\mathrm{CH}_{4}$ emission by dairy cows. These three indicators are indicative for true $\mathrm{CH}_{4}$ emission but not necessarily identical to true $\mathrm{CH}_{4}$ emission. The use of these different indicators for $\mathrm{CH}_{4}$ emission in selective breeding might have different effects on the reduction of true $\mathrm{CH}_{4}$ emission. Two of the three indicators are based on milk and the other is based on breath measurements using sensors, and all three indicators use different information sources to predict $\mathrm{CH}_{4}$. These differences might be reflected in the genetic background of predicted $\mathrm{CH}_{4}$ emission based on these indicators. Estimated correlations between sensor measured and milk MIR predicted $\mathrm{CH}_{4}$ emission are low ranging between 0.03 and 0.16 (standard errors (s.e.) $=0.03$, chapter 4 ). These low correlations suggest that different parents will be selected to produce the next generation based on milk MIR predicted $\mathrm{CH}_{4}$ emission than based on sensor measured $\mathrm{CH}_{4}$ emission. Moreover, these correlations suggest that the indicators have a different genetic background. I would like to get a better understanding of predicted $\mathrm{CH}_{4}$ emission based on these indicators and know whether there are genes with large effects underlying $\mathrm{CH}_{4}$ emission determined via these three indicators. Therefore, I have performed genome-wide association studies (GWAS) on $\mathrm{CH}_{4}$ emission determined via these three indicators. The results of a GWAS show whether there are genes with large effects influencing these $\mathrm{CH}_{4}$ indicators and whether there is overlap between these genes. This overlap can be used to study the genetic background of these three $\mathrm{CH}_{4}$ indicators.

A description of the data, phenotypes, and models (to which a SNP effect was added) used for the GWAS can be found in chapters 2, 3, and 4. In short, GWAS were performed on milk FA predicted $\mathrm{CH}_{4}$ emission traits (Methane1, Methane2, and Methane3; Chapter 2) expressed in $\mathrm{g} / \mathrm{kg}$ dry matter intake (DMI), sensor measured $\mathrm{CH}_{4}$ emission traits $\left(\mathrm{CH}_{4} \log , \mathrm{CO}_{2} \mathrm{log}\right.$, and Ratiolog; Chapter 3 ) expressed in ppm, and milk MIR predicted $\mathrm{CH}_{4}$ emission traits $\left(\mathrm{CH}_{4}\right.$ production, $\mathrm{CH}_{4}$ yield, and $\mathrm{CH}_{4}$ intensity; Chapter 4). $\mathrm{CH}_{4}$ production is expressed in $\mathrm{g} /$ day, $\mathrm{CH}_{4}$ yield in $\mathrm{g} / \mathrm{kg} \mathrm{DMI}$, and $\mathrm{CH}_{4}$ intensity in $\mathrm{g} / \mathrm{kg}$ fat and protein corrected milk (FPCM). The prediction equations for milk FA predicted $\mathrm{CH}_{4}$ emission were as follows: 
Methane1 $($ in $\mathrm{g} / \mathrm{kg} \mathrm{DMI})=24.60+8.74 * \mathrm{C} 17: 0$ anteiso $-1.97 * \mathrm{C} 18: 1$ trans $-10+11-$ $9.09 *$ C18:1 cis- $11+5.07 *$ C18:1 cis-13

Methane2 $($ in g/kg DMI) $=28.60-1.13 * \mathrm{C} 4: 0+0.36 * \mathrm{C} 18: 0-2.57 * \mathrm{C} 18: 1$ trans$10+11-9.29 *$ C18:1 cis-11

Methane3 $($ in g/kg DMI $)=27.13-3.04 * \mathrm{C} 4: 0+2.71 * \mathrm{C} 6: 0-1.63 * \mathrm{C} 18: 1$ trans$10+11$

Data for the GWAS on milk FA predicted $\mathrm{CH}_{4}$ emission where milk fat composition was determined via gas chromatography were available for approximately 1,900 dairy cows. Data of sensor measurements taken during AMS visits of approximately 1,500 dairy cows were available for the GWAS on sensor measured $\mathrm{CH}_{4}$ emission. Most of these dairy cows also had data from milk production recording (MPR) and resulting milk MIR spectra were used for the GWAS on milk MIR predicted $\mathrm{CH}_{4}$ emission. Genotype information was available for most of these dairy cows. An overview of the numbers of phenotypes, animals with phenotypes and genotypes, and single nucleotide polymorphisms (SNP) per trait can be found in Table 6.1. A 50K SNP panel was used in the GWAS for milk FA predicted $\mathrm{CH}_{4}$ emission while a 30K SNP panel was used in the GWAS for sensor measured and milk MIR predicted $\mathrm{CH}_{4}$ emission. SNP that were present on the $50 \mathrm{~K}$ panel were not present on the $30 \mathrm{~K}$ panel.

To perform the GWAS, a single SNP effect was added as a fixed effect to the models as described in chapters $\mathbf{2 , 3}$, and $\mathbf{4}$. For the GWAS of sensor measured $\mathrm{CH}_{4}$ emission, the DayAMS effect was included as random instead of fixed. The number of SNP used for the GWAS (Table 6.1) was the amount after editing. The SNP for the GWAS of milk FA predicted $\mathrm{CH}_{4}$ emission were edited as described in Stoop et al. (2009). The SNP for the GWAS of sensor measured $\mathrm{CH}_{4}$ emission and milk MIR predicted $\mathrm{CH}_{4}$ emission were edited by removal of monomorphic SNP, SNP with a call rate below $90 \%$, and SNP with genotype classes with less than 10 observations. Furthermore, SNP deviating from Hardy Weinberg equilibrium with a p-value of 0.001 or lower were removed. To correct for multiple testing, the R-package 'q-value' was used to calculate the false discovery rate (FDR) per SNP. SNP with a FDR below 0.10 were declared significantly associated with the trait. 
Table 6.1 Overview of the number of phenotypic observations per trait ( $\mathbf{N}$ phenotypes), number of animals with phenotypic and genetic observations ( $\mathbf{N}$ animals), and number of single nucleotide polymorphisms (N SNP) used as data for the genome-wide association study of methane $\left(\mathrm{CH}_{4}\right)$ emission based on three different indicators. The three indicators are $\mathrm{CH}_{4}$ emission predicted with milk fatty acids (FA) determined via gas chromatography, $\mathrm{CH}_{4}$ emission measured with sensors in automatic milking systems, and $\mathrm{CH}_{4}$ emission predicted with milk mid-infrared (MIR) spectra

\begin{tabular}{|c|c|c|c|}
\hline $\mathrm{CH}_{4}$ emission phenotype & $\mathrm{N}$ phenotypes & $\mathrm{N}$ animals & N SNP \\
\hline \multicolumn{4}{|l|}{ Milk FA predicted $\mathrm{CH}_{4}$ emission } \\
\hline Methane1 (g/kg DMI) ${ }^{1}$ & 1,651 & 1,651 & 44,470 \\
\hline Methane2 (g/kg DMI) ${ }^{1}$ & 1,704 & 1,704 & 44,563 \\
\hline Methane3 (g/kg DMI) ${ }^{1}$ & 1,704 & 1,704 & 44,563 \\
\hline \multicolumn{4}{|l|}{ Sensor measured $\mathrm{CH}_{4}$ emission } \\
\hline $\mathrm{CH}_{4} \log (\mathrm{ppm})^{2}$ & 71,160 & 819 & 22,052 \\
\hline $\mathrm{CO}_{2} \log (\mathrm{ppm})^{2}$ & 71,160 & 819 & 22,052 \\
\hline Ratiolog $(\mathrm{ppm})^{2}$ & 71,160 & 819 & 22,052 \\
\hline \multicolumn{4}{|c|}{ Milk MIR predicted $\mathrm{CH}_{4}$ emission } \\
\hline $\mathrm{CH}_{4}$ production (g/day) & 763 & 763 & 22,052 \\
\hline $\mathrm{CH}_{4}$ yield $(\mathrm{g} / \mathrm{kg} \mathrm{DMI})^{1}$ & 763 & 763 & 22,052 \\
\hline $\mathrm{CH}_{4}$ intensity $(\mathrm{g} / \mathrm{kg} \mathrm{FPCM})^{3}$ & 763 & 763 & 22,052 \\
\hline
\end{tabular}

${ }^{1} \mathrm{DMI}=$ Dry matter intake.

2 Sensor measured phenotypes were $\log _{10}$-transformed.

${ }^{3}$ Fat and protein corrected milk (FPCM) was calculated as FPCM $=$ milk (in kg) $*(0.337+(0.116$

* fat percentage $)+(0.06 *$ protein percentage $))$.

\subsubsection{Results of genome-wide association studies}

The Manhattan-plots of the associations between the SNP and milk FA predicted $\mathrm{CH}_{4}$ emission (Methane1, Methane2, and Methane3) are given in Figure 6.1. No significant associations (FDR < 0.10) were found for Methane1. Significant associations were found for Methane2 and Methane3 on chromosome 14, and for Methane3 on chromosome 19. The Manhattan-plots of the associations between the SNP and sensor measured $\mathrm{CH}_{4}$ emission are given in Figure 6.2. No significant associations were found for sensor measured $\mathrm{CH}_{4}$ emission. The Manhattan-plots of the associations between the SNP and milk MIR predicted $\mathrm{CH}_{4}$ emission are given in Figure 6.3. No significant associations were found for $\mathrm{CH}_{4}$ intensity, whereas $\mathrm{CH}_{4}$ production and $\mathrm{CH}_{4}$ yield showed significant association on chromosome 14 .

Significant associations for milk FA and milk MIR predicted $\mathrm{CH}_{4}$ emission were detected on the beginning of chromosome 14. The most significant SNP for milk FA predicted Methane2 and Methane3 were ULGR_SNP_AJ318490_1c and ULGR_SNP_AJ318490_1b. These SNP are known to be the SNP coding for the 


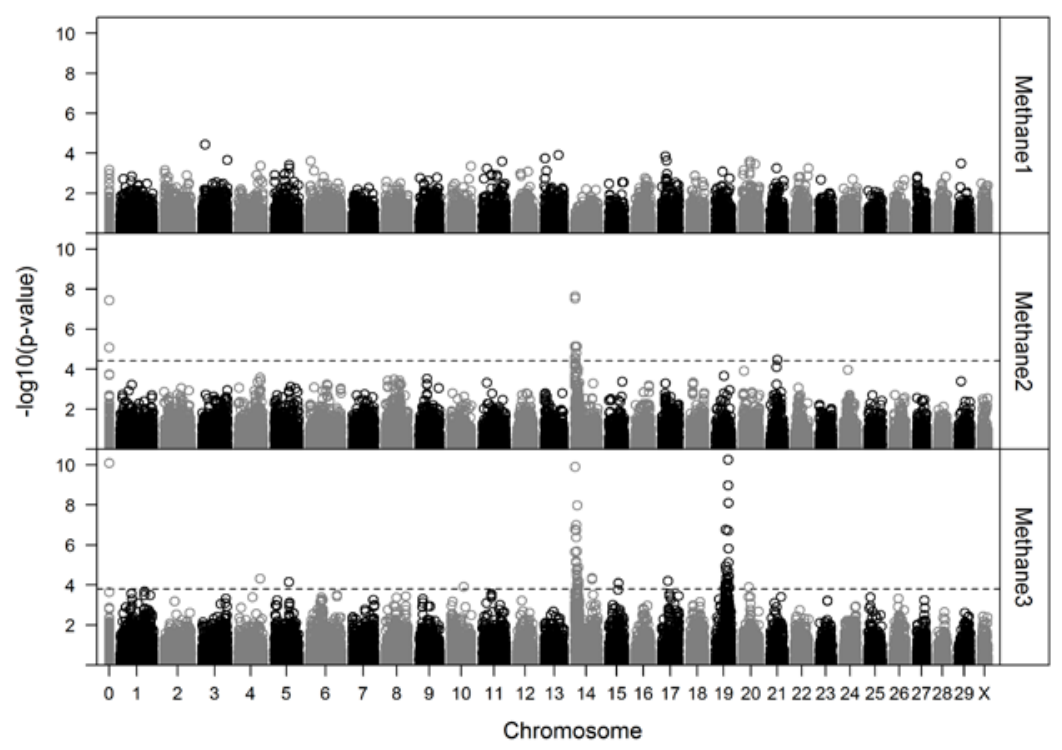

Figure 6.1 Manhattan-plot of associations found between SNP and milk fatty acids (FA) predicted methane $\left(\mathbf{C H}_{4}\right)$ emission. Dotted lines represent the false discovery rate (FDR) of 0.10 for each trait

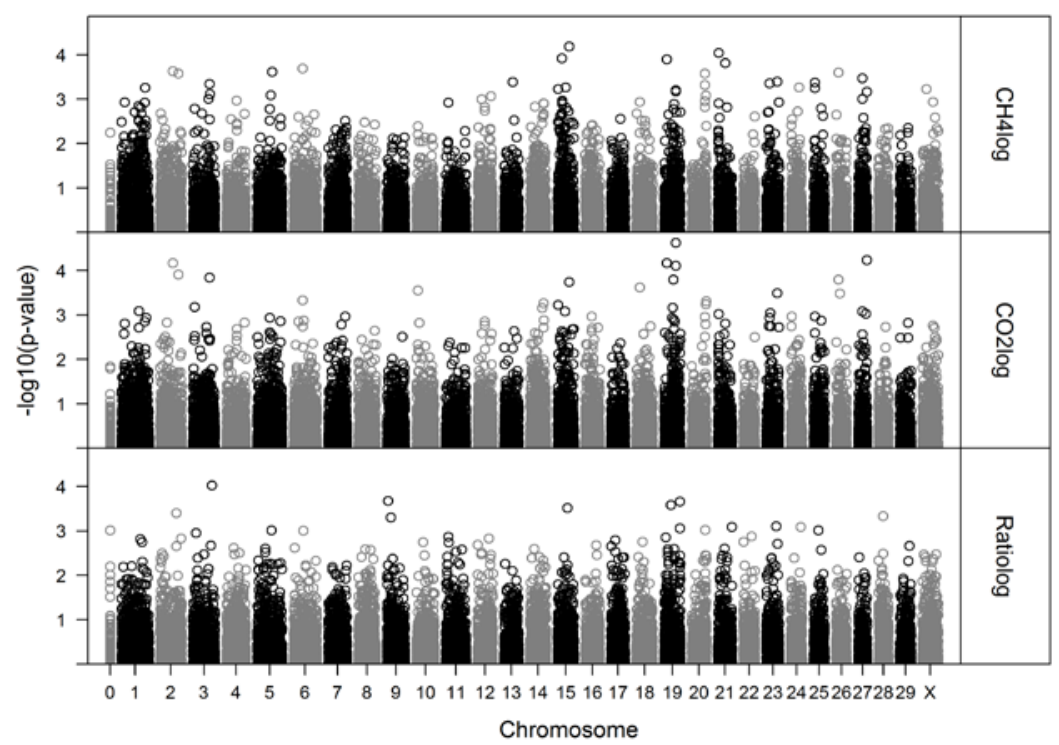

Figure 6.2 Manhattan-plot of associations found between SNP and sensor measured methane $\left(\mathrm{CH}_{4}\right)$ emission 


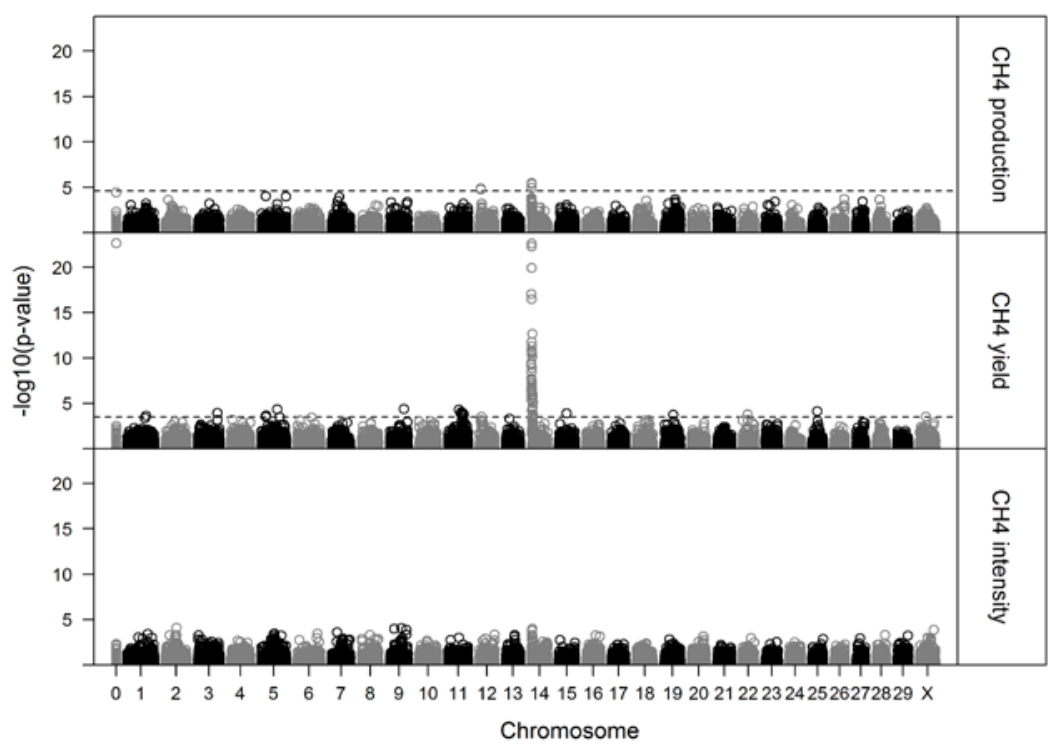

Figure 6.3 Manhattan-plot of associations found between SNP and milk mid-infrared (MIR) predicted methane $\left(\mathrm{CH}_{4}\right)$ emission. Dotted lines represent the false discovery rate (FDR) of 0.10 for each trait

diacylglycerol O-acyltransferase 1 (DGAT1) K232A polymorphism (Bouwman et al., 2011). The effects of the two most significant SNP on milk FA predicted $\mathrm{CH}_{4}$ emission are presented in Table 6.2. The most significant SNP for $\mathrm{CH}_{4}$ production and $\mathrm{CH}_{4}$ yield was BovineHD1400000188 ( $r$ 134892687). This SNP is located close to the DGAT1 K232A polymorphism (just over 200,000 base pairs distance). It is likely that this SNP is in high linkage disequilibrium with the DGAT1 K232A polymorphism as it has a similar effect on fat percentage (data not shown). The effects of this significant SNP on milk MIR predicted $\mathrm{CH}_{4}$ emission are presented in Table 6.2.

The sizes of the effects of the significant SNP for both milk FA and milk MIR predicted $\mathrm{CH}_{4}$ emission were moderate to large. The effect of the DGAT1 polymorphism on milk FA predicted $\mathrm{CH}_{4}$ emission ranged between 8.3 and $37.2 \%$ of the respective variance (Table 6.2). The effect of the most significant SNP for milk MIR predicted $\mathrm{CH}_{4}$ emission was $3.4 \%$ of the variance of $\mathrm{CH}_{4}$ production and $125.3 \%$ of the variance of $\mathrm{CH}_{4}$ yield.

Significant association was found for Methane3 on chromosome 19 with the most significant SNP being ULGR_MARC_10099_486 and ULGR_BTA-45788. The lead SNP (ULGR_MARC_10099_486) had a - $\log _{10}(p$-value) of 10.27. The effect of the SNP was 
Table 6.2 Significance and size of the effect of the DGAT1 K232A polymorphism on methane $\left(\mathrm{CH}_{4}\right)$ predicted with milk fatty acids (FA) determined via gas chromatography and of the most significant SNP (BovineHD1400000188) on $\mathrm{CH}_{4}$ predicted with milk mid-infrared (MIR) spectra. Effect size as percentage of the variance ${ }^{1}$

\begin{tabular}{|c|c|c|c|c|c|}
\hline Trait & Variance & $A B$ & BB & $-\log _{10}(p$-value $)$ & Effect size \\
\hline \multicolumn{6}{|c|}{ Milk FA predicted $\mathrm{CH}_{4}$ emission } \\
\hline Methane1 (g/kg DMI) ${ }^{2}$ & 1.38 & 0.02 & 0.11 & 0.46 & $8.3 \%$ \\
\hline Methane2 (g/kg DMI) ${ }^{2}$ & 1.23 & 0.23 & 0.46 & 7.66 & $37.2 \%$ \\
\hline Methane3 (g/kg DMI) ${ }^{2}$ & 0.82 & 0.25 & 0.25 & 9.91 & $30.6 \%$ \\
\hline \multicolumn{6}{|c|}{ Milk MIR predicted $\mathrm{CH}_{4}$ emission } \\
\hline $\mathrm{CH}_{4}$ production (g/day) & 342.86 & -7.84 & -11.72 & 5.47 & $3.4 \%$ \\
\hline $\mathrm{CH}_{4}$ yield (g/kg DMI) ${ }^{2}$ & 0.95 & -0.65 & -1.19 & 22.29 & $125.3 \%$ \\
\hline
\end{tabular}

${ }^{1} \mathrm{AA}$ genotype is set to zero, DGAT1 $\mathrm{K}$ allele is B allele in table.

${ }^{2} \mathrm{DMI}$ is dry matter intake.

-0.275 for the AG genotype and -0.314 for the GG genotype, with the AA genotype set to zero. The size of the effect was $38.3 \%$ of the variance in Methane3.

\subsubsection{Genetic background of $\mathrm{CH}_{4}$ emission}

The genetic background of $\mathrm{CH}_{4}$ emission has been studied before in beef and dairy cattle (De Haas et al., 2011; Manzanilla-Pech et al., 2016). No specific regions of the genome were found to be significantly associated in the GWAS on $\mathrm{CH}_{4}$ emission predicted with feed intake in 665 dairy cows (De Haas et al., 2011). The GWAS on $\mathrm{CH}_{4}$ emission of 1,020 beef cows measured in $\mathrm{CRC}$ gave significant associations with regions of the genome associated with body weight (Manzanilla-Pech et al., 2016). These results suggest that genes associated with body weight might have an impact on $\mathrm{CH}_{4}$ emission as measured in CRC. These associations, however, are reported on beef cattle and different genes might regulate $\mathrm{CH}_{4}$ emission in dairy cattle (Manzanilla-Pech et al., 2016).

The results of the GWAS of this general discussion show that there are two regions of the bovine genome linked with predicted $\mathrm{CH}_{4}$ emission: chromosome 14 and chromosome 19. Regions that gave significant associations with $\mathrm{CH}_{4}$ production in beef cattle that were linked with genes for body weight included chromosome 14 (Manzanilla-Pech et al., 2016). The association with chromosome 14, however, was not significant for $\mathrm{CH}_{4}$ production in dairy cows, but was significant for DMI and body weight (Manzanilla-Pech et al., 2016). The specific region or genes that had a significant association with chromosome 14 were not mentioned in the article, though, like our results, the association seems to be on the beginning of chromosome 14. 
The production of $\mathrm{CH}_{4}$ in the rumen is the result of complex mechanisms that involve rumen microbiota and is partially regulated by the genes of the host. The impact of the genetics of the host on the processes in the rumen and its microbiota is not yet fully known and understood. The genetic background of $\mathrm{CH}_{4}$ emission might be linked with DMI or body weight as suggested by Manzanilla-Pech and colleagues. In this part I will explore the relationship between the significant regions on chromosomes 14 and 19, predicted $\mathrm{CH}_{4}$ emission and true $\mathrm{CH}_{4}$ emission.

The two lead SNP of chromosome 14 were located in the DGAT1 K232A polymorphism that has been linked to milk production and composition in previous studies (e.g. Winter et al., 2002; Schennink et al., 2007; Bovenhuis et al., 2015)). DGAT1 mediates the final step of triglyceride synthesis (Winter et al., 2002) and around $98 \%$ of the fat in milk is present in the form of triglycerides (Jensen, 2002). In clinical studies, DGAT1 was found to play an important role in fat absorption with a possible impact on gut hormones (DeVita and Pinto, 2013). Moreover, DGAT1 knock out mice showed more resistance to diet induced obesity, increased sensitivity towards insulin and leptin, and increased energy expenditure (Chen, 2006; DeVita and Pinto, 2013).

The lead SNP of chromosome 19 (ULGR_MARC_10099_486) was located in the regulatory associated protein of mTOR complex (RPTOR). The mTOR complex coordinates eukaryote cell growth and metabolism which affects processes like protein, lipid, and nucleotide synthesis (Saxton and Sabatini, 2017). The same region on chromosome 19 was also found to be related to fat content and composition (Bouwman et al., 2014).

Figure 6.4 gives a schematic overview of the relationship between true $\mathrm{CH}_{4}$ emission, milk predicted $\mathrm{CH}_{4}$ emission, and sensor measured $\mathrm{CH}_{4}$ emission. Significant associations on chromosome 14 and 19 were identified only for milk predicted $\mathrm{CH}_{4}$ emission (II) and not for sensor measured $\mathrm{CH}_{4}$ emission. The associations identified either relate to area $\mathrm{A}$ or to area $\mathrm{B}$ (Figure 6.4). These associations with $\mathrm{CH}_{4}$ emission could relate metabolic processes in the rumen that affect the production or emission of $\mathrm{CH}_{4}$, to milk composition, or both. When the associations relate to area $A$, associations relate to true $\mathrm{CH}_{4}$ emission and are, thus, likely to be related to metabolic processes. When the associations relate to area $B$, associations relate to milk composition and are, thus, likely to be related to the prediction equation of milk predicted $\mathrm{CH}_{4}$ emission. 


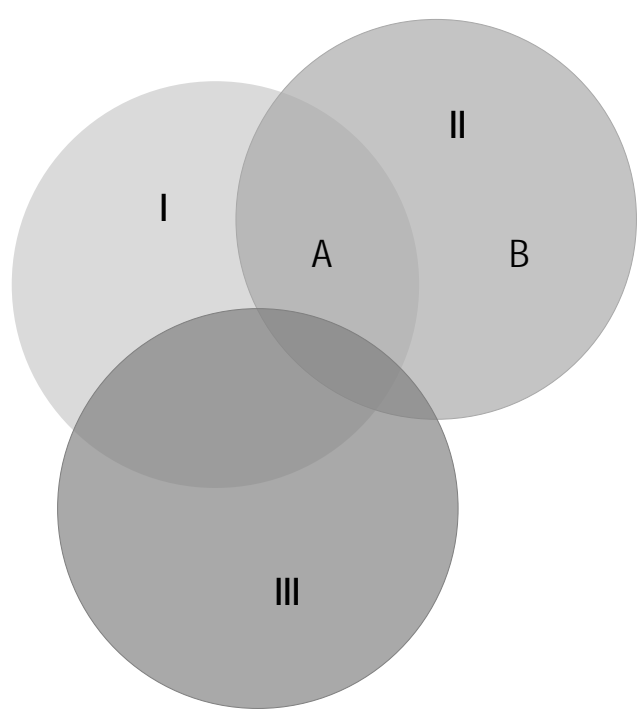

Figure 6.4 Schematic overview of the relationships between true methane $\left(\mathrm{CH}_{4}\right)$ emission (I), milk predicted $\mathrm{CH}_{4}$ emission (II), and sensor measured $\mathrm{CH}_{4}$ emission (III)

When the associations relate to milk composition (area B), selection based on milk predicted $\mathrm{CH}_{4}$ emission might favour cows with a certain DGAT1 genotype as parents for the next generation. There is no indication that current selection strategies favors one of the DGAT1-alleles as the A-allele had a frequency of 0.6 in the Dutch dairy population (Schennink et al., 2007). Results from previous studies show that the Aallele of the DGAT1 polymorphism is associated with higher milk yield and lower fat, protein, and lactose percentages compared to the K-allele (Schennink et al., 2007; Bovenhuis et al., 2015). Moreover, saturation level of milk fat is also influenced by the DGAT1 polymorphism with the A-allele associated with lower levels of C10, C12, $\mathrm{C} 14$, and $\mathrm{C} 16$ unsaturated fatty acids and higher levels of C18 unsaturated fatty acids (Schennink et al., 2008). In this study, the A-allele of the DGAT1 polymorphism was associated with lower $\mathrm{CH}_{4}$ emission (Methane2 and Methane3). The use of milk predicted $\mathrm{CH}_{4}$ emission in selective breeding could result in higher milk yield and decrease fat, protein, and lactose percentages.

When the associations relate to metabolic processes in the rumen (area A) and, thus, affect $\mathrm{CH}_{4}$ production and emission, $\mathrm{CH}_{4}$ emission measured in $\mathrm{CRC}$ should be affected by the DGAT1 genotype. The impact of the DGAT1 polymorphism on $\mathrm{CH}_{4}$ emission by dairy cows has been studied by Van Gastelen et al. (2017). The results of that study show no significant effect of the DGAT1 K232A polymorphism on $\mathrm{CH}_{4}$ emission measured in CRC (Van Gastelen et al., 2017). The impact of the DGAT1 
K232A polymorphism on predicted $\mathrm{CH}_{4}$ emission is expected to be moderate to large as suggested by the effect sizes found in the GWAS. The impact of the DGAT1 K232A polymorphism on true $\mathrm{CH}_{4}$ emission is expected to be smaller, as predicted $\mathrm{CH}_{4}$ emission does not explain all variation in true $\mathrm{CH}_{4}$ emission. The variation explained by milk predicted $\mathrm{CH}_{4}$ emission was limited as the coefficients of variation (CV) of milk predicted $\mathrm{CH}_{4}$ emission were low. Although the DGAT1 K232A polymorphism might explain a moderate to large part of the variation in predicted $\mathrm{CH}_{4}$ emission, the impact on true $\mathrm{CH}_{4}$ emission is smaller. The number of animals in the study of Van Gastelen and colleagues $(n=24)$ may have been too small to pick up the relatively small effect anticipated.

No definite statement can be made whether the associations with milk predicted $\mathrm{CH}_{4}$ emission are due to the impact of these association on metabolic processes, on milk composition, or both. Sensor measured $\mathrm{CH}_{4}$ emission, however, did not show significant associations and effects of the DGAT1 K232A polymorphisms were not confirmed in the CRC. It is most likely that the associations relate to milk composition which impacts milk predicted $\mathrm{CH}_{4}$ emission via the prediction equations.

\subsection{Selection indexes}

Selective breeding for reduced $\mathrm{CH}_{4}$ emission could be implemented using the different indicators of $\mathrm{CH}_{4}$ emission. In chapter 4 the relationship between $\mathrm{CH}_{4}$ emission predicted with milk MIR spectra was compared to $\mathrm{CH}_{4}$ emission measured with breath sensors. The phenotypic correlations between milk MIR predicted $\mathrm{CH}_{4}$ emission and sensor measured $\mathrm{CH}_{4}$ emission ranged between 0.03 and 0.16 . The genetic correlations ranged between -0.89 and 0.71 , and had large standard errors (s.e.) ranging between 0.27 and 0.87 . The results of chapter 4 suggest that the two indicators for $\mathrm{CH}_{4}$ emission provide relatively independent information on true $\mathrm{CH}_{4}$ emission. Combining information from these two sources was suggested in chapter 4 as a useful next step for selective breeding for reduced $\mathrm{CH}_{4}$ emission.

To study the effect of combining information for selective breeding for reduced $\mathrm{CH}_{4}$ emission, I calculated the accuracy of estimated breeding values (EBV) for $\mathrm{CH}_{4}$ emission. The accuracies were calculated for the EBV based on both indicators for $\mathrm{CH}_{4}$ emission separately and combined. The accuracy of an EBV indicates how close it is to the true breeding value (TBV) of an animal. A higher accuracy of EBV implies that we can better distinguish genetically superior animals from average or inferior animals. Therefore, an interesting question is: what is the accuracy of the EBV when based on one of the two sources of information (i.e. one of the two indicators for 
$\mathrm{CH}_{4}$ emission)? Another interesting question is will the accuracy of the EBV improve when information from these two sources is combined, as compared to using them separately?

To answer these questions, selection index theory was used to calculate the accuracies of estimated breeding values (EBV) based on the different sources of information, i.e. both indicators for $\mathrm{CH}_{4}$ emission. The breeding goal is to select for reduced true $\mathrm{CH}_{4}$ emission and, therefore, you would like to know the genotype for true $\mathrm{CH}_{4}$ emission $(\mathbf{H})$, the breeding goal. This genotype is based on breeding goal trait $(\mathbf{A})$ that is $\mathrm{CH}_{4}$ emission as measured in $\mathrm{CRC}$ :

$\mathrm{H}=\mathrm{ACRC}$

CRC measured $\mathrm{CH}_{4}$ emission is seen as the 'golden standard' (Storm, 2012; Hill et al., 2016). Advantages of $\mathrm{CRC}$ measurements of $\mathrm{CH}_{4}$ emission are that the environment is stabilized and controlled (Johnson and Johnson, 1995; Storm, 2012). The measurements of $\mathrm{CH}_{4}$ emission can also be taken accurately and include the small portion of $\mathrm{CH}_{4}$ that is emitted from the rectum (Johnson and Johnson, 1995). Disadvantages of $\mathrm{CRC}$ measurements of $\mathrm{CH}_{4}$ emission are that the measurements are labour intensive and costly (Johnson and Johnson, 1995; Storm, 2012). Furthermore, the measuring capacity of CRC is low and the circumstances in the CRC might be artificial as animal movement and feed intake are restricted (Johnson and Johnson, 1995; Storm, 2012; Hill et al., 2016). It could be that CRC measurements of $\mathrm{CH}_{4}$ emission do not capture all possible variation present in true $\mathrm{CH}_{4}$ emission as the environment is artificial. Of all methods available, however, I expect that CRC measured $\mathrm{CH}_{4}$ emission comes closest to true $\mathrm{CH}_{4}$ emission and, thus, should be used as the breeding goal trait $(\mathrm{A})$.

Breeding for reduced true $\mathrm{CH}_{4}$ emission, however, requires data on many individual dairy cows. This is difficult to acquire for the breeding goal trait $\mathrm{CRC}$ measured $\mathrm{CH}_{4}$ emission. Therefore, an indicator trait $(\mathbf{X})$ can be used for selective breeding instead of the breeding goal trait. One or multiple indicator traits can be combined into a selection index (I). The selection index is used to estimate the breeding goal trait. Three different selection indexes will be used. In scenario 1 only information from sensor measured $\mathrm{CH}_{4}$ emission was assumed to be available for each daughter of a test bull:

$I_{1}=b_{\text {sensor }} * X_{\text {sensor }}$ 
where $b$ is the regression coefficient of sensor measurements and $X$ is the sensor measurements. In scenario 2 only information from milk MIR predicted $\mathrm{CH}_{4}$ emission was assumed to be available for each daughter of a test bull:

$\mathrm{I}_{2}=\mathrm{b}_{\mathrm{MIR}} * \mathrm{X}_{\mathrm{MIR}}$

where $b$ is the regression coefficients of milk MIR measurements and $X$ is the milk MIR measurements. In scenario 3 information from both indicators was assumed to be available for each daughter of a test bull:

$\mathrm{I}_{3}=\mathrm{b}_{\text {sensor }} * \mathrm{X}_{\text {sensor }}+\mathrm{b}_{\mathrm{MIR}} * \mathrm{X}_{\mathrm{MIR}}$

In all three scenarios the accuracy of the EBV was calculated for 1 bull with 50 (halfsib) daughters. The phenotypes used in the three different scenarios were $\mathrm{CH}_{4}$ log (measured with sensors, chapter 3 ) and $\mathrm{CH}_{4}$ production (predicted with milk MIR spectra, chapter 4 ). As suggested in chapter 3 , in scenario 1 and $3 \mathrm{I}$ assumed that each daughter had 10 days of data on sensor measured $\mathrm{CH}_{4}$ emission available. These 10 days of data would result in 25 repeated observations on sensor measured $\mathrm{CH}_{4}$ emission per daughter. In scenario 2 and 3, I assumed that each daughter had 10 repeated milk MIR predicted $\mathrm{CH}_{4}$ emission observations available. Cows that take part in the MPR participate every 3 to 6 weeks, resulting in approximately 10 MPR observations per cow per lactation.

An overview of the variances and genetic parameters used in the selection index calculations can be found in Table 6.3. The phenotypic correlation between the two indicators was 0.15 (s.e. $=0.03$; chapter 4 ) and the genetic correlation was 0.09 (s.e. $=0.36$; chapter 4$)$. The coefficient of determination $\left(\mathbf{R}^{2}\right)$ between the indicators and CRC measured $\mathrm{CH}_{4}$ emission was used as a basis for the phenotypic and genetic correlations between the indicators and $\mathrm{CRC}$ measured $\mathrm{CH}_{4}$ emission. The phenotypic and genetic correlation between sensor measured $\mathrm{CH}_{4}$ emission and $\mathrm{CRC}$ measured $\mathrm{CH}_{4}$ emission were assumed to be the same and equal to 0.50 , as the $\mathrm{R}^{2}$ was 0.25 (chapter 3 ). The phenotypic and genetic correlation between milk MIR predicted $\mathrm{CH}_{4}$ emission and $\mathrm{CRC}$ measured $\mathrm{CH}_{4}$ emission were assumed to be the same and equal to 0.55 , as the $R^{2}$ was 0.30 (chapter 4).

\subsubsection{Results of selection index scenarios}

The accuracy of the EBV of the bull with 50 half-sib daughters based on sensor measured $\mathrm{CH}_{4}$ emission information (scenario 1 ) is 0.46 . The accuracy of the EBV 
Table 6.3 Overview of parameters used for the selection index theory

\begin{tabular}{lc}
\hline Parameters & Value \\
\hline $\mathrm{CRC}$ measured $\mathrm{CH}_{4}$ emission & 2905.21 \\
Phenotypic variance & 0.20 \\
Heritability & \\
Sensor measured $\mathrm{CH}_{4}$ emission & 0.04 \\
Phenotypic variance & 0.11 \\
Heritability & 0.27 \\
Repeatability & \\
Milk MIR predicted $\mathrm{CH}_{4}$ emission & 342.86 \\
Phenotypic variance & 0.17 \\
Heritability & 0.27 \\
Repeatability & \\
\hline
\end{tabular}

using only information on milk MIR predicted $\mathrm{CH}_{4}$ emission (scenario 2 ) is 0.51 . The difference between both accuracies can be explained by the assumed genetic correlation between the indicator traits and the breeding goal trait and the heritabilities of the indicator traits. The genetic correlation between sensor measured $\mathrm{CH}_{4}$ emission and $\mathrm{CRC}$ measured $\mathrm{CH}_{4}$ emission (0.50) was slightly lower than the assumed genetic correlation between milk MIR $\mathrm{CH}_{4}$ emission and CRC measured $\mathrm{CH}_{4}$ emission (0.55). The heritability of sensor measured $\mathrm{CH}_{4}$ emission $\left(\mathrm{h}^{2}\right.$ $=0.12$ ) was slightly lower than the heritability of milk MIR predicted $\mathrm{CH}_{4}$ emission $\left(\mathrm{h}^{2}\right.$ $=0.17$ ). This resulted in a lower accuracy for scenario 1 compared to scenario 2 . Combining information from both sources increases the accuracy to a value of 0.66 (scenario 3).

Several assumptions have been made for calculating the accuracies of the EBV in scenarios 1 to 3 and these assumptions influence the estimated accuracies. One of the assumptions is the number of daughters for which the bull has information on. In all three scenarios this number was fixed at 50 daughters. The impact of the number of daughters on the accuracy of the EBV in scenario 1 is illustrated in Figure 6.5. The accuracy of the EBV of the bull improves when information on more daughters becomes available. However, the increase is not linear: adding information of 1 extra daughter improves the accuracy more when only information of a small number of daughters is available $(<10)$ compared to when the number of daughters is larger (>80). Increasing the number of daughters to more than the 50 chosen for this general discussion seems to have a minor impact on the accuracy of the EBV.

Another assumption that affects the accuracy of the EBV is the number of repeated observations per daughter. The impact of the number of repeated observations available for scenario 1 and 2 on the accuracy of the EBV is shown in Figure 6.6. Like 


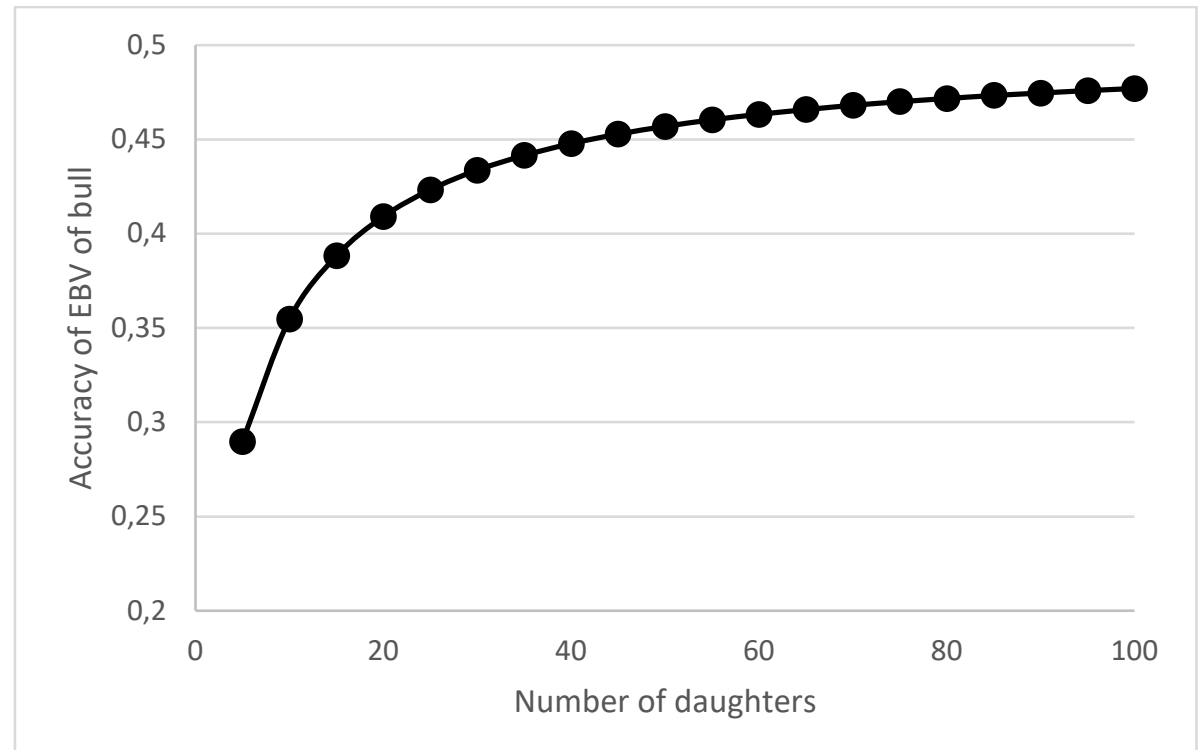

Figure 6.5 Accuracy of the estimated breeding value (EBV) of a bull based on 25 sensor measured methane $\left(\mathrm{CH}_{4}\right)$ emission records per daughter

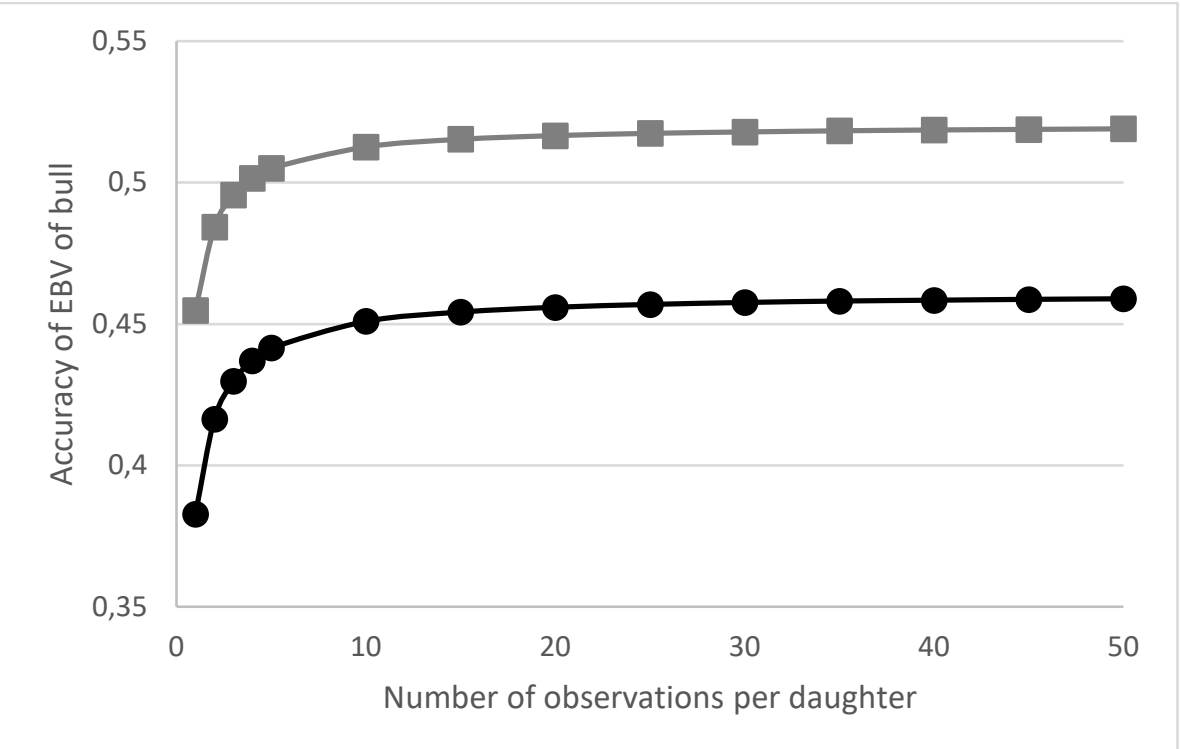

Figure 6.6 Accuracy of the estimated breeding value (EBV) of a bull based on 50 daughters with either observations on sensor measured methane $\left(\mathbf{C H}_{4}\right)$ emission (black) or observations on milk mid-infrared (MIR) predicted $\mathrm{CH}_{4}$ emission (light grey) 
the number of daughters, increasing the number of observations per daughter improved the accuracy of the EBV of the bull. This improvement is also not linear: the improvement is larger when the number of observations increases from 1 to 2 compared with an increase from 20 to 21 observations. Increasing the number of observations to more than the numbers chosen for this general discussion ( 25 for sensor measured $\mathrm{CH}_{4}$ emission and 10 for milk MIR predicted $\mathrm{CH}_{4}$ emission) would result in only a minor increase in the accuracy of the EBV of the bull.

Another assumption that affects the accuracy of the EBV is the genetic correlation between $\mathrm{CRC}$ measured $\mathrm{CH}_{4}$ emission and the two indicators. In scenarios 1 to 3 it was assumed that these equalled the square root of the $R^{2}$ as reported in chapters 3 and 4 . The relationship as described by the $R^{2}$ is likely to be only partially due to genetics, and the genetic correlation might thus be lower or higher than assumed in scenarios 1 to 3 . In alternative scenario $\mathbf{3 A}$, I have adapted scenario 3 to test the influence of a lower genetic correlation between the breeding goal trait and the indicators. The $\mathrm{R}^{2}$ of sensor measured $\mathrm{CH}_{4}$ emission was reduced from 0.25 to 0.15 , resulting in a genetic correlation of 0.39 between $\mathrm{CRC}$ measured $\mathrm{CH}_{4}$ emission and sensor measured $\mathrm{CH}_{4}$ emission. The $\mathrm{R}^{2}$ of milk MIR predicted $\mathrm{CH}_{4}$ emission was reduced from 0.30 to 0.20 , resulting in a genetic correlation of 0.45 between CRC measured $\mathrm{CH}_{4}$ emission and milk MIR predicted $\mathrm{CH}_{4}$ emission. The accuracy of the EBV of the bull based on alternative scenario $3 \mathrm{~A}$ is 0.53 and, thus, lower than in scenario 3. A lower genetic correlation between $\mathrm{CRC}$ measured $\mathrm{CH}_{4}$ emission and the two indicators would also reduce the accuracies in scenarios 1 and 2 .

Alternative scenario $3 \mathrm{~A}$ shows that the EBV of the bull has a lower accuracy when the information sources of the selection index explain less of the variation in true $\mathrm{CH}_{4}$ emission as measured in $\mathrm{CRC}$. As the two indicators of $\mathrm{CH}_{4}$ emission explain less of the variation in true $\mathrm{CH}_{4}$ emission, the relationship between the EBV based on these indicators and the TBV decreases. In Figure 6.7 this effect can be seen as the overlap between the indicators and true $\mathrm{CH}_{4}$ emission being smaller as compared with scenario 3.

Another assumption that affects the accuracy of the EBV is the genetic correlation between sensor measured $\mathrm{CH}_{4}$ emission and milk MIR predicted $\mathrm{CH}_{4}$ emission. The genetic correlation between the two indicators was estimated to be 0.09 with a standard error of 0.36 . Based on this estimation, the true genetic correlation can deviate considerably from the estimate. Therefore, in alternative scenario 3B I have adapted scenario 3 and set the genetic correlation between sensor measured $\mathrm{CH}_{4}$ emission and milk MIR predicted $\mathrm{CH}_{4}$ emission to $0.45(0.09+0.36)$. The accuracy of the EBV of the bull in alternative scenario $3 \mathrm{~B}$ is 0.58 and, thus, lower than in scenario 3. In alternative scenario $3 \mathrm{C}$ I have adapted scenario 3 and set the genetic 
A

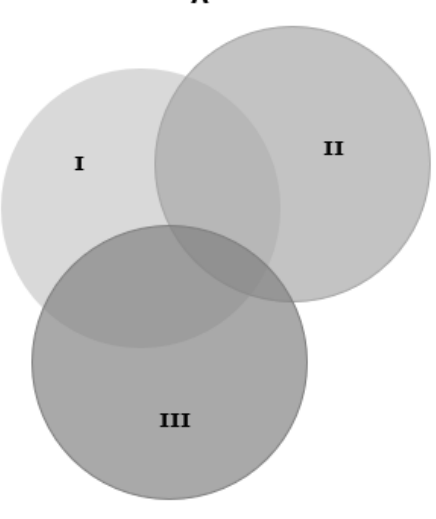

B

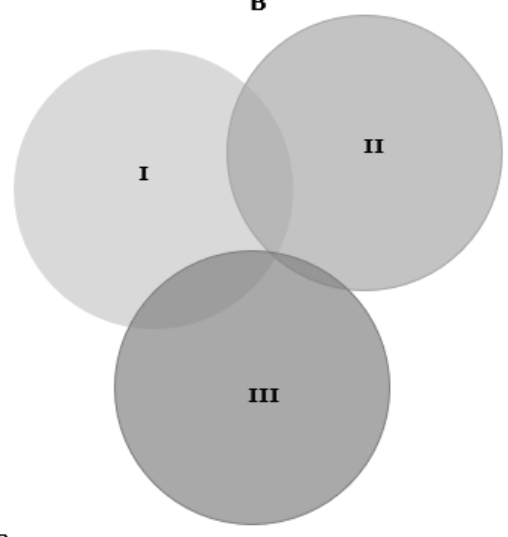

C

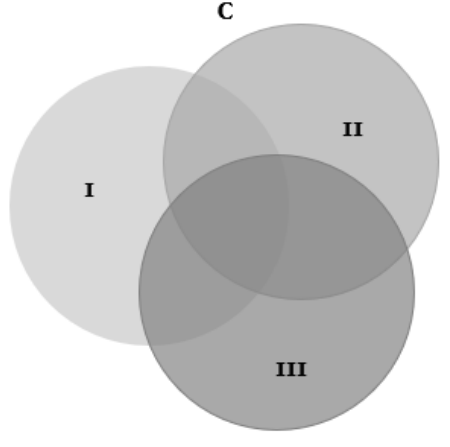

Figure 6.7 Schematic overview of the assumptions and their influence on the accuracy of the breeding value estimation with I being the variation in the true breeding value (methane $\left(\mathbf{C H}_{4}\right)$ measured in the climate respiration chamber); II being the variation in sensor measured $\mathrm{CH}_{4}$ emission; and III being the variation in milk mid-infrared (MIR) predicted $\mathrm{CH}_{4}$ emission. This figure illustrates three scenarios: A) original scenario 3; B) alternative scenario $3 A$ (lower $R^{2}$ of sensor measured and milk MIR predicted $\mathrm{CH}_{4}$ emission ); $\mathrm{C}$ ) alternative scenario $3 \mathrm{~B}$ (higher genetic correlation between sensor measured and milk MIR predicted $\mathrm{CH}_{4}$ emission)

correlation to $-0.27(0.09-0.36)$. The accuracy of the EBV in alternative scenario $3 C$ is 0.79 and, thus, higher than in scenario 3.

In scenario 3, the genetic correlation between sensor measured and milk MIR predicted $\mathrm{CH}_{4}$ emission was 0.09 . This correlation indicates that the variation in either indicator is not explained by the other indicator. The increase in the accuracy of the EBV when combining both indicators depends partially on the overlap between the indicators. When the two indicators explain more of the same variation of the TBV, i.e. larger overlap between indicators, the increase in the accuracy when combining the indicators will be smaller (see Figure 6.7). In alternative scenario 3B, 
this overlap between both sources of information increases and, therefore, the accuracy decreases compared to scenario 3. In alternative scenario 3C, the accuracy increases compared to scenario 3 as both sources of information are systematically not overlapping due to their negative genetic correlation. Combining sources of information will improve the accuracy of the EBV of the bull when their genetic correlation is not 1 .

\subsubsection{Combining sources of information}

Combining information from sensor measured $\mathrm{CH}_{4}$ emission with milk MIR predicted $\mathrm{CH}_{4}$ emission increases the accuracy of the EBV. It was estimated that combining information from two indicators would improve accuracy with 15 to $35 \%$ compared to using only one indicator (Negussie et al., 2017). I estimated an increase in the accuracy of the EBV of 15 to $20 \%$ in line with Negussie et al. (2017). The accuracy when using both sources of information is 0.66 , meaning that the EBV could explain $44 \%$ of the variation in the TBV. There is no minimum for the accuracy of an EBV before it can be implemented in selective breeding, but higher accuracies will lead to more genetic improvement (Falconer, 1960).

Combining information will not only increase the accuracy of the EBV, it will also give a better estimation of true $\mathrm{CH}_{4}$ emission (Negussie et al., 2017). Ranking animals for their genetic potential is likely to result in a different ranking for each of the two indicators as the genetic correlation between the indicators is low. Ranking of animals based on combined information of both indicators is expected to be closer to the ranking for true $\mathrm{CH}_{4}$ emission. Selective breeding on combined indicators, however, requires cows with information on both indicators. Information on milk MIR predicted $\mathrm{CH}_{4}$ emission is readily available from the milk production recording. Information on sensor measured $\mathrm{CH}_{4}$ emission, however, is currently not available and sensor and sensor measurement protocol need to be developed further before these measurements can be taken on all farms. Although sensor measurements are not available, using two indicators is recommended, because a shortcoming in one of the indicators can be overcome by the other indicator (Negussie et al., 2017). Therefore, I recommend combining information from sensor measured $\mathrm{CH}_{4}$ emission with milk MIR predicted $\mathrm{CH}_{4}$ emission when breeding for reduced $\mathrm{CH}_{4}$ emission.

\subsection{Correlations between estimated breeding values}

The discussion in this thesis so far has focussed on breeding for reduced $\mathrm{CH}_{4}$ emission by taking $\mathrm{CH}_{4}$ emission as the only breeding goal trait. Breeding for reduced $\mathrm{CH}_{4}$ 
emission will in practice always be combined with selection for other traits. Before adding $\mathrm{CH}_{4}$ emission to the breeding goal, it is important to understand the relationship between $\mathrm{CH}_{4}$ emission and the other breeding goal traits. These relationships give an indication of the potentially unfavourable responses in other breeding goal traits when selecting for reduced $\mathrm{CH}_{4}$ emission.

Part of the correlations between $\mathrm{CH}_{4}$ emission and current breeding goal traits have been studied in chapter $\mathbf{5}$. In chapter $\mathbf{5}$ correlations between on the one hand $\mathrm{CH}_{4}$ emission measured with sensors and predicted with milk MIR spectra, and on the other hand, test-day production and fertility traits were calculated. These genetic correlations were estimated to be low to moderate, but they also had large standard errors. This indicates that true correlations might differ from the reported estimates. These estimates could get closer to the true correlations when more data is available for the calculation of these correlations. Furthermore, the traits studied in chapter 5 are not all traits that are part of the current breeding goal. Additional data that might be interesting are estimated breeding values (EBV) of breeding goal traits of sires with daughters with $\mathrm{CH}_{4}$ emission phenotypes. To get a better understanding of what might happen when $\mathrm{CH}_{4}$ emission is added to the breeding goal, correlations between EBV for breeding goal traits and EBV for $\mathrm{CH}_{4}$ emission were calculated.

Data on EBV of bulls with at least 5 daughters with either sensor measured $\mathrm{CH}_{4}$ emission or milk MIR predicted $\mathrm{CH}_{4}$ emission were made available by the cooperative cattle improvement organization CRV (Arnhem, the Netherlands). In total, data were available on 70 bulls with daughters with sensor measured $\mathrm{CH}_{4}$ emission and 63 bulls with daughters with milk MIR predicted $\mathrm{CH}_{4}$ emission. These bulls also had EBV on current breeding goal traits available of which I selected six that were expected to have a relationship with $\mathrm{CH}_{4}$ emission: milk yield, body weight, dry matter intake (DMI), longevity, udder health, and fertility. An overview of the descriptive statistics of these EBV are shown in Table 6.4. Three of the six breeding goal EBV (body weight, udder health, and fertility) are standardized EBV (mean of 100 and a standard deviation of 4) whereas the other EBV are not. Values above 100 of the standardized EBV means a positive effect on that trait. For example, an EBV for fertility above 100 means a better fertility than the average cow.

These EBV are estimated and, thus, not the true breeding values (TBV). The accuracy (correlation between the EBV and TBV) of the EBV for sensor measured $\mathrm{CH}_{4}$ emission and milk MIR predicted $\mathrm{CH}_{4}$ emission was estimated in the previous part of the general discussion. The reliabilities of the EBV (squared accuracy (VanRaden and Wiggans, 1991)) from CRV were estimated as described in Liu and colleagues (2004). The reliabilities as shown in Table 6.4 were a rough estimate of reliabilities of an 
Table 6.4 Descriptive statistics of estimated breeding values (EBV) of bulls with at least 5 daughters with either sensor measured methane $\left(\mathbf{C H}_{4}\right)$ emission or milk mid-infrared (MIR) predicted $\mathrm{CH}_{4}$ emission ${ }^{1}$

\begin{tabular}{|c|c|c|c|c|c|}
\hline Trait & Mean & sd & Minimum & Maximum & Reliability \\
\hline \multicolumn{6}{|c|}{ Sensor measured $\mathrm{CH}_{4}$ emission } \\
\hline $\mathrm{CH}_{4} \log (\mathrm{ppm})^{2}$ & -0.03 & 0.05 & -0.18 & 0.08 & \\
\hline $\mathrm{CO}_{2} \log (\mathrm{ppm})^{2}$ & -0.02 & 0.04 & -0.14 & 0.08 & \\
\hline Ratiolog $(\mathrm{ppm})^{2}$ & 0.00 & 0.01 & -0.03 & 0.02 & \\
\hline \multicolumn{6}{|c|}{ Milk MIR predicted $\mathrm{CH}_{4}$ emission } \\
\hline $\mathrm{CH}_{4}$ production (g/day) & -1.37 & 3.94 & -10.12 & 9.20 & \\
\hline $\mathrm{CH}_{4}$ yield $(\mathrm{g} / \mathrm{kg} \mathrm{DMI})^{3}$ & -0.03 & 0.25 & -0.58 & 0.77 & \\
\hline $\mathrm{CH}_{4}$ intensity $(\mathrm{g} / \mathrm{kg} \mathrm{FPCM})^{4}$ & -0.10 & 0.31 & -0.07 & 0.95 & \\
\hline \multicolumn{6}{|l|}{ Current breeding goal traits } \\
\hline Milk yield & 204.6 & 473.6 & -718 & 1525 & $>0.95$ \\
\hline Body weight & 102.0 & 3.9 & 93 & 110 & 0.80 \\
\hline Dry matter intake & 38.7 & 71.0 & -108 & 252 & 0.60 \\
\hline Longevity & 157.0 & 223.0 & -194 & 765 & 0.70 \\
\hline Udder health & 101.0 & 3.8 & 91 & 109 & 0.80 \\
\hline Fertility & 101.0 & 4.5 & 90 & 109 & 0.80 \\
\hline
\end{tabular}

${ }_{1}^{1}$ Descriptive statistics are the mean, standard deviation (sd), minimum, maximum, and reliability (on a scale of 0 to 1 ) of the EBV.

2 Sensor measured $\mathrm{CH}_{4}$ emissions are $\log _{10}$-transformed.

${ }^{3} \mathrm{DMI}$ is dry matter intake.

${ }^{4}$ Fat and protein corrected milk (FPCM) was calculated as FPCM $=$ milk $($ in $\mathrm{kg}) *(0.337+(0.116$

$*$ fat percentage $)+(0.06 *$ protein percentage $))$.

average bull of CRV. The most reliable EBV was for milk yield and the least reliable EBV was for dry matter intake.

The correlations were estimated in $\mathrm{R}$ ( $\mathrm{R}$ Core Team, 2017) and are reported in Table 6.5. The correlations found between the EBV of the $\mathrm{CH}_{4}$ indicators and the EBV of the six breeding goal traits were low to medium ranging between -0.44 and 0.09 for sensor measured $\mathrm{CH}_{4}$ emission. Moreover, correlations with milk MIR predicted $\mathrm{CH}_{4}$ emission were also low and range between -0.30 and 0.31 .

\subsubsection{Correlations between $\mathrm{EBV}$ for $\mathrm{CH}_{\mathbf{4}}$ and milk yield}

A relationship between $\mathrm{CH}_{4}$ emission and milk yield is anticipated via feed intake; cows that have a higher milk yield are expected to have a higher feed intake and, thereby, have a higher $\mathrm{CH}_{4}$ emission. Correlations calculated in this general discussion between the EBV for $\mathrm{CH}_{4}$ and the EBV for milk yield were low. All correlations were negative for both sensor measured $\mathrm{CH}_{4}$ emission and milk MIR predicted $\mathrm{CH}_{4}$ emission. This suggest that adding $\mathrm{CH}_{4}$ emission to the breeding goal would result in a favourable response in milk yield. 
Table 6.5 Correlations between the estimated breeding values (EBV) of 70 bulls with at least 5 daughters with sensor measured methane $\left(\mathbf{C H}_{4}\right)$ emission and six breeding goal traits, and correlations between EBV of 63 bulls with at least 5 daughters with milk mid-infrared (MIR) predicted $\mathrm{CH}_{4}$ emission and six breeding goal traits ${ }^{1}$

\begin{tabular}{|c|c|c|c|c|c|c|}
\hline Breeding goal trait & KGM & BW & DMI & LON & UDH & FER \\
\hline \multicolumn{7}{|c|}{ Sensor measured $\mathrm{CH}_{4}$ emission } \\
\hline $\mathrm{CH}_{4} \log (\mathrm{ppm})^{2}$ & -0.23 & -0.28 & -0.44 & -0.11 & -0.27 & -0.05 \\
\hline $\mathrm{CO}_{2} \log (\mathrm{ppm})^{2}$ & -0.26 & -0.26 & -0.44 & -0.15 & -0.29 & -0.10 \\
\hline Ratiolog $(\mathrm{ppm})^{2}$ & -0.01 & -0.25 & -0.25 & 0.09 & -0.06 & -0.11 \\
\hline \multicolumn{7}{|c|}{ Milk MIR predicted $\mathrm{CH}_{4}$ emission } \\
\hline $\mathrm{CH}_{4}$ production (g/day) & -0.29 & 0.04 & -0.08 & 0.06 & 0.16 & 0.29 \\
\hline $\mathrm{CH}_{4}$ yield $(\mathrm{g} / \mathrm{kg} \mathrm{DMI})$ & -0.24 & 0.31 & 0.21 & 0.04 & 0.20 & 0.24 \\
\hline $\mathrm{CH}_{4}$ intensity $(\mathrm{g} / \mathrm{kg} \mathrm{FPCM})^{3}$ & -0.19 & -0.30 & -0.25 & -0.20 & -0.09 & 0.01 \\
\hline
\end{tabular}

${ }^{1}$ Breeding goal traits: milk yield (KGM), body weight (BW), dry matter intake (DMI), longevity (LON), udder health (UDH), and fertility (FER).

2 Sensor measured $\mathrm{CH}_{4}$ emissions are $\log _{10}$-transformed.

${ }^{3}$ Fat and protein corrected milk (FPCM) was calculated as FPCM $=$ milk (in $\left.\mathrm{kg}\right) *(0.337+(0.116$

* fat percentage $)+(0.06 *$ protein percentage $))$.

The relationship between $\mathrm{CH}_{4}$ emission and milk yield is also presented in chapters 4 and $\mathbf{5}$. In chapter $\mathbf{4}$ the phenotypic correlations with milk yield were low, ranging between -0.16 and 0.11 for milk MIR predicted $\mathrm{CH}_{4}$ emission and between 0.17 and 0.22 for sensor measured $\mathrm{CH}_{4}$ emission. In chapter $\mathbf{5}$ the phenotypic correlations with milk yield were also low, ranging between -0.21 and 0.03 for milk MIR predicted $\mathrm{CH}_{4}$ emission and between 0.06 and 0.09 for sensor measured $\mathrm{CH}_{4}$ emission. The genetic correlations were low to medium, ranging between -0.47 and 0.24 for milk MIR predicted $\mathrm{CH}_{4}$ emission and between 0.19 and 0.51 for sensor measured $\mathrm{CH}_{4}$ emission.

The relationship between $\mathrm{CH}_{4}$ emission and milk yield has been discussed in chapter 4 and 5. The main conclusions from these discussions were that the relationship between $\mathrm{CH}_{4}$ emission and milk yield depends on the $\mathrm{CH}_{4}$ emission phenotype, but was expected to be moderately positive (higher milk yield resulting in higher $\mathrm{CH}_{4}$ emission). The correlations between the EBV for $\mathrm{CH}_{4}$ emission and the EBV for milk yield are in line with the correlations reported in chapter $\mathbf{4}$ and 5, even though they are negative. Based on the literature and the previous chapters, it can be anticipated that selective breeding for reduced $\mathrm{CH}_{4}$ emission will lead to an increase in milk yield. 


\subsubsection{Correlations between EBV of $\mathrm{CH}_{4}$, body weight, and dry matter intake}

Feed fermentation in the rumen drives the production of $\mathrm{CH}_{4}$ and a higher DMI is expected to result in higher $\mathrm{CH}_{4}$ emission. A relationship between $\mathrm{CH}_{4}$ emission and body weight is anticipated via DMI, heavier cows are expected to be larger with a larger rumen and, thus, might have a higher DMI. The correlations between the EBV for $\mathrm{CH}_{4}$ emission and body weight were weak, ranging between -0.28 and -0.25 for sensor measured $\mathrm{CH}_{4}$ emission and between -0.30 and 0.31 for milk MIR predicted $\mathrm{CH}_{4}$ emission. Moreover, the correlations between the EBV for $\mathrm{CH}_{4}$ emission and DMI were moderate to weak, ranging between -0.44 and -0.25 for sensor measured $\mathrm{CH}_{4}$ emission and between -0.25 and 0.21 for milk MIR predicted $\mathrm{CH}_{4}$ emission. Most correlations were negative, suggesting that adding $\mathrm{CH}_{4}$ emission to the breeding goal would result in a higher DMI (unfavorable) and heavier cows.

Although the direct relationship between body weight and $\mathrm{CH}_{4}$ emission in dairy cows was not studied, this relationship was studied via DMI in literature. In the study of De Haas et al. (2011), body weight and DMI were used to predict $\mathrm{CH}_{4}$ emission in dairy cows. This predicted $\mathrm{CH}_{4}$ emission had a high phenotypic correlation with DMI $\left(r_{p}=0.99\right)$. Furthermore, body weight and DMI were used to predict $\mathrm{CH}_{4}$ emission (in $\mathrm{MJ} /$ day) per kg of gross energy intake in dairy cows with a $\mathrm{R}^{2}$ ranging between 0.50 and 0.63 (Yan et al., 2010). Methane emission measured in climate respiration chambers was also found to be highly correlated $(r=0.77)$ with DMI in sheep (Moorby et al., 2015). Body weight, however, was indicated in the same study to be a poor indicator for $\mathrm{CH}_{4}$ emission with correlations ranging between 0.39 and 0.50 for different pasture types (Moorby et al., 2015). Based on these studies a moderate to strong relationship between $\mathrm{DMI}$ and $\mathrm{CH}_{4}$ emission is expected and a weak to moderate relationship between body weight and $\mathrm{CH}_{4}$ emission.

The correlations between the EBV for $\mathrm{CH}_{4}$ emission and body weight were in line with literature as they were weak to moderate. Correlations between the EBV for $\mathrm{CH}_{4}$ emission and DMI, however, were lower than expected. The EBV for $\mathrm{CH}_{4}$ emission had a low accuracy and the EBV for DMI had a low reliability (accuracy squared). The EBV for $\mathrm{CH}_{4}$ emission were determined on a small dataset of 1,508 dairy cows with sensor measured $\mathrm{CH}_{4}$ emission and 1,302 dairy cows with milk MIR predicted $\mathrm{CH}_{4}$ emission. The EBV for DMI was also based on a small dataset as DMI of cows is not normally measured. The low accuracy of both EBV might explain why the correlation between these two EBV is lower than anticipated.

The correlations as calculated in this general discussion suggest that adding $\mathrm{CH}_{4}$ emission to the breeding goal will result in a higher DMI and higher body weight. The impact of the inclusion of $\mathrm{CH}_{4}$ emission in the breeding goal gives an unfavourable 
response in DMI. The impact of the inclusion of $\mathrm{CH}_{4}$ emission in the breeding goal on body weight is neither favourable nor unfavourable. Body weight of cows has been increased in the past to enable high milk production, but there is currently no need to either increase or decrease the weight of cows.

\subsubsection{Correlations between $\mathrm{EBV}$ for $\mathrm{CH}_{\mathbf{4}}$ and longevity}

A relationship between $\mathrm{CH}_{4}$ emission and longevity is expected via feed intake and milk yield. Cows that have a higher milk yield are expected to have a higher feed intake and $\mathrm{CH}_{4}$ emission and are expected to have a lower longevity (Haworth et al., 2008). The correlation between the EBV for longevity and the EBV for sensor measured $\mathrm{CH}_{4}$ emission were low ranging between -0.15 and 0.09 . The correlations with the EBV for milk MIR predicted $\mathrm{CH}_{4}$ emission were also low, ranging between 0.20 and 0.06 . This suggest that adding $\mathrm{CH}_{4}$ emission to the breeding goal would result in a favourable response in longevity.

To the best of my knowledge, no other studies have reported direct correlations between $\mathrm{CH}_{4}$ emission and longevity. An indirect relationship between the profitable life index, an index which includes parameters like milk yield, fertility, and longevity, and $\mathrm{CH}_{4}$ emission has been reported (Dong et al., 2015). That study showed that $\mathrm{CH}_{4}$ emission was not significantly affected by the profitable life index. Another indirect relationship between $\mathrm{CH}_{4}$ emission and longevity was studied by Grandl and colleagues (2016). That study showed that $\mathrm{CH}_{4}$ emission increased during the first three lactations, and decreased thereafter, likely due to changes in fibre digestibility (Grandl et al., 2016). The literature suggests that a longer productive life is expected to have a favourable impact on $\mathrm{CH}_{4}$ emission. The correlations estimated in this general discussion are in line with this suggestion, showing that selective breeding for reduced $\mathrm{CH}_{4}$ emission is likely to have a minor, favourable impact on longevity.

\subsubsection{Correlations between EBV for $\mathrm{CH}_{4}$ and udder health}

The EBV for udder health is based on the EBV of subclinical mastitis combined with the EBV of clinical mastitis (CRV, 2016). Mastitis is one of the most costly production diseases in dairy cattle and is associated with a loss in milk yield (e.g. Bell et al., 2013). Because of milk yield an indirect relationship between udder health and $\mathrm{CH}_{4}$ emission is expected. Cows that have a higher milk yield and a higher $\mathrm{CH}_{4}$ emission could have a higher incidence of mastitis (Shook and Schutz, 1994). The correlations between the standardized EBV for udder health and the EBV for $\mathrm{CH}_{4}$ emission ranged between -0.29 and 0.20 . Most correlations were negative, suggesting that adding 
$\mathrm{CH}_{4}$ emission to the breeding goal would result in a favourable response in udder health.

Correlations between udder health and $\mathrm{CH}_{4}$ emission that have been reported in literature and in chapter 5 were low (Bell et al., 2013; Yin et al., 2015). In the study of Yin and colleagues, $\mathrm{CH}_{4}$ emission predicted with either body weight and milk production or feed intake gave low phenotypic and genetic correlations with clinical mastitis. The study of Bell et al. (2013) modelled that a decrease in somatic cell count (SCC; indicator for mastitis) resulted in a decrease in $\mathrm{CH}_{4}$ emission on whole herd level. In chapter $\mathbf{5}$ the phenotypic and genetic correlations between somatic cell score (SCS; based on SCC) and $\mathrm{CH}_{4}$ emission were low. Phenotypic correlations between SCS and milk MIR predicted $\mathrm{CH}_{4}$ emission ranged between -0.01 and 0.08 (s.e. $=0.03$ ) and genetic correlations between -0.61 and -0.06 (s.e. $=0.32-0.38$ ). Phenotypic correlations between SCS and sensor measured $\mathrm{CH}_{4}$ emission ranged between -0.06 and -0.01 (s.e. $=0.02$ ) and genetic correlations between -0.28 and 0.04 (s.e. $=0.06-0.08$ ). The correlations reported here are in line with literature and chapter 5, suggesting that selective breeding for reduced $\mathrm{CH}_{4}$ emission is likely to have a minor favourable impact on udder health.

\subsubsection{Correlations between $\mathrm{EBV}$ for $\mathrm{CH}_{\mathbf{4}}$ and fertility}

The EBV of fertility consists of the EBV for interval between first and last insemination and calving interval during the first three parities (CRV, 2015). A relationship between the EBV for $\mathrm{CH}_{4}$ emission and the EBV for fertility is expected via feed intake and milk yield. Cows that have a higher milk yield are expected to have a higher feed intake and $\mathrm{CH}_{4}$ emission and are expected to have lower fertility (Berry et al., 2003; Veerkamp et al., 2003). The correlations between the standardized EBV of fertility and the EBV of $\mathrm{CH}_{4}$ emission were low ranging between -0.11 and 0.29 . The correlations between the EBV for sensor measured $\mathrm{CH}_{4}$ emission and fertility were negative, suggesting that adding $\mathrm{CH}_{4}$ emission to the breeding goal would result in a favourable response in fertility. The correlations between the EBV for milk MIR predicted $\mathrm{CH}_{4}$ emission and fertility were positive, suggesting an unfavourable response.

Correlations between $\mathrm{CH}_{4}$ emission and fertility traits can be found in chapter 5 and in literature (Bell et al., 2013; Yin et al., 2015). In the study of Yin and colleagues (2015), $\mathrm{CH}_{4}$ emission predicted with either body weight and milk production or feed intake had high genetic correlations at the end of the lactation with fertility traits. These correlations indicated that breeding for reduced $\mathrm{CH}_{4}$ emission would lead to a favourable response in fertility. Bell et al. (2013) modelled that a decrease in fertility resulted in a decrease in $\mathrm{CH}_{4}$ emission on whole herd level. The correlations reported 
in chapter 5 between sensor measured $\mathrm{CH}_{4}$ emission and fertility traits ranged between -0.32 and 0.38 (s.e. $=0.12-0.68$ ).

The correlations reported here are in line with chapter 5 and are partially in line with literature. The correlations with sensor measured $\mathrm{CH}_{4}$ emission are in line with literature, though they are weak. The correlations with milk MIR predicted $\mathrm{CH}_{4}$ emission are not in line, but are also weak. The strength of the correlation between $\mathrm{CH}_{4}$ emission and fertility as reported in Yin et al. (2015) varied substantially over the lactation. This could indicate that the impact of inclusion of $\mathrm{CH}_{4}$ emission in the breeding goal might be limited. Moreover, in chapter 5 the estimates of these correlations had large standard errors. These numbers indicate a possible favourable response in fertility when $\mathrm{CH}_{4}$ emission is included in the breeding goal, though the response is expected to be minimal.

\subsubsection{Selective breeding on reduced methane emission}

Globally, agriculture is responsible for $24 \%$ of the greenhouse gas emissions (IPCC, 2014) of which $40 \%$ is $\mathrm{CH}_{4}$ produced via enteric fermentation by ruminants (FAOstat, 2014). The Paris agreements signed by 195 countries have a clear focus on the reduction of greenhouse gas emissions from agriculture. Furthermore, the Dutch government agreement of 2017 shows that also in the Netherlands politicians have a clear focus on reduction of greenhouse gas emissions from agriculture. Although $\mathrm{CH}_{4}$ emission has no economic value at the moment, penalties for emitting $\mathrm{CH}_{4}$ emission might be installed in the future. Selective breeding for reduced $\mathrm{CH}_{4}$ emission will be the 'license to produce' for the future of the dairy sector.

This thesis shows that there is a possibility to use selective breeding to reduce $\mathrm{CH}_{4}$ emission. The correlations estimated as part of this general discussion show that inclusion of $\mathrm{CH}_{4}$ emission in the breeding goal is anticipated to have a minor impact on the six breeding goal traits studied. The minor impact that is anticipated for the breeding goal traits is favorable towards including $\mathrm{CH}_{4}$ emission in the breeding goal with an eye on the future.

\subsection{References}

Bell, M. J., R. J. Eckard, M. Haile-Mariam, and J. E. Pryce. 2013. The effect of changing cow production and fitness traits on net income and greenhouse gas emissions from Australian dairy systems. J. Dairy Sci. 96(12):7918-7931. 
Berry, D. P., F. Buckley, P. Dillon, R. D. Evans, M. Rath, and R. F. Veerkamp. 2003. Genetic Relationships among Body Condition Score, Body Weight, Milk Yield, and Fertility in Dairy Cows. J. Dairy Sci. 86(6):2193-2204.

Bouwman, A. C., H. Bovenhuis, M. H. P. W. Visker, and J. A. M. van Arendonk. 2011. Genome-wide association of milk fatty acids in Dutch dairy cattle. BMC Genet. 12(43).

Bouwman, A. C., M. H. P. W. Visker, J. A. M. van Arendonk, and H. Bovenhuis. 2014. Fine mapping of a quantitative trait locus for bovine milk fat composition on Bos taurus autosome 19. J. Dairy Sci. 97(2):1139-1149.

Bovenhuis, H., M. H. P. W. Visker, H. J. F. van Valenberg, A. J. Buitenhuis, and J. A. M. van Arendonk. 2015. Effects of the DGAT1 polymorphism on test-day milk production traits throughout lactation. J. Dairy Sci. 98(9):6572-6582.

Chen, H. C. 2006. Enhancing energy and glucose metabolism by disrupting triglyceride synthesis: Lessons from mice lacking DGAT1. Nutrition and Metabolism 3.

CRV. 2015. Kengetallen E-17 fokwaarde vruchtbaarheid.

CRV. 2016. Kengetallen E-27 fokwaarde uier gezondheid.

De Haas, Y., J. J. Windig, M. P. L. Calus, J. Dijkstra, M. de Haan, A. Bannink, and R. F. Veerkamp. 2011. Genetic parameters for predicted methane production and potential for reducing enteric emissions through genomic selection. J. Dairy Sci. 94(12):6122-6134.

DeVita, R. J. and S. Pinto. 2013. Current Status of the Research and Development of Diacylglycerol O-Acyltransferase 1 (DGAT1) Inhibitors. Journal of Medicinal Chemistry 56(24):9820-9825.

Dong, L. F., T. Yan, C. P. Ferris, D. A. McDowell, and A. Gordon. 2015. Is there a relationship between genetic merit and enteric methane emission rate of lactating Holstein-Friesian dairy cows? Animal 9(11):1807-1812.

Falconer, D. S. 1960. Introduction into quantitative genetics. Oliver and Boyd, Edinburgh and London.

FAOstat. 2014. Agriculture total emissions, url: http://www.fao.org/faostat/en/\#data/GT, last accessed: 25-11-2017.

Grandl, F., S. P. Luzi, M. Furger, J. O. Zeitz, F. Leiber, S. Ortmann, M. Clauss, M. Kreuzer, and A. Schwarm. 2016. Biological implications of longevity in dairy cows: 1. Changes in feed intake, feeding behavior, and digestion with age. J. Dairy Sci. 99(5):3457-3471.

Haworth, G. M., W. P. Tranter, J. N. Chuck, Z. Cheng, and D. C. Wathes. 2008. Relationships between age at first calving and first lactation milk yield, and lifetime productivity and longevity in dairy cows. Veterinary Record 162(20):643. 
Hill, J., C. McSweeney, A.-D. G. Wright, G. Bishop-Hurley, and K. Kalantar-zadeh. 2016. Measuring Methane Production from Ruminants. Trends in Biotechnology 34(1):26-35.

IPCC. 2014. Climate change 2014: Synthesis report. Contribution of working groups i, ii and iii to the fifth assessment report of the intergovermental panel on climate change, ed. R.K. Pachauri and I.A. Meyer. Geneva, Switzerland.

Jensen, R. G. 2002. The composition of bovine milk lipids: January 1995 to December 2000. J. Dairy Sci. 85(2):295-350.

Johnson, K. A. and D. E. Johnson. 1995. Methane emissions from cattle. J Anim Sci 73.

Liu, Z., F. Reinhardt, A. Bünger, and R. Reents. 2004. Derivation and Calculation of Approximate Reliabilities and Daughter Yield-Deviations of a Random Regression Test-Day Model for Genetic Evaluation of Dairy Cattle. J. Dairy Sci. 87(6):18961907.

Manzanilla-Pech, C. I. V., Y. De Haas, B. J. Hayes, R. F. Veerkamp, M. Khansefid, K. A. Donoghue, P. F. Arthur, and J. E. Pryce. 2016. Genomewide association study of methane emissions in Angus beef cattle with validation in dairy cattle1. J. Anim. Sci. 94(10):4151-4166.

Moorby, J. M., H. R. Fleming, V. J. Theobald, and M. D. Fraser. 2015. Can live weight be used as a proxy for enteric methane emissions from pasture-fed sheep? Scientific Reports 5.

Negussie, E., Y. de Haas, F. Dehareng, R. J. Dewhurst, J. Dijkstra, N. Gengler, D. P. Morgavi, H. Soyeurt, S. van Gastelen, T. Yan, and F. Biscarini. 2017. Invited review: Large-scale indirect measurements for enteric methane emissions in dairy cattle: A review of proxies and their potential for use in management and breeding decisions. J. Dairy Sci. 100(4):2433-2453.

R Core Team. 2017. R: A language and environment for statistical computing. R Foundation for Statistical Computing, Vienna, Austria.

Saxton, R. A. and D. M. Sabatini. 2017. mTOR Signaling in Growth, Metabolism, and Disease. Cell 168(6):960-976.

Schennink, A., J. M. L. Heck, H. Bovenhuis, M. H. P. W. Visker, H. J. F. Van Valenberg, and J. A. M. Van Arendonk. 2008. Milk fatty acid unsaturation: Genetic parameters and effects of stearoyl-CoA desaturase (SCD1) and Acyl CoA: Diacylglycerol acyltransferase 1 (DGAT1). J. Dairy Sci. 91(5):2135-2143.

Schennink, A., W. M. Stoop, M. H. P. W. Visker, J. M. L. Heck, H. Bovenhuis, J. J. Van Der Poel, H. J. F. Van Valenberg, and J. A. M. Van Arendonk. 2007. DGAT1 underlies 
large genetic variation in milk-fat composition of dairy cows. Anim. Genet. 38(5):467-473.

Shook, G. E. and M. M. Schutz. 1994. Selection on Somatic Cell Score to Improve Resistance to Mastitis in the United States. J. Dairy Sci. 77(2):648-658.

Stoop, W. M., A. Schennink, M. H. P. W. Visker, E. Mullaart, J. A. M. van Arendonk, and H. Bovenhuis. 2009. Genome-wide scan for bovine milk-fat composition. I. Quantitative trait loci for short- and medium-chain fatty acids. J. Dairy Sci. 92(9):4664-4675.

Storm, I. M. L. D., A.L.F. Hellwing, N. I. Nielsen and J. Madsen 2012. Methods for Measuring and Estimating Methane Emission from Ruminants. Animals 2(2):160183.

van Gastelen, S., M. H. P. W. Visker, J. E. Edwards, E. C. Antunes-Fernandes, K. A. Hettinga, S. J. J. Alferink, W. H. Hendriks, H. Bovenhuis, H. Smidt, and J. Dijkstra. 2017. Linseed oil and DGAT1 K232A polymorphism: Effects on methane emission, energy and nitrogen metabolism, lactation performance, ruminal fermentation, and rumen microbial composition of Holstein-Friesian cows. J. Dairy Sci. 100(11):8939-8957.

VanRaden, P. M. and G. R. Wiggans. 1991. Derivation, Calculation, and Use of National Animal Model Information. J. Dairy Sci. 74(8):2737-2746.

Veerkamp, R. F., B. Beerda, and T. van der Lende. 2003. Effects of genetic selection for milk yield on energy balance, levels of hormones, and metabolites in lactating cattle, and possible links to reduced fertility. Livestock Production Science 83(2):257-275.

Winter, A., W. Krämer, F. A. O. Werner, S. Kollers, S. Kata, G. Durstewitz, J. Buitkamp, J. E. Womack, G. Thaller, and R. Fries. 2002. Association of a lysine-232/alanine polymorphism in a bovine gene encoding acyl-CoA:Diacylglycerol acyltransferase (DGAT1) with variation at a quantitative trait locus for milk fat content. Proc Nat Acad Sci USA 99(14):9300-9305.

Yan, T., C. S. Mayne, F. G. Gordon, M. G. Porter, R. E. Agnew, D. C. Patterson, C. P. Ferris, and D. J. Kilpatrick. 2010. Mitigation of enteric methane emissions through improving efficiency of energy utilization and productivity in lactating dairy cows.

J. Dairy Sci. 93(6):2630-2638.

Yin, T., T. Pinent, K. Brügemann, H. Simianer, and S. König. 2015. Simulation, prediction, and genetic analyses of daily methane emissions in dairy cattle. J. Dairy Sci. 98(8):5748-5762. 

Summary 


\section{Summary}

Dairy products are important food sources which contain nutrients that are essential for human development and healthy ageing. The demand for dairy products is expected to increase in the future as the human population is growing. The production of dairy products, however, also has a negative impact on the environment as during its production greenhouse gasses (GHG) are being formed. Global milk production is responsible for $2.9 \%$ of the total anthropogenic GHG emissions of which methane $\left(\mathrm{CH}_{4}\right)$ emission by dairy cows is the single largest source. Methane is a harmful GHG that is $\mathbf{2 8}$ times more harmful than carbon dioxide $\left(\mathbf{C O}_{2}\right)$ over a time period of 100 years. A reduction in $\mathrm{CH}_{4}$ emission by dairy cows is therefore wanted.

A reduction in $\mathrm{CH}_{4}$ emission could be achieved by using different $\mathrm{CH}_{4}$ mitigation strategies like management, feeding, microbial, and breeding strategies. Management strategies focus more on the reduction of $\mathrm{CH}_{4}$ emission on the whole farm level rather than on individual animal level. Feeding strategies are a proven method to reduce $\mathrm{CH}_{4}$ emission, but their reduction has been found to be short-term or costly to maintain. Microbial strategies have not been found to give a consistent and long-term reduction of $\mathrm{CH}_{4}$ emission. Breeding strategies have the advantage that they are cost-effective to implement and could give permanent and cumulative reduction in $\mathrm{CH}_{4}$ emission.

The influence of the genetics of the host on $\mathrm{CH}_{4}$ production could be utilized by selective breeding for reduced $\mathrm{CH}_{4}$ emission. Breeding for reduced $\mathrm{CH}_{4}$ emission by dairy cows, however, requires individual $\mathrm{CH}_{4}$ emission of many dairy cows. As measuring $\mathrm{CH}_{4}$ in climate respiration chambers (the 'golden standard') is impractical and expensive for many dairy cows, the use of indicators for $\mathrm{CH}_{4}$ emission as a phenotype that could be used in selective breeding has been proposed.

This thesis focuses on three different types of indicators for $\mathrm{CH}_{4}$ emission: 1) indicator based on milk fat composition; 2) indicator based on milk mid-infrared (MIR) spectra; 3 ) indicator based on $\mathrm{CH}_{4}$ and $\mathrm{CO}_{2}$ concentrations measured in the breath of the cow. Indicators based on milk composition utilize the relationship between microorganisms present in the rumen, $\mathrm{CH}_{4}$ emission, and milk fat composition. Methane emission is linked through the VFA produced in the rumen with milk fat composition. Cows producing high or low levels of $\mathrm{CH}_{4}$ have different microorganisms, but also show a distinction in VFA produced by these microorganisms. Most of the VFA produced will be absorbed from the rumen and some will be transported to the mammary gland where they are used for de-novo 
synthesis of milk fatty acids (FA). Indicator based on sensor measurements of $\mathrm{CH}_{4}$ and $\mathrm{CO}_{2}$ concentrations in the breath of the cow during automatic milking system (AMS) visits are a direct indicator for $\mathrm{CH}_{4}$ emission. Methane emitted during an AMS visit is measured and this is an indicator of $\mathrm{CH}_{4}$ emission during a full day.

In chapter 2, indicators of $\mathrm{CH}_{4}$ production based on milk fatty acids (FA) have been used to predict $\mathrm{CH}_{4}$ emission. The milk fat composition of 1,905 first lactation Dutch Holstein-Friesian cows was used to investigate three different predicted $\mathrm{CH}_{4}$ yields (in g/kg DMI): Methane1, Methane2, and Methane3. The first indicator (Methane1) was reported in literature and applied to our dataset. A second prediction equation (Methane2) was derived excluding FA that were present in relatively different concentrations (difference between datasets larger than $40 \%$ ) in our dataset compared to the one used to develop Methane1 on. A third prediction equation (Methane3) was derived excluding FA with relatively different concentrations and FA with concentrations $<1 \mathrm{~g} / 100 \mathrm{~g}$ fat in our dataset. Predicted $\mathrm{CH}_{4}$ yields were demonstrated to be heritable traits, with heritabilities between 0.12 and 0.44 . Breeding can, thus, be used to decrease methane production predicted based on milk fatty acids.

In chapter 3, genetic variation of $\mathrm{CH}_{4}$ emission by Dutch Holstein Friesian cows measured using infrared sensors installed in automatic milking systems (AMS) was estimated. Measurements of $\mathrm{CH}_{4}$ and carbon dioxide $\left(\mathrm{CO}_{2}\right)$ on 1,508 Dutch Holstein Friesian cows were available. Phenotypes per AMS visit were the mean of $\mathrm{CH}_{4}$ ( $\mathrm{CH}_{4}$ mean), mean of $\mathrm{CO}_{2}\left(\mathrm{CO}_{2}\right.$ mean), $\mathrm{CH}_{4}$ mean divided by $\mathrm{CO}_{2}$ mean (Ratiomean). Ratiomean was included in chapter 3 because it was reported in other studies and can be used to quantify methane production. $\mathrm{CH}_{4}$ mean and $\mathrm{CO}_{2}$ mean are the underlying traits to Ratiomean. The residuals of these traits were not normally distributed and, therefore, phenotypes were $\log _{10}$-transformated into $\mathrm{CH}_{4} \log$, $\mathrm{CO}_{2} \log$, and Ratiolog. The repeatabilities of the $\log _{10}$-transformated $\mathrm{CH}_{4}$ phenotypes ranged between 0.14 and 0.31 . The heritabilities of these phenotypes ranged between 0.03 and 0.12 . Breeding can, thus, be used to decrease methane production predicted based on breath sensor measurements in AMS. The use of $\mathrm{CH}_{4}$ log for selection instead of Ratiolog would be expected to give a greater reduction of methane emission by dairy cows as Ratiolog had a lower repeatability and heritability than $\mathrm{CH}_{4}$ log. Furthermore, It is important to account for farm, AMS, day of measurement, time of day, and lactation stage when estimating genetic parameters for methane phenotypes. Moreover, increasing the amount of sensor measurements increases the repeatabilities of the methane phenotypes. Therefore, It is recommended to measure $\mathrm{CH}_{4}$ and $\mathrm{CO}_{2}$ on at least 10 consecutive days to maximize repeatabilities of the methane phenotypes. 
In chapter 4, genetic parameters of milk mid-infrared (MIR) predicted $\mathrm{CH}_{4}$ emissions and their relationship with $\mathrm{CH}_{4}$ measured with sensors in AMS. Milk production and $\mathrm{CH}_{4}$ data on 1,302 cows were available with three milk MIR predicted $\mathrm{CH}_{4}$ phenotypes: $\mathrm{CH}_{4}$ production (g/day), $\mathrm{CH}_{4}$ yield ( $\mathrm{g} / \mathrm{kg} \mathrm{DMI}$ ), and $\mathrm{CH}_{4}$ intensity $(\mathrm{g} / \mathrm{kg}$ fat and protein corrected milk) and three sensor measured phenotypes (chapter 3 ). The heritabilities of the milk MIR predicted $\mathrm{CH}_{4}$ phenotypes ranged between 0.17 and 0.21. Correlations between milk MIR predicted $\mathrm{CH}_{4}$ phenotypes and sensor measured phenotypes were weak with phenotypic correlations ranging between 0.03 and 0.16 . This indicates that milk MIR predicted $\mathrm{CH}_{4}$ phenotypes provide information that is independent of sensor measured phenotypes. Combining indicators could overcome some of their shortcomings and is useful when indicators contain information that is independent of each other. Combining the information from the two types of $\mathrm{CH}_{4}$ phenotypes could be a useful next step. Moreover, the amount of variation explained by the milk production traits was moderate for $\mathrm{CH}_{4}$ yield and $\mathrm{CH}_{4}$ intensity ( $\mathrm{R}^{2}=0.45$ and 0.63 , respectively), whereas the $\mathrm{R}^{2}$ for $\mathrm{CH}_{4}$ production and sensor measured phenotypes were low $(0.01-0.13)$. The variation that is not explained by these production traits $\left(1-R^{2}\right)$ is indicative for the additional information provided by the $\mathrm{CH}_{4}$ phenotypes.

Incorporating $\mathrm{CH}_{4}$ emission into the breeding goal could result in unfavourable responses in other breeding goal traits. Therefore, the relationship between $\mathrm{CH}_{4}$ emission and other breeding goal traits needs to be studied. In chapter 5 , the aim was to estimate the correlations between $\mathrm{CH}_{4}$ emission indicators and test-day milk production and fertility traits. $\mathrm{CH}_{4}$ emission was either sensor measured or predicted based on milk MIR spectra. Most genetic correlations between $\mathrm{CH}_{4}$ emission and test-day milk production traits and fertility traits were either weak or moderate. Moderate correlations between milk MIR predicted $\mathrm{CH}_{4}$ yield and percentages of fat and lactose, and between sensor measured $\mathrm{CH}_{4}$ emission and yield traits (yields of fat, protein and lactose) were found in this study. The percentage of fat and lactose and the yields of fat, protein and lactose might decrease when selecting for reduced $\mathrm{CH}_{4}$ emission. The results show that inclusion of $\mathrm{CH}_{4}$ emission in the breeding goal is expected to have a minor negative impact on the other breeding goal traits.

To get a better understanding of predicted $\mathrm{CH}_{4}$ emission based on these indicators, I have performed genome-wide association studies (GWAS) on $\mathrm{CH}_{4}$ emission determined via the three indicators of this thesis (chapter 6). The DGAT1 K232A polymorphism on chromosome 14 was found to be significantly associated with milk predicted $\mathrm{CH}_{4}$ emission indicators and has been linked to milk production and composition in previous studies. Furthermore, significant association was found for Methane3 on chromosome 19 of which the lead SNP was located in the regulatory 
associated protein of mTOR complex (RPTOR). These associations with $\mathrm{CH}_{4}$ emission could relate metabolic processes in the rumen that affect the production or emission of $\mathrm{CH}_{4}$, to milk composition, or both. When the associations relate to milk composition, selection based on milk predicted $\mathrm{CH}_{4}$ emission might favour cows with a certain DGAT1 genotype as parents for the next generation. When the associations relate to metabolic processes in the rumen and, thus, affect $\mathrm{CH}_{4}$ production and emission, $\mathrm{CH}_{4}$ emission measured in $\mathrm{CRC}$ should be affected by the DGAT1 genotype. No definite statement can be made whether the associations with milk predicted $\mathrm{CH}_{4}$ emission are due to the impact of these association on metabolic processes, on milk composition, or both. It is most likely that the associations relate to milk composition which impacts milk predicted $\mathrm{CH}_{4}$ emission via the prediction equations.

Combining information from sensor measured $\mathrm{CH}_{4}$ emission with milk MIR predicted $\mathrm{CH}_{4}$ emission was suggested in chapter 4 as a useful next step for selective breeding for reduced $\mathrm{CH}_{4}$ emission. To study the effect of combining information for selective breeding for reduced $\mathrm{CH}_{4}$ emission, the accuracy of the estimated breeding value (EBV) when based on one of the two sources of information (i.e. one of the two indicators for $\mathrm{CH}_{4}$ emission) was calculated. The accuracy of the EBV based on sensor measured $\mathrm{CH}_{4}$ emission information is 0.46 . The accuracy of the EBV using only information on milk MIR predicted $\mathrm{CH}_{4}$ emission is 0.51 . Combining information from both sources increases the accuracy to a value of 0.66. Although sensor measurements are not available in practice currently, using multiple indicators is recommended as shortcoming in one of the indicators can be overcome by the other indicator.

The relationship between $\mathrm{CH}_{4}$ emission and the other breeding goal traits could give an indication of the potentially unfavorable responses in other breeding goal traits when selecting for reduced $\mathrm{CH}_{4}$ emission. The correlations found between the EBV of the $\mathrm{CH}_{4}$ indicators and the EBV of the six breeding goal traits were low to medium ranging between -0.44 and 0.09 for sensor measured $\mathrm{CH}_{4}$ emission. Moreover, correlations with milk MIR predicted $\mathrm{CH}_{4}$ emission were also low and range between -0.30 and 0.31 . The correlations estimated show that inclusion of $\mathrm{CH}_{4}$ emission in the breeding goal is anticipated to have a minor impact on the breeding goal traits studied.

This thesis shows that there is a possibility to use selective breeding to reduce $\mathrm{CH}_{4}$ emission. Correlations between milk MIR predicted $\mathrm{CH}_{4}$ phenotypes and sensor measured phenotypes were low. This indicates that milk MIR predicted $\mathrm{CH}_{4}$ phenotypes provide information that is independent of sensor measured phenotypes. Using multiple indicators is recommended as shortcoming in one of the indicators can be overcome by the other indicator. The correlations estimated in this 
thesis show that inclusion of $\mathrm{CH}_{4}$ emission in the breeding goal is anticipated to have a minor impact on milk composition and on the breeding goal traits. The minor impact that is anticipated for the breeding goal traits is favorable towards including $\mathrm{CH}_{4}$ emission in the breeding goal with an eye on the future. 


\section{Samenvatting}




\section{Samenvatting}

Zuivelproducten zijn een belangrijke voedselbron voor mensen en bevatten voedingsstoffen die essentieel zijn voor de ontwikkeling en het gezond ouder worden van mensen. Zo zijn zuivelproducten rijk aan eiwitten en bevatten ze mineralen, zoals calcium, die belangrijk zijn voor humane gezondheid. De verwachting is dat de vraag naar melk en andere zuivelproducten verder zal toenemen in de toekomst, omdat de wereldbevolking aan het groeien is. Daarnaast heeft deze groeiende bevolking een steeds hogere levensverwachting. Ouderen zijn gebaat bij de consumptie van zuivelproducten en zodoende zal de vraag naar zuivel groeien.

De productie van zuivel levert helaas ook een negatieve bijdrage aan het klimaat, omdat er broeikasgassen vrijkomen tijdens de productie van melk. Broeikasgassen dragen bij aan het broeikaseffect en zorgen voor een opwarming van de aarde, wat bijdraagt aan klimaatverandering. De productie van melk is wereldwijd verantwoordelijk voor $2,9 \%$ van de broeikasgassen geproduceerd door toedoen van mensen. De grootste bron van deze broeikasgassen is methaan $\left(\mathrm{CH}_{4}\right)$ geproduceerd door melkkoeien. Methaan wordt gevormd in de pens, een van de vier magen van een koe, om daarna opgerispt en uitgeademd te worden. Om de negatieve bijdrage van zuivelproductie aan het klimaat te verminderen is het belangrijk om de uitstoot van methaan door melkkoeien te verminderen.

In dit proefschrift heb ik gekeken of het mogelijk is om deze methaanuitstoot te verminderen door middel van fokkerij. Het gebruik van fokkerij om de methaanuitstoot te verminderen heeft als voordeel dat het kostenefficiënt is. Daarnaast is de mogelijke vermindering van methaan permanent en cumulatief. Dat wil zeggen dat de lagere methaanuitstoot kan worden doorgegeven van generatie op generatie en dat deze vermindering niet tijdelijk is.

Er zijn een aantal randvoorwaarden voordat fokkerij gebruikt kan worden om de methaanuitstoot van koeien te verminderen. $\mathrm{Er}$ is een verschil in methaanuitstoot tussen koeien nodig dat gedeeltelijk bepaald wordt door het DNA van de koeien. Als alle koeien evenveel methaan uitstoten (geen variatie in methaanuitstoot) kan door middel van fokkerij de methaanuitstoot van koeien niet verlaagd worden. De variatie tussen koeien kan ontstaan door de omgeving van de koe (bijvoorbeeld, het voer van de koe) of door het DNA van de koe (het genetische materiaal van de koe). Als de verschillen tussen koeien in methaanuitstoot alleen ontstaan door verschillen in de omgeving van de koe, kan door middel van fokkerij de methaanuitstoot van koeien niet verlaagd worden. 
In hoofdstuk 2, 3, en 4 heb ik met behulp van drie verschillende methodes gekeken naar de variatie in methaanuitstoot tussen koeien. In hoofdstuk 2 heb ik gekeken naar de samenstelling van het melkvet en heb ik door middel van voorspelformules de methaanuitstoot voorspeld. In hoofdstuk 3 heb ik een ademsensor in melkrobotten gehangen en op deze manier de methaanuitstoot tijdens het melken gemeten. In hoofdstuk 4 heb ik de methaanuitstoot voorspeld met behulp van voorspelformules gebaseerd op infraroodspectra van de melk. Uit dit onderzoek blijkt dat er inderdaad variatie is tussen melkkoeien in methaanuitstoot.

Om het gedeelte van de variatie in methaanuitstoot dat wordt bepaald door het DNA te kunnen vergelijken tussen de verschillende methodes is de erfelijkheidsgraad berekend voor elke methode. De erfelijkheidsgraad laat zien hoeveel van de totale variatie bepaald wordt door het DNA van de koe. Als alle variatie in een kenmerk bepaald wordt door het DNA dan is de erfelijkheidsgraad $100 \%$ en als alle variatie bepaald wordt door de omgeving is de erfelijkheidsgraad $0 \%$. Bij de meeste kenmerken wordt alleen een gedeelte van de variatie bepaald door het DNA. Bijvoorbeeld, als de variatie in een kenmerk voor $20 \%$ bepaald wordt door het DNA is de erfelijkheidsgraad van dat kenmerk $20 \%$.

Uit hoofdstuk 2, 3, en 4 blijkt dat een gedeelte van de variatie tussen koeien in methaanuitstoot bepaald wordt door het DNA van de melkkoeien. Op basis van melkvet (hoofdstuk 2) varieerde de erfelijkheidsgraad tussen de 12 en 44\%. Op basis van sensormetingen (hoofdstuk 3 ) varieerde de erfelijkheidsgraad tussen de 3 en $12 \%$. Op basis van de infraroodspectra (hoofdstuk 4) varieerde de erfelijkheidsgraad tussen de 17 en 21\%. Deze resultaten laten zien dat het inderdaad mogelijk is om te fokken op verminderde methaanuitstoot door melkkoeien.

De erfelijkheidsgraad van de meeste methaankenmerken was vrij laag $(<30 \%)$. Ondanks de lage erfelijkheidsgraden van methaanuitstoot heeft het wel degelijk nut om te fokken op verminderde methaanuitstoot. In de praktijk zien we dat zelfs met het fokken op kenmerken met hele lage erfelijkheidsgraden $(<5 \%)$ zoals vruchtbaarheid en mastitis mooie resultaten behaald worden.

Naast de erfelijkheidsgraad van methaanuitstoot is het ook belangrijk om de relaties tussen methaanuitstoot en andere kenmerken van de koe te onderzoeken. Een aantal voorbeelden van voor melkkoeien belangrijke kenmerken zijn melkproductie, vetgehalte van de melk, uiergezondheid, en vruchtbaarheid. Deze zogeheten fokdoelkenmerken zijn onderdeel van het huidige fokprogramma van melkkoeien en vertegenwoordigen een bepaalde economische waarde. Verder zijn deze kenmerken van belang voor het welzijn van de koeien. Fokken op een verminderde methaanuitstoot, door het toe te voegen aan het fokprogramma, zou dus geen grote 
negatieve invloed moeten hebben op de andere kenmerken van het fokprogramma en de algemene gezondheid van de koe.

Om deze relaties te onderzoeken zijn de correlaties tussen methaanuitstoot en huidige fokdoelkenmerken berekend (hoofdstuk 5 en 6). Een correlatie kan variëren tussen de -1 en 1 . Wanneer de correlatie dichtbij de nul ligt is er (bijna) geen relatie tussen methaanuitstoot en fokdoelkenmerken. Wanneer de correlatie dichtbij de -1 of 1 ligt is er een zeer sterke relatie tussen methaanuitstoot en fokdoelkenmerken. De meeste correlaties tussen methaanuitstoot en fokdoelkenmerken waren vrij laag (tussen de $-0,3$ en 0,3 ), dit betekent dus dat er een zwakke relatie is tussen methaanuitstoot en fokdoelkenmerken. Er zijn matige correlaties (tussen de -0,5 en $-0,3$ of tussen de 0,3 en 0,5 ) gevonden tussen methaanuitstoot en de percentages van vet en lactose in de melk. Ook zijn er matige correlaties gevonden tussen methaanuitstoot en de totale opbrengst van vet, eiwit, en lactose uit de melk.

De relatie tussen methaanuitstoot en de samenstelling van de melk is dus matig. Dit betekent dat de melksamenstelling mogelijk een klein beetje kan veranderen wanneer methaanuitstoot wordt toegevoegd aan het fokprogramma. Daarom is het belangrijk om dit in de gaten te houden.

Concluderend, dit proefschrift laat zien dat er inderdaad verschillen zijn tussen koeien in methaanuitstoot. Deze verschillen worden voor een gedeelte bepaald door het DNA van melkkoeien. Zodoende is methaanuitstoot geschikt om toegevoegd te worden aan het fokprogramma van melkkoeien. Wanneer methaanuitstoot wordt toegevoegd kan de samenstelling van de melk een beetje veranderen, wat goed in de gaten moet worden gehouden. Het fokken van melkkoeien met een verminderde methaanuitstoot kan een bijdrage leveren aan het verminderen van de hoeveelheid broeikasgassen geproduceerd door de zuivelindustrie. 


\section{Curriculum Vitae}




\section{About the author}

Sabine van Engelen was born in ' $t$ Harde, municipality Elburg, on the $18^{\text {th }}$ of April 1989. In 2007, she graduated from high school Lambert Franckens College in Elburg. In that same year she started her study Animal Sciences at Wageningen University. During her bachelor she did a minor in Agricultural Economics and Consumers. The topic of her bachelor thesis was "Do dogs with different types of aggression react differently in the Socially Acceptable Behavior test?". During her master she followed the specialization Animal Breeding and Genetics and followed a minor in Animal Behavior. The topic of her minor thesis was "Individual differences in giving and receiving of social support among pigs". The topic of her major thesis was "Estimation of genetic parameters between performance in young horse competitions and performance in regular competitions in Dutch warmblood horses". In 2012 she finished her master and started working at the Animal Breeding and Genomics group of Wageningen University as research and teaching assistant. In 2013 she started her PhD at the Animal Breeding and Genomics group of Wageningen University. The results of her PhD are presented in this thesis. Since October 2017, Sabine is working as data scientist for YOR Innovation, part of Wageningen Metropolitan Food Cluster. 


\section{Peer reviewed publications}

Van Engelen, S., H. Bovenhuis, J. Dijkstra, J.A.M. van Arendonk, and M.H.P.W. Visker. 2015. Short communication: Genetic study of methane production predicted from milk fat composition in dairy cows. J. Dairy Sci. 98:8223-8226.

Van Engelen, S., H. Bovenhuis, P.P.J. van der Tol, and M.H.P.W. Visker. 2018. Genetic background of methane emission by Dutch Holstein Friesian cows measured with infrared sensors in automatic milking systems. J. Dairy Sci. Accepted.

\section{Publications in preparation}

Van Engelen, S., H. Bovenhuis, and M.H.P.W. Visker. Genetic background of milk mid infrared predicted methane emission and relationship with sensor measured methane emission in Dutch dairy cows. Submitted.

Van Engelen, S., H. Bovenhuis, and M.H.P.W. Visker. Correlations of milk mid infrared predicted and sensor measured methane emission with production and fertility traits in Dutch dairy cows. In preparation.

\section{Conference proceedings}

Van Engelen, S., H. Bovenhuis, J. Dijkstra, J.A.M. van Arendonk, and M.H.P.W. Visker. 2014. Genome wide association studies of milk fatty acids as a basis for methane prediction. 10 $10^{\text {th }}$ World Congress on Genetics Applied to Livestock Production. Vancouver, Canada.

M.H.P.W. Visker, S. van Engelen, J. Dijkstra, J.A.M. van Arendonk, and H. Bovenhuis. 2014. Genetic parameters for methane emission of dairy cows predicted based on milk fatty acids. $10^{\text {th }}$ World Congress on Genetics Applied to Livestock Production. Vancouver, Canada.

Van Engelen, S., H. Bovenhuis, P.P.J. van der Tol, J.A.M. van Arendonk, and M.H.P.W. Visker. 2015. Methane production by dairy cows measured in an automatic milking system. $66^{\text {th }}$ Annual Meeting of the European Federation of Animal Sciences. Warsaw, Poland.

Van Engelen, S., H. Bovenhuis, P.P.J. van der Tol, and M.H.P.W. Visker. 2016. Methane production phenotypes of dairy cows measured in automatic milking systems. $6^{\text {th }}$ Greenhouse Gas and Animal Agriculture conference. Melbourne, Australia. 
Van Gastelen, S., S. van Engelen, J. Dijkstra, and M.H.P.W. Visker. 2016. The effect of DGAT1 K232A polymorphism and linseed oil supplementation on methane emission of dairy cows. $6^{\text {th }}$ Greenhouse Gas and Animal Agriculture conference. Melbourne, Australia. 


\section{Training and supervision plan (TSP)}

The Basic Package (3 ECTS)

Year

WIAS Introduction course

2014

Ethics and Philosophy in Life Sciences

2015

\section{Scientific Exposure (19 ECTS)}

International conferences

$10^{\text {th }}$ WCGALP, Vancouver, Canada

2014

$66^{\text {th }}$ EAAP, Warsaw, Poland

2015

$6^{\text {th }}$ GGAA, Melbourne, Australia

2016

Seminars and workshops

WIAS Science day, Wageningen, the Netherlands (4x)

$2014-2017$

F\&G connection, Ellecom/Doorwerth, the Netherlands (2x)

2014 / 2017

Yearly ASGGN meeting, Vancouver, Canada / Melbourne, Australia (2x)

2014 / 2016

How to write a worldclass paper, Wageningen, the Netherlands

2013

10 years Milk Genomics Initiative, Wageningen, the Netherlands

2014

WGS PhD Workshop Carousel, Wageningen, the Netherlands

2014

TIFN PhD Workshop, Ede, the Netherlands

2015

World lecture: "Stront aan de knikker", Wageningen, the

Netherlands

2015

COST-Methagene Workshop, Wageningen, the Netherlands

2015

TIFN Annual Conference, Wageningen, the Netherlands

2016

Genome Editing: Kansen en grenzen van modern genetische modificatietechnieken, Amsterdam, the Netherlands

2016

TIFN seminar: "Minder methaanemissie door melkvee",

Wageningen, the Netherlands

2017

\section{Presentations}

Poster presentation at WIAS Science day, Wageningen, the

Netherlands

2014

Oral presentation at $10^{\text {th }}$ WCGALP, Vancouver, Canada

2014

Poster presentation at $66^{\text {th }}$ EAAP, Warsaw, Poland

2015

Oral presentation at COST-Methagene workshop, Wageningen, the Netherlands

2015 
Poster presentation at WIAS Science day, Wageningen, the Netherlands

2016

Oral presentation at yearly ASGGN meeting, Melbourne, Australia 2016

Poster presentation at $6^{\text {th }}$ GGAA, Melbourne, Australia 2016

Oral presentation at WIAS Science day, Wageningen, the

Netherlands

2017

Oral presentation at F\&G Connection, Doorwerth, the Netherlands

2017

Oral presentation at TIFN seminar, Wageningen, the Netherlands

2017

\section{In-Depth Studies (8 ECTS)}

Disciplinary and interdisciplinary courses

ABGC course Getting started in ASReml, Wageningen, the Netherlands

2012

Genetic analysis using ASREML4.0, Wageningen, the Netherlands 2014

Methane Physiology \& Modelling for Geneticists, Rostock, Germany 2014

Environmental Impact Assessment of Livestock Systems,

Wageningen, the Netherlands

2015

Methagene Training School on Large Scale Methane Data Handling,

Analysis and Interpretation, Poznan, Poland

PhD student's discussion groups

Quantitative Genetics Discussion group, Wageningen, the

Netherlands

\section{Professional Skills Support Courses (5 ECTS)}

Techniques of Writing and Presenting a Scientific Paper

PhD Competence Assessment

Effective Behaviour in your Professional Surroundings

2016

Career Orientation

2016

The Final Touch: Writing the General Introduction and Discussion

2016

\section{Research Skills Training (3 ECTS)}

Preparing own PhD research proposal

\section{Didactic Skills Training (7 ECTS)}

Supervising Genetic Improvement of Livestock (2x) 
Supervising BSc thesis

2015

Management Skills Training (3 ECTS)

WIAS Associated PhD Student Council (Education committee)

$2015-2017$

Education and Training Total

48 ECTS 



\section{Acknowledgements}




\section{Acknowledgements}

En dan nu, dames en heren, het dankwoord van mijn proefschrift. Een van de belangrijkste onderdelen van het proefschrift. Gedurende mijn PhD heb ik vaak nagedacht over hoe het zou zijn om een dankwoord te schrijven. Ik kan zeggen dat het erg goed voelt! Zoals sommigen van jullie weten heeft de totstandkoming van dit proefschrift een hoop voeten in de aarde gehad. Ik heb zelfs gedacht dat het helemaal niet meer af zou komen, maar zo zie je maar weer: "the only limit is your own imagination". Ik weet zeker dat ik zonder hulp dit proefschrift niet had kunnen afronden. Daarom wil ik een aantal mensen bedanken die mij geholpen hebben om dit proefschrift te schrijven.

Henk en Marleen, bedankt voor jullie tomeloze inzet! Zonder jullie steun en kennis had ik dit proefschrift zeker niet kunnen afronden. Bedankt voor alle interessante inhoudelijke discussies en gesprekken die mij zeker verder hebben geholpen. Jullie vragen en feedback hebben mij altijd gestimuleerd om verder te zoeken en verder na te denken over mijn resultaten. Bedankt daarvoor! Ik wil ook Johan bedanken. Alhoewel je niet mijn promotor meer bent, heb je zeker bijgedragen aan de totstandkoming van dit proefschrift.

Mijn proefschrift is onderdeel van het TIFN project en ik wil ook de mensen van het TIFN team bedanken voor hun bijdrage! Hauke, Caroline, Tom, Joan, Jueeli, Kasper, Elsa, Sanne, Henk, Jan, Noelle, Johan, Henk, en Marleen. Thank you for your input and new perspectives on my work. I really enjoyed working in this multi-disciplinairy team.

Als onderdeel van mijn proefschrift heb ik ook data verzameld op 11 melkveebedrijven. Bij deze wil ik alle melkveehouders bedanken voor de prettige samenwerking en gastvrijheid. Ook wil ik Rik van der Tol en Jan Kortmann bedanken voor hun bijdrage aan het verzamelen en verwerken van de data.

Ook wil ik de collega's van ABG bedanken voor de gezellige tijd en alle interessante discussies in de coffeecorner. Thank you all for the nice time and discussions! Ada en Lisette, bedankt voor het regelen van alle administratieve zaken rondom mijn PhD! Op 28 maart zal ik niet alleen op het podium staan, gelukkig maar. Tetske en Tessa, bedankt dat jullie mij willen supporten op deze belangrijke dag. Jullie steun is er vanaf het begin van mijn PhD geweest en zonder jullie was het zeker een stuk moeilijker geweest. Tetske, samen studeren en daarna promoveren: mijn PhD was echt anders geweest zonder jou. Bedankt voor je steun en je vriendschap! Tessa, zonder jou was het een heel stuk saaier op kantoor. Bedankt voor je luisterende oor en ik mis onze wandelrondjes! 
Ik ben een gezegend mens met zoveel goede vrienden om mij heen! Dames van de twee-en-halfste, bedankt voor jullie vriendschap door de jaren heen! Ik kan me nog goed herinneren dat we tegen elkaar zeiden op de $16^{\text {de }}$ verjaardag van iemand dat we het volgende jaar echt rollators nodig zouden gaan hebben. Nu hebben we die zeker nodig! Ik hoop dat we vrienden blijven tot we oud en rimpelig zijn!

Dames en Heren van HANTT, studeren en het leven na de studie zouden echt anders zijn zonder jullie! Bedankt voor alle steun, hulp, humor, diepgaande gesprekken en leuke activiteiten die we door de jaren heen hebben ondernomen! We zijn een bijzonder stel, maar dat maakt het juist zo leuk! Misschien hebben we nu geen dierentuin (alhoewel dat misschien nog wel gaat gebeuren), een gedeelte van ons werkt nu wel samen. Ik kan niet anders zeggen dat ik vooruit kijk naar een toekomst vol samenwerken en leuke dingen doen met jullie!

Last, but not least: familie. Bijna waren we niet meer compleet. Bijna hadden we iemand moeten missen. Gelukkig zijn we er nog en ik hoop dat dat nog heel lang zo blijft in alle gezondheid! Papa en mama, dank jullie wel voor alle steun die ik door de jaren heen heb gekregen van jullie. Jullie hebben me altijd gestimuleerd om het beste uit mezelf te halen! Ook wil ik mijn kleine zusje bedanken, die nu 1 hele $\mathrm{cm}$ langer is dan mij (en ja, dat is heel belangrijk). Dank je wel Daniëlle voor al je zusterliefde! Ome Peter, bedankt voor het helpen wanneer dat maar kon. De kaft van dit boekje is daar zeker een voorbeeld van. Ezel Tooske, er is geen mooiere ezel te vinden aan de koeweg, jij gekke meid!

Zoals het woord dankwoord al aangeeft staat er nu heel erg vaak bedankt, dank, en bedanken, maar ik kan alleen maar dankbaar zijn voor de kans die ik heb gehad. Het is zeker niet altijd makkelijk geweest, maar ik heb zo ontzettend veel geleerd de afgelopen jaren. Niet alleen over fokkerij en genetica, maar misschien juist wel meer over mezelf.

"If these were the last beats of my heart, I would dance to them"

\section{Sabine}




\section{Colophon}

The studies presented in this thesis were performed in the framework of Top Institute Food and Nutrition.

Cover Design: Sabine van Engelen and Peter Stok.

Printed by Digiforce, De Limiet 24, 4131 NR Vianen, the Netherlands 